
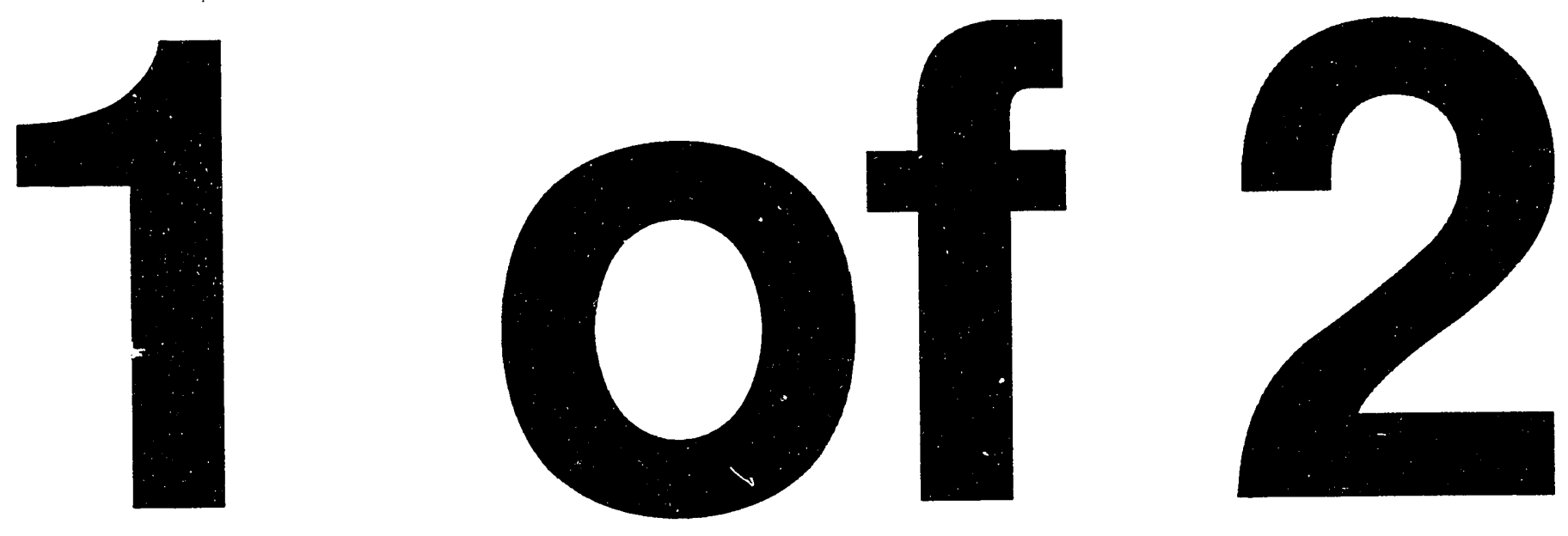
SAND93-1987

Unlimited Release

Printed October 1993

Distribution

Category UC-423

\title{
PLASMA FACING COMPONENTS \\ GENERIC FACILITIES REVIEW PANEL (PFC-GFRP) FINAL REPORT
}

\author{
Chartered by \\ U.S. Department of Energy \\ Office of Fusion Energy \\ ITER and Technology Division
}

\author{
Review Panel Members \\ Robert McGrath, Chairman \\ Magnetic Fusion Energy Programs \\ Sandia National Laboratories \\ Albuquerque, New Mexico 87185 \\ Steven Allen, Lawrence Livermore National Laboratory \\ Jeffrey Brooks, Argonne National Laboratory \\ John Davis. McDonnell Douglas \\ David Hill. Lawrence Livermore National Laboratory \\ Bruce Lipschultz, Massachusetts Institute of Technology \\ Richard Mattas, Argonne National Laboratory \\ Michael Ulrickson, Princeton Plasma Physics Laboratory
}

\begin{abstract}
The Plasma Facing Components (PFC) Facilities Review Panel was chartered by the U.S. Department of Energy, Office of Fusion Energy, ITER (International Thermonuclear Experimental Reactor) and Technology Division, to outline the program plan and identify the supporting test facilities that lead to reliable, longlived plasma facing components for ITER. This report summarizes the panel's findings and identifies the necessary and sufficient set of test facilities required for ITER PFC development.
\end{abstract}


(This page intentionally left blank.) 


\title{
Plasma Facing Components \\ Generic Facilities Review Panel Report
}

\author{
Table of Contents
}

I. Executive Summary 1

II. Introduction 5

II. 1 Charter to the Panel 5

II.2 Issues for ITER PFC Development 5

II.3 Generic PFC Test Facilities Considered 6

II.4 Evaluation Process and Conclusion Summary 7

III. PFC Development Issues and Test Facility Evaluations 15

III.1 Overview 15

III. 2 Dissipative Divertor Validation and Impact on Confinement 15

III.3 Impurity Entrainment 21

III.4 Density Control and Fueling 22

III.5 Erosion/Redeposition 23

III.6 Disruption Effects $\quad 29$

III.7 Helium Exhaust 33

III.8 PFC Lifetime/Reliability and Heat Removal 36

$\begin{array}{lll}\text { III.9 Safety } & 47\end{array}$

III. 10 Tritium 48

III.11 Neutron Effects $\quad 50$

IV. Summary and Conclusions: PFC Development Plan 57

IV.1 Divertor Concept Validation and Related Physics Issues 57

IV.2 Erosion/Redeposition 58

IV.3 Disruptions

IV.4 Helium Exhaust $\quad 59$

IV.5 Lifetime/Reliability and Heat Removal 60

IV.6 Safety $\quad 60$

IV.7 Tritium $\quad 60$

IV.8 Neutron Effects 61

IV.9 Test Facilities Considered and Not Selected as Necessary to Develop and
Validate PFCs for ITER 
(This page intentionally left blank.) 


\section{Executive Summary}

The Executive Summary is by necessity a condensed summation of a carefully reviewed. complex subject. Extensive technical and programmatic discussions follow in the body of the report. The panel outlined a program plan for development of reliable, long-lived Plasma Facing Components (PFCs) for ITER, and identified the test facilities required to support that plan. Critical development issues for both divertor physics concept development and PFC technology were considered. Cost, schedule, and risk for ITER were evaluated in defining the plans for issue resolution.

\section{I.1 Charter to the Panel}

The Plasma Facing Components (PFC) Generic Facilities Review F'anel (GFRP) was formed at the direction of the DOE/OFE ITER and Technology Division. The charter to the panel was issued on September 3, 1992. The panel was asked to

1. Review the current ITER EDA (Engineering Design Activities) divertor design concepts and edge plasma parameters.

2. Define the minimum set of generic facilities, along with necessary and sufficient conditions, for

- definition and testing of baseline and alternative divertor design concepts,

- divertor performance verification testing.

- qualification of divertor concept engineering lifetime and reliability.

3. Define time lines for the divertor development and verification program and their relationships to the overall ITER schedule.

4. Consider the cost-effectiveness of options considered in the divertor development and verification program.

5. Differentiate between R\&D that must be done on tokamaks and that could be accomplished in single or multiple effects test facilities. Address necessary and sufficient synergistic effects.

\section{I.2 The Panel's Major Conclusion on the Minimum, Necessary, and Sufficient Set of Test Facilities}

The test facilities, identified below, which support the overall PFC issue resolution program plan. represent the minimum, most cost-effective set of test facilities required for development of reliable, long-lived PFCs for ITER:

- High power density tokamaks,

- Small linear plasma simulation devices,

- Ion/electron beam high heai flux test stands,

- Pulsed, high power density plasma guns for simulation of disruption thermal loads,

- Fission reactors for neutron irradiation damage studies.

As discussed more completely in the body of the report, this set allows for resolution of all physics and technology issues listed above and sufficiently minimizes the risks associated with PFC development and validation.

\section{I.3 The Panel's Additional Findings on the Minimum, Necessary, and Sufficient Set of Test Facilities}

- Any divertor physics operational mode proposed for ITER will need to be successfully demonstrated on an operating tokamak. The risks to ITER of not performing divertor physics concept validation testing on tokamaks is 
unacceptably high. Only tokamaks provide the synergistic physics environment for concept validation testing. linking divertor action to critical core plasma performance. such as particle/energy confinement, impurity contamination, density/fueling control, helium exhaust and ELM/disruption behavior.

- Presently operating tokamaks provide most of the test conditions required for divertor concept development and validation. To develop and validate a divertor physics concept for ITER. the committee concluded that within the U.S. program the best use of available funds was for installation and operation of new divertor configurations both on DIII-D and C-Mod.

- Pulse lengths on present tokamaks of 5-10 s are sufficient for development of a divertor physics concept for ITER since all important atomic, molecular. radiative and transport processes take place on sub-millisecond time scales. Steady state wall interactions can be achieved through various wall conditioning techniques. Short pulse lengths on present tokamaks limit their ability to address PFC technology issues, but these issues are completely addressed by the other test facilities, listed above, which support the development plan.

- At present, there are a number of tokamaks available worldwide, representing considerable capital investment, that could be used for divertor concept development for ITER. Significant amounts of tokamak operation time must be dedicated specifically for divertor studies if the necessary data is to be obtained. In the United States run time on both DIII-D and C-Mod is limited by available budgets. These machines could be available for divertor studies if incremental operating funds are provided. This is the most cost-effective approach for obtaining the divertor physics data required to develop and verify a concept for ITER.

- Measurements on small plasma discharge systems are necessary. Data obtained on divertor physics issues will assist in understanding fundamental processes and is required for model validation. These systems also provide controlled environments for measurement of tritium and plasma interaction with PFC materials.

- Operation of several single effects tests facilities allows for resolution of all critical PFC technology issues. Sample rotation among the various tests stands must be carried out to address the possible synergistic effects.

- Neutron damage testing has a strong influence on definition of program plans for PFC technology development and component lifetime/reliability. The technology test program must be directed towards the validation of the divertor design in its irradiated state.

\section{I.4 The Panel's Findings on Test Facilities Not Selected for the Minimum Set of Generic Facilities}

\section{I.4.1 Large Linear Plasma Simulation Devices (LLPS), Such as IDEAL}

The committee spent considerable time evaluating the contributions to be made to divertor physics and to PFC technology development by an LLPS. As a basis for our evaluations, we accepted the performance parameters, cost, and schedule postulated for IDEAL, but did not independently verify them.

Considering that a more cost-effective and timely path for obtaining the same or similar data was identified, the LLPS was not included in the minimum, most 
cost-effective set of test facilitates required to support PFC physics and technology development for ITER.

- The LLPS did not reduce the number or complexity of physics validation experiments required to be executed elsewhere in the development program plan. primarily on tokamaks. The committee noted that the LLPS provided some basic physics data on atomic. molecular, radiative and transport processes supporting divertor physics concept development. but more directly applicable data can be obtained at significantly lower cost on tokamaks.

- The LLPS cannot contribute useful data on the physics issues of dissipative divertor impact on the core plasma behavior since it obviously has no high current, central plasma confined inside a separatrix to influence. Consequently, the LLPS received low ratings for contributions in the areas of Confinement. Density/Fueling Control and Disruptions.

- Plasma flow conditions in the LLPS are significantly different from those found in tokamaks. There is no field curvature to influence particle and energy cross field transport $\left(c_{\perp}\right.$ and $\left.D_{\perp}\right)$, and there is no plasma flow across a separatrix driving the system. IDEAL proposes to use direct ICRF particle heating. Ion and electron distribution functions will be markedly different from those found in tokamak boundary regions.

- Direct extrapolation of results obtained on the LLPS to tokamak conditions will be difficult. Plasma wall interactions in tokamaks and in mirror machines have been found to strongly influence the local plasma conditions. A significant modeling effort will therefore be required to interpret LLPS results, understand the important parameters influencing the results, and extrapolate to ITER tokamak conditions.

- The LLPS does not replace other expensive technology test facilities and does not significantly reduce the number of tests which need to be conducted outside of the LLPS. Therefore, the U.S. PFC development budget would have to be increased by more than a factor of two to include the LLPS and still maintain other critically needed testing and development efforts. Effective utilization of the available PFC budget and timeliness of the data provided also influenced the decision of the committee not to include the LLPS in the minimum PFC test facility set. Construction of a device like IDEAL is expected to take three years. With a total capital cost of at least $\$ 30 \mathrm{M}$, the construction project would require an annual budget of $\$ 10 \mathrm{M}$. The U.S. FY93 budget for PFC technology development was $\sim \$ 8 \mathrm{M}$.

- Data on Erosion/Redeposition processes can be most cost effectively obtained by properly diagnosing operating tokamaks and small simulators. The LLPS was evaluated as contributing to the fundamental physics of erosion processes in the presence of strong sheaths and glancing magnetic field incidence (e.g., sputtering yield, ejected atom direction and energy, sheath magnitude and spatial extent, ionization in the sheath and charge state achieved). However, similar data, adequate for design of ITER PFCs. can be obtained on tokamaks. Small plasma discharge devices can be used to generate thick redeposited films for subsequent materials property measurements.

The LLPS also contributes no data on the technology aspects of PFU response to disruptions. Existing plasma gun disruption simulation facilities coupled with measurements in operating tokamaks such as DIII-D provide an acceptable approach. 
- An LLPS operating at high power flux density, delivering heat fluxes of $5-50 \mathrm{MW} / \mathrm{m}^{2}$ and capable of reliable cyclic operation could provide technology data on Heat Removal and Lifetime/Reliability. The LLPS could conduct thermal cyclic, heat removal and accident testing on large scale, unirradiated PFC mock-ups. The same high heat flux data as in the LLPS can be generated, in a much more cost-effective manner. on ion/electron beam test stands.

- The test conditions in the LLPS cannot completely reproduce the ITER environment since Neutron Effects cannot be included. Inclusion of the LLPS in the test plan provided an alternative, more expensive path for some of the high heat flux testing, but did not reduce the number or complexity of lifetime/reliability tests which would have to be performed. outside of the LLPS, to address synergistic effects of neutron damage on thermal cyclic fatigue, material embrittlement, etc.

\section{I.4.2 Low Power Density Tokamaks}

Small. low power density tokamaks were identified as capable of providing some data on divertor physics concept development issues. However, the data obtained would be at plasina densities. temperatures, sheath strengths and fluxes below those provided by high power density tokamaks. For this reason, low power density tokamaks are not included in the minimum, most cost-effective test facility set.

\section{I.4.3 Small, Low Power Density Steady State Tokamaks}

A steady state tokamak could provide additional data on erosion/redeposition beyond that obtained on short rulse tokamaks. A more cost-effective and timely alternative path for resolution of this issue, utilizing thin film measurements on short pulse machines and using small plas.na discharge devices to produce thicker redeposited films, was identified. The required high heat flux testing was determined to be most cost effectively carried out on ion/electron beam test stands. 


\section{Introduction}

\section{II.1 Charter to the Panel}

The Plasma Facing Components (PFC) Generic Facilities Review Panel (GFRP) was formed at the direction of the U.S. Department of Energy, Office of Fusion Energy. ITER and Technology Division, on Seotember 3, 1992. The panel was chartered to address five topics for PFC development for ITER.

1. Revis: the current ITER (EDA) divertor design concepts and edge plasma paramcters.

2. Define the minimum set of generic facilities, along with their necessary and sufficient conditions, for

- definition and testing of baseline and alternative divertor design concepts,

- divertor performance verification testing,

- qualification of divertor concept engineering lifetime and reliability.

3. Define time lines for the divertor development and verification program, and their relationships to the overall ITER schedule.

4. Consider the cost-effectiveness of options considered in the divertor development and verification program.

5. Differentiate between R\&D which must be done on tokamaks and that which could be accomplished in single or multiple effects test facilities. Address necessary and sufficient synergistic effects.

\section{II.2 Issues for ITER PFC Development}

Present PFC technology, as evaluated during the ITER CDA (Conceptual Design Activities), appears to be only marginally acceptable for removal of unmodified power and particle fluxes flowing in the ITER scrape off layer (SOL). Based upon extrapolations from present tokamaks, a narrow channel boundary layer flow with a power density of $1 \mathrm{GW} / \mathrm{m}^{2}$ is anticipated or. ITER. Unabated, this flow leads to divertor surface heat fluxes near $30 \mathrm{MW} / \mathrm{m}^{2}$ which are at the limit of present heat removal technologies. In addition, normal sputter erosion, coupled with armor erosion during disruptions, leads to unacceptably short divertor lifetimes for low and medium atomic number armor materials (e.g., $\mathrm{Be}, \mathrm{C}$ ) and under some conditions for high armor materials.

In an attempt to improve divertor reliability and lifetime, the ITER Joint Central Team (JCT) has been emphasizing modification of the divertor region plasma by means of dissipative divertor operation. Atomic, molecular, and radiative processes are to be utilized to spread ihe deposited energy over a larger surface area and to minimize material erosion by reduction of the plasma teinperature over the divertor surface.

Unfortunately, dissipative divertor operation has neither been moideled in sufficient detail nor adequately demonstrated on operating tokamaks to permit confident extrapolation to ITER. There exist large uncertainties regarding the control of the physical processes involved with a dissipative divertor operation and regarding the impact of divertor region dissipative processes on central plasma confinement. 
The critical physics and technology issues for development of reliable, long-lived PFCs for ITER are listed in Table II.2-1. Many of the issues listed are closely coupled. Each is discussed in greater detail in Section III. Successful development of PFCs for ITER can only be achieved if all critical issues are simultaneously resolved. Advancements in either physics or technology areas will lead to improved lifetime and reliability of ITER PFCs.

\section{Table II.2-1 Critical Issues for Development of Reliable, Long-Lived PFCs} for ITER

\section{Physics Issues}

$\begin{array}{ll}\text { - } & \text { Dissipative Divertor Development } \\ \text { - } & \text { Impact on Confinement } \\ \text { - } & \text { Densirity Entrainment } \\ \text { - } & \text { Helium Exhaung Control } \\ \text { - } & \text { Erosion/Redeposition } \\ & \text { Disruption Effects }\end{array}$

\section{Technology Issues}

$\begin{array}{ll}\text { - } & \text { Heat Removal } \\ \text { - } & \text { Component Lifetime/Reliability } \\ \text { - } & \text { Tritium Inventory } \\ \text { - } & \text { Helium Exhaust } \\ \text { - } \quad \text { Erosion/Redeposition } \\ \quad \quad \text { Disruption Effects } \\ & \text { Neutron Irradiation Effects }\end{array}$

\section{II.3 Generic PFC Test Facilities Considered}

In order to identify the most cost-effective development plan and to balance the development risks, the committee chose to begin by evaluating the contributions toward resolution of each PFC issue that could be made by various test facilities.

Eight generic classes of test facilities were evaluated in detail:

1. Large high power density tokamaks - with parallel heat fluxes of $0.5-1.0 \mathrm{GW} / \mathrm{m}^{2}$. Examples include DIII-D, JI-60U, JET, Alcator C-Mod, Tore Supra and TFTR. TPX will fall into this classification.

2. Smaller, more flexible tokamaks with dedicated divertor physics and/or PFC development missions. Examples include TEXTOR, TEXT, VTFD, and others.

3. Steady state low power density tokamaks—such as the Small Steady Sta ce Tokamak (SSST) proposed by ORNL.

4. Large Linear Plasma Simulators (LLPS)-systems with $100 \mathrm{MW} / \mathrm{m}^{2}$ or more of convective power flow along the magnetic field lines, plasma cross sections larger than $0.01 \mathrm{~m}^{2}$, electron and ion energies greater than $100 \mathrm{eV}$, pulse lengths of $1000 \mathrm{~s}$ or more. and capital costs of $\$ 30 \mathrm{M}$ or more. Examples of systems in this class are the IDEAL machine proposed by PPPL and the Super-PISCES machine proposed by UCLA. 
5. Small Linear Plasma Simulators (SLPS)-discharge systems producing plasmas representative of those to be expected in the ITER divertor region. Pulse lengths, $T_{e}, T_{i}$, plasma cross sections, wetted area. etc., as large as possible, but extrapolation in most parameters is required to apply the results obtained to ITER. Facility capital costs in this category are presumed to be less than $\$ 5 \mathrm{M}$. Examples of test systems in this class include PISCES, PISCES-Lipgrade, and the Tritium Plasma Experiment (TPE).

6. Electron and ion beam high heat flux (HHF) test stands delivering $1-50 \mathrm{~N} / \mathrm{W} / \mathrm{m}^{2}$ onto actively cooled. full-scale-sized $\left(\sim 1 \mathrm{~m}^{2}\right)$ PFC design concept prototypes. These systems need to be capable of steady state operation, of reliably and quickly producing tens of thousands of thermal cycles, and of accommodating component failure testing both under normal and accident (LOCA/LOFA) operating conditions. Examples of electron beam test facilities include PMTF at SNL and JEBIS at JAERI. Examples of ion beam test stands include those at JET and at KFA Jülich.

7. Plasma guns - for simulation of PMI processes during disruptions, and of materials and component response to disruption loads. A number of modest energy $(30-100 \mathrm{~kJ})$ test facilities are presently available. such as PLADIS at the University of New Mexico, SIRENS at North Carolina State University, and VIKA at the Efremov Institute at St. Petersburg. Much larger energy systems, in the range of 1-7 MJ, are also operating at Phillips Laboratory in Albuquerque, NM, and at Kurchatov and Etremov laboratories in the Russian Federation.

8. Neutron irradiation test facilities-in this category, some materials data are being provided by irradiation in fission reactors such as HIFR and EBR-II. The committee noted the need for continued and expanded generation of data in fission reactor spectra. The committee further discussed the desirability of a $14 \mathrm{MeV}$ neutron source for proper assessment of simultaneous lattice damage and helium production. Measurements of material properties of irradiated samples will have to be made in hot cells.

\section{II.4 Evaluation Process and Conclusion Summary}

The committee next developed a program plan for PFC development for ITER. The process for program plan development began with evaluation of the potential contributions that could be made by each generic facility type toward resolution of each of the critical PFC development issues. This evaluation was done initially without regard to cost or schedule for obtaining the data. The results of this evaluation are summarized in Table II.2-1. A numerical rating system ranging from 0 to 4 was used.

\section{Ratiog}

0

1

\section{Description}

No data provided.

Some useful data on the PFC issue in question will be provided, but many open questions remain. This rating implies that useful data will be generated, but it will not be sufficient to allow confident design of reliable, long-lived PFCs for ITER. Supplemental data are required to resolve this issue. 


\section{Rating}

2

3

4

\section{Description}

Important data will be provided. Resolution of a PFC development issue entirely by reliance of data rated as 2 represents the minimally acceptable development path, and incorporates a high, but marginally acceptable, level of risk.

Essential data will be provided that can support the design of PFCs for ITER. Resolution of an issue using data rated at 3 will give more confidence in acceptable ITER PFC performance. The risk to ITER is the lowest possible without access to actual ITER data.

ITER conditions fully reproduced in the test environment.

The rationale behind the individual ratings listed in the table is discussed in detail in Section III.

\section{II.4.1 Test Facilities Required for PFC Development}

The committee members outlined a plan for resolution of each physics and technology critical issue, and identified which test facilities were required to support that plan. In defining the program plan for issue resolution and selecting the test facilities required, we considered cost, schedule, and PFC development risks. Since the committee was considering generic facility types and developing an overall PFC development strategy, rough cost and schedule estimates were sufficient. When more detailed estimates were available from published tokamak program plans or test facility proposals, we utilized this information to refine cost and schedule estimates for generic facilities.

The bottom row of Table II.2-1 indicates which generic facility types were selected as the minimum, most cost-effective set required to support the PFC development plan. The test facilities selected were

- High power density tokamaks,

- Small linear plasma simulation devices,

- Ion/electron beam high heat flux test stands.

- Pulsed, high power density plasma guns for simulation of disruption thermal loads,

- Fission reactors for neutron irradiation damage studies.

How these test facilities support the PFC development program plan is discussed in detail in Section IJI. 


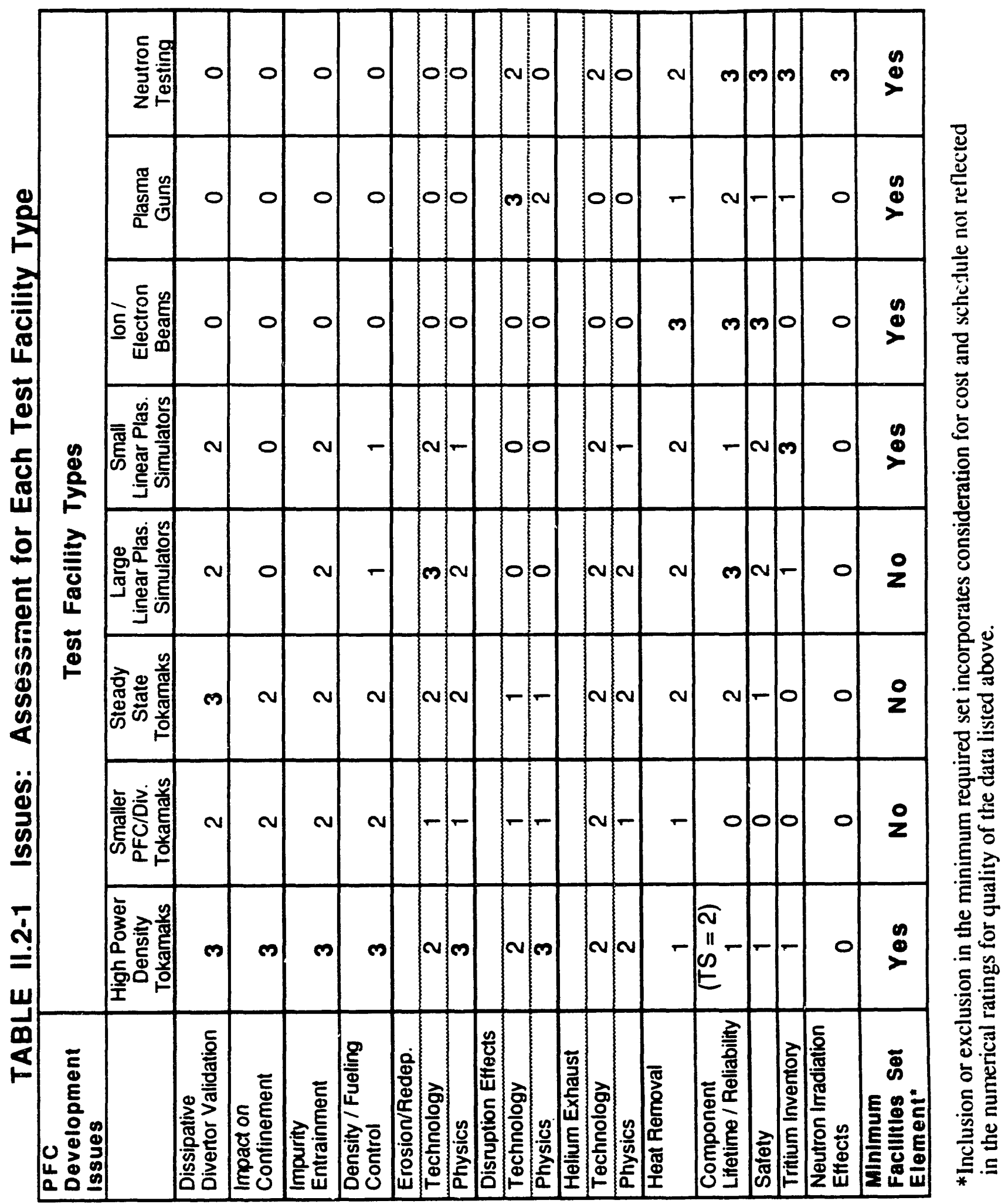




\section{II.4.2 Test Facilities Considered and Not Selected}

The generic test facility types considered and not selected as part of the minimum. most costeffective set required to support the development plan were

- Small tokamaks with only modest boundary layer power flux densities,

- Small low power density steady state tokamaks,

- Large linear divertor piasma simulation devices.

As shown in Table II.2-1, each of these test facility types can contribute useful data to the required PFC design data base. They have been excluded from the minimum required test facility set because

1. the same or similar data can be obtained from another test facility in a more cosi effective manner, and/or

2. the schedule for data delivery was inconsistent with the schedule for ITER.

\section{II.4.2.1 Small Pulsed Tokamaks}

A number of small tokamaks are presently in operation throughout the world (TEXTOR, TEXT, and others). These tokamaks have diverse missions, for example, optimization of a particular heating scheme. Many presently do, and will continue to, contribute to the boundary layer physics and PFC technology data base. Their exclusion from the minimum set of required PFC development test facilities results because similar data at higher power densities can be obtained on larger tokamaks.

\section{II.4.2.2 Small Steady State Tokamaks}

A small, steady state tokamak, similar to the SSST design proposed by ORNL, was discussed. Such a machine could contribute valuable data addressing PFC issues in many areas. Long pulse operation is attractive for investigating (1) dissipative divertor validation, (2) the impact of dissipative divertor action on confinement, (3) impurity entrainment, (4) density/fueling control, (5) erosion/redeposition, and (6) helium exhaust. The data obtained would be at relatively low power densities $\left(<0.5 \mathrm{GW} / \mathrm{m}^{2}\right.$ parallel flow in the SOL), and considerable extrapolation to ITER conditions would be required.

The time scales for critical physics processes controlling the boundary layer behavior, such as sputtering cascades, neutral/ionized particle transit times, collisional excitation/ionization and radiation, are sub-millisecond. Consequently, similar data on these important processes can be obtained at higher power densities conditions more closely resembling those expected for ITER on larger, short pulse $(\sim 10 \mathrm{~s})$ tokamaks.

Useful data and operational experience would also be provided on heat removal and lifetime/reliability issues. Here too, however, conditions are far from those anticipated for TTER. Heat fluxes would be relatively low, $\sim 1 \mathrm{MW} / \mathrm{m}^{2}$, and more relevant thermal cyclic and thermal stress data could be easily obtained from ion/electron beam testing of actively cooled PFC mockups. Note that no data on neutron effects would be included.

Finally, we note that no facility of this type presently exists. Assuming a flat EDA projected budget for ITER, construction of such a device would draw essential funding away from other portions of the development plan. 


\section{II.4.2.3 Large Linear Divertor Plasma Simulations Devices (LLPS) Such as IDEAL}

The committee spent considerable time evaluating the contributions to be made to divertor physics and to PFC technology development by the LLPS. Information available on the IDEAL device, proposed by PPPL, and on Super PISCES, proposed by UCLA, was extremely valuable.

The potential contributions to be made by an LLPS for resolution of critical issues for ITER PFCs are summarized in Table II.2-1. The ratings provided assume that the test device operates reliably and with high $(>75 \%)$ availability. We assumed that the device would provide plasma conditions representative of those to be expected in the ITER divertor region, $\mathrm{q}_{11} \sim 1 \mathrm{GW} / \mathrm{m}^{2}, \mathrm{n}_{\mathrm{e}} \sim 0.1-1.0 \mathrm{x}$ $10^{21} / \mathrm{m}^{3}, \mathrm{~T}_{\mathrm{e}}>100 \mathrm{eV}, \mathrm{T}_{\mathrm{i}}>300 \mathrm{eV}, \mathrm{B} \sim 2-3 \mathrm{~T}$, connection lengths $\sim 10 \mathrm{~m}$, heated areas $\sim 0.01$ $\mathrm{m}^{2}$, and pulse durations of $>1000 \mathrm{~s}$. In our assessment, we assumed the capital cost for the device considered to be $\$ 30 \mathrm{M}$.

On the physics issues that require assessment of the impact of dissipative divertor action on tire core plasma behavior, the LLPS cannot contribute useful data since it obviously has no high current, central plasma confined inside a separatrix to influence. Consequently, the LLPS received low ratings for contributions in the areas of Confinement, Density/Fueling Control and Disruptions. The LLPS also contributes no data on the technology aspects of PFC response :0 disruptions.

The LLPS provides some data on Dissipative Divertor Concept Validation, Impurity Entrainment, and Helium Exhaust, but data more easily extrapolated to ITER is provided by tokamaks. Some useful information would be contributed to the fundamental physics data base on plasma/neutral gas interaction, collisional processes for fuel and impurity species, and the dynamics of the plasma and exhaust gas flows. We note, though, that flow conditions would be significantly different from those found in tokamaks. There is no field curvature to influence particle and energy cross field transport, $\chi_{\perp}$ and $D_{\perp}$. There is no separatrix driving the system, so an essential boundary condition is absent. Since the plasma heating scheme is very different in the LLPS, for example, IDEAL would use direct particle ICRF heating while the tokamak boundary is heated by charged particle diffusion across the separatrix, ion and electron distribution functions will be different from those found in tokamaks. Plasma wall interactions in tokamaks and in mirror machines have been found to strongly influence the local plasma conditions. Because of differences in the heating schemes and in plasma wall interactions, direct extrapolation of results obtained on the LLPS to tokamak conditions will be difficult. A significant modeling effort will, therefore, be required to interpret LLPS results, understand the important parameters influencing the results, and extrapolate to ITER tokamak conditions.

Any proposed divertor physics concept for ITER will have to be successfully demonstrated on a high power density tokamak. The risk for ITER of not performing divertor physics concept validation experiments on tokamaks is unacceptably high. In deciding not to include the LLPS in the minimum set of required PFC test facilities, the committee was strongly influenced by the fact that inclusion of the LLPS provided some unique and valuable data, but did not reduce the number or complexity of physics validation experimen's required to be executed elsewhere in the development program plan.

The most notable contribution provided by the LLPS was in the area of Erosion/Redeposition. The LLPS is well suited for investigation of the fundamental physics of erosion processes in the presence of strong sheaths and glancing magnetic field incidence (e.g., sputtering yield, ejected atom direction and energy, sheath magnitude and spatial extent, ionization in the 
sheath and charge state achieved). Additionally, the LLPS would be capable of generating thick redeposited films for subsequent materials property measurements.

The conclusion of the committee was that similar data on erosion/redeposition processes could be obtained in a more cost-effective manner by properly diagnosing operating tokamaks. A program plan for resolution of erosion/redepositior processes is described in Section III.5. The essential physics elements for understanding and controlling erosion/redeposition process are (1) sputter source strength, (2) subsequent atom/molecule ionization and transport. and (3) redeposition. Thin film measurements made on PFC surfaces using implanted markers or simple profilometry, inside the tokamaks or on components removed after exposure to many discharges, can provide detailed estimates of erosion and redeposition rates. Spatial profiles have already been obtained on several machines such as JET. TFTR. DIII-D and JT-60U which provide insight into sputtered atom transport. More detailed and controlled experiments on eroded material transport are planned on DIII-D using the Divertor Materials Evaluation System (DIMES). Additional information on impurity atom transport can be obtained by installation of spectroscopic diagnostics looking at the SOL and divertor regions on tokamaks. Refined measurements of erosion and redeposition rates are planned on DDI-D using laser interometric and elipsometry measurements. These diagnostics will measure erosion/redeposition rates during the tokamak discharge.

Tokamaks can further provide thin film samples of redeposited material, on the order of tens of microns thick depending upon exposure times. These thin films can be analyzed to determine the redeposited material composition and microstructure. For thick films, a key question is to what extent the ITER environment must be reproduced in generating films for further study. It may be sufficient to use a fairly simple plasma discharge device, without the magnetic field strength, oblique field-surface geometry, sheath potential structure, plasma fluxes, densities, temperatures and gradients expected for ITER. For carbon, deposition conditions strongly affect the microstructure of the deposited film. Microstructures ranging from hydrogen rich soot to high purity diamond can be obtained using simple, low power discharge devices. The data base for redeposited metal films is smaller than that for carbon, but one would expect less sensitivity of the film structure to deposition conditions. It should be possible, then, to utilize small, high fluence plasma discharge systems such as TPE and PISCES Upgrade to generate thick redeposited films with composition and microstructure similar to that produced in the tokamak thin films. These thicker films can be utilized for determination of the physical properties of redeposited layers.

An LLPS operating at high power flux density, delivering heat fluxes of 5-50 MW/m 2 and capable of reliable cyclic operation could provide very valuable technology data on Heat Removal and Lifetime/Reliability. As proposed, the LLPS would be capable of conducting thermal cyclic, heat removal and accident testing on large scale, unirradiated PFC mock-ups. This same data can be generated on ion/electron beam test stands. The ion/electron beam facilities were found to be an order of magnitude cheaper than the LLPS (\$3-5M for the beam systems vs. \$30M or more for the LLPS). Several ion and several electron beam systems have been in operation for several years at SNL. JET, KFA Jülich, CEA, JAERI and Efremov. These systems will continue to be available for fusion studies. Upgrades to higher power levels or to accommodate different coolant options are relatively inexpensive ( $1 \mathrm{~N}^{\mathrm{T}} \mathrm{W}$ of electron beam heating capability costs $\$ 1 \mathrm{M}$; a small, high pressure helium gas coolant loop recently installed on SNL's EBTS cost $\$ 0.2 \mathrm{M}$ ).

The test conditions in the LLPS would not be a complete reproduction of the ITER environment since Neutron Effects could not be included. There are no irradiation facilities capable of accommodating large area $\left(\sim 1 \mathrm{~m}^{2}\right)$ PFC mock-ups, and construction of such an facility cannot be considered within the present budgetary limits of the worldwide fusion research program. The program plan for resolution of PFC lifetime/reliability issues is described in Sections III.8 and III. 11. Inclusion did not, however, reduce the number or complexity of tests required outside the LLPS to develop reliable, long-lived PFCs for ITER. As shown in Section III, neutron damage 
and its synergistic impact on thermal cyclic fatigue and PFC reliability require rotation of samples through a number of single effects test stands. Inclusion of the LLPS in the lifetime/reliability test plan provides a parallel, but significantly more expensive, path for high heat flux testing of unirradiated samples. The lifetime/reliability test sequence. which includes neutron damage effects, is completely unaffected by inclusion of the LLPS.

Effective utilization of the available PFC budget and timeliness of the data provided also influenced the decision of the committee not to include the LLPS in the minimum PFC test facility set. Construction of a device like IDEAL is expected to take three years. With a total capital cost of $\$ 30 \mathrm{M}$, the construction project would require an annual budget of $\$ 10 \mathrm{M}$. The U.S. FY93 budget for PFC technology development was $-\$ 8 \mathrm{M}$. Since the LLPS does not replace other expensive test facilities and does not significantly reduce the number of tests which need to be conducted outside of the LLPS, the U.S. PFC development budget would have to be increased by more than a factor of two to include the LLPS and still maintain other critically needed testing and development efforts. From experience in the mirror program, it is estimated that an LLPS such as IDEAL would require a three-year start-up period before reliable operation with full parameters could be expected. This means that test data for ITER would not be forthcoming until 1999. assuming that construction began immediately. Considering this schedule for data delivery and the fact that a more cost-effective path for obtaining the same or similar data was identified, the LLPS was not included in the minimum, most cost-effective set of test facilitates required to support PFC physics and technology development for ITER. 
(This page intentionally left blank.) 


\section{PFC Development Issues and Test Facility Evaluations}

\section{III.1 Overview}

For each of the critical PFC physics and technology issues listed in Table II.2-1. the committee evaluated the value of potential contributions provided by each of the eight generic test facility types listed in Table II.2-1. These potential contributions are discussed below. A program plan for resolution of each issue was outlined and the most cost-effective set of test facilities required to support that plan identified. The plan and supporting facilities described below lead to resolution of each PFC physics and technology issue. All important synergistics effects are addressed. The test facilities included in the set required to support the program plan are both necessary and sufficient for development of reliable. long-lived PFCs for ITER.

\section{III.2 Dissipative Divertor Validation and Impact on Confinement}

Current estimates of ПIER divertor heat loads indicate they are so large that they impose severe engineering and materials restrictions on the overall divertor design. The actual amount of exhaust power is not large, but it is concentrated in the very narrow region of the scrape off layer (SOL). One technique proposed to reduce the divertor heat loads is to dissipate or spread out the heat flux before it reaches the divertor plate. The basic idea is to introduce either deuterium or impurity gases into the discharge that wili, in turn, radiate and spread out the heat flux. Various degrees of dissipation have been proposed: from reducing the heat flux to a level that can be handled with conventional engineering techniques, to a complete exhaust of the divertor power before it reaches the plate. In the latter case, the divertor plate would only be used as a backup when the full heat flux reduction from the radiative divertor was not achieved.

\section{III.2.1 Data Base Needs}

The design of a dissipative divertor for ITER will have to address several critical issues. It would seem that the most useful information to ITER would be "proof of principle" operation of a dissipative divertor in a tokamak environment with only a modest (factor of $~ 2-3$ ) extrapolation to ITER. The major issues are the heat flux reduction and the influence on the core plasma. These plasmas would be sufficiently diagnosed to understand the basic physics of the operation. In turn. this would lead to a benchmarked computer model that can be used to calculate specific ITER cases. Other issues include

A. Heat Flux Issues

1. Heat flux reduction required for ITER

2. Radiation efficiency (deuterium, impurities, hybrid)

B. Effect on Confinement (Related to Entrainment-Section III)

1. Energy confinement

2. Density

3. Core Zeff

C. Plasma Configuration and Interface with Divertor Configuration

D. Location of Radiating Zone

1. Detached plasmas

2. MARFE-like phenomena

3. Radiating SOL (not just divertor)

E. Steady State Capability

F. "Extrapolation" to ITER

1. Extent of extrapolation from current machines

2. Benchmarked computer models 
As discussed above, the heat flux issues center around the amount of heat flux reduction and the radiating species-deuterium or impurities. The current ITER baseline seems to be a "gaseous" radiative divertor, in which high level gas puffing is used to completely exhaust the power flow to the divertor plate. Other more conservative approaches use modest gas puffing of deuterium. impurities, or a mixture, to radiate power and spread out the heat flux. (Even the pure deuterium case will most likely be a hybrid case because of intrinsic impurities present in the divertor.) Current experiments on DIII-D and JET with open divertors and "modest" gas puffing have demonstrated heat flux reduction factors of two up to about five; this reduction has not been linked in an absolute sense with divertor radiation. (Absolutely calibrated experiments are in progress.) Also, it has not been shown conclusively whether the increase in divertor radiation is due to increase in impurity density or electron density (the radiation depends linearly on both quantities); detailed divertor spectroscopy and density measurements will be required to distinguish these two possibilities.

The dissipative divertor must reduce the divertor heat flux, while at the same time not significantly degrade the core plasma performance. The most basic figure of merit is that the energy confinement. for whatever reason, should not be substantially degraded from the baseline ITER design. Experiments on DIII-D and JET have been performed with gas puffing that show heat flux reduction with modest changes in the core energy confinement times. However, in some cases, particularly high gas puffing rates with high- $Z$ impurities, the core plasma has been affected. In deuterium puffing experiments, the core density usually rises; this may be controlled by active pumping or more careful control of the gas puffing rate with feedback. When using impurities in the divertor for radiation, the core $Z_{\text {eff }}$ cannot be increased beyond ITER requirements; this is related to the issue of impurity entrainment which is treated in more detail in Section III.

It is currently felt that the influence on the core plasma can be mininuzed by a more closed divertor design. either using slots or baffles to cause more localized recycling of either puffed deuterium or impurities in the divertor. Structures and pumping can be used to enhance the plasma flow and increase the frictional force on impurities, thereby increasing entrainment.

The location of the radiating zone is very important in the ITER design. Present experiments on JET and DIII-D show detached or MARFE-like structures during gas puffing experiments. Experiments must determine the stability of these modes, and whether they are always present and necessary. Feedback techniques may be required to obtain stable operation. There also seems to be some discussion about the exact location of these structures (i.e.. inside or outside the separatrix, inner or outer region of the plasma) and whether they occur with impurity puffing. Another dissipative technique is to expand the radiation zone into the whole plasma periphery (not just the divertor), much like the I-mode experiments at TEXTOR. The current data base for these experiments on diverted machines is small.

An obvious data need is whether these dissipative schemes will operate in steady state. Present experiments will operate in the tens of seconds regime, and this should be adequate to determine whether long-term trends are important (walls and plates should be saturated in this time scale).

The final step is the prediction of actual ITER performance with the dissipative divertor. Ideally, the experimental extrapolation (e.g.. power, heat flux) will be modest with a configuration that is similar to that of ITER. A very important tool in this extrapolation will be the development of benchmarked computer models of the scrape-off plasma and the interactions of neutrals and impurities. The model should address impurity entrainment. radiation, and wall interactions. The diagnostic data base on machines will have to be sufficient to obtain reasonable confidence that the physics in the models is correct. 


\section{III.2.2 Test Facility Requirements}

The ideal facility is a tokamak with a divertor and plasma configuration as close to that of TTER as possible. Short of building ITER, the device should provide a modest extrapolation. In addition. other devices with similar physics (but. perhaps. reduced power fluxes, etc.) should be used to test the physics in the computer models. The diagnostic capability can be sufficient to (1) determine the data base needs outlined in the section above (II.1) and (2) benchmark the computer models.

\section{III.2.3 Test Facility Evaluations}

As discussed above, the ideal facility is a tokamak operating as close to ITER parameters as possible, with adequate diagnostics to benchmark computer models. Clearly, high power density tokamaks and steady state tokamaks are the most suited for this particular test facility, as they provide an integrated test of the divertor and core plasma performance. Examples of the parameters for two present machines. DIII-D and C-Mod, are ircluded in Table III.2-1, along with anticipated parameters for ITER. Smaller tokamaks can provide information, particularly o: code validation, albeit they require a larger extrapolation to ITER operating parameters.

Divertor structures relevant to the ITER divertor are either installed or planned for C-Mod. DIII-D, and JET. Sufficient diagnostics must be available to assess the suitability of these designs for ITER and to provide input into the computer models.

As indicated in the ratings in Table II-1. large and small plasma simulators were judged less desirable because of the inability to perform an integrated test, i.e., to measure the influence of the dissipative divertor on the core plasma. Basic physics processes, such as atomic physics, could be addressed in large and small plasma simulators.

\section{III.2.4 Program Plan for Issue Resolution}

ITER has indicated the need for input on this issue by late in calendar year 1997. The program plans presented at U.S. DOE Field Work Proposals indicate that progress will be made on both DIII-D and C-Mod by this time period. The program plan adopted relies on the tokamak divertor development plans on existing tokamaks, such as C-Mod. DIII-D. JET and JT-60, to validate an overall design for ITER. This will require careful organization and interaction both nationally and internationally to make sure relevant experiments are planned and carried out. In addition. adequate diagnostic development will be required both to achieve the basic results and benchmark the computer models.

\section{III.2.5 Program Cost and Schedule}

We have estimated the program cost and schedule from the program plans of a representative set of confinement machines based on the presentations at the 1993 Field Work Proposals. Divertor development time lines for C-Mod and DIII-D appear here as Tables M.3-1 and -2. Note that both should achieve tests of divertor structures by the 1997 date. Additional funding is required in order to meet these schedules; DIII-D has requested an additional $\sim \$ 3 \mathrm{M}$ per year, and C-Mod has estimated an additional $\sim \$ 2 \mathrm{M}$ per year is required to maintain their schedule. These schedules are important to obtain results in time to impact the ITER divertor design.

These plans include a modest amount of funds to modify diagnostics for the new divertors. The modeling effort required to support tokamak measurements will need to receive continued funding roughly at its present, or slightly increased, level. Within the U.S. OFE, support for divertor modeling is being provided by Confinement Systems, ITER and Technology and AP\&T divisions. Consequently, the modeling effort is not sufficiently coordinated. 
Table III.2-1

DIVERTOR PARAMETERS

\begin{tabular}{|c|c|c|c|c|}
\hline Parameter & $\begin{array}{c}\text { Anticipated } \\
\text { ITER }\end{array}$ & DIII-D & Alcator C-Mod & Notes \\
\hline $\begin{array}{c}\text { Field line length, } \\
L_{\|}\end{array}$ & $>10 \mathrm{~m}$ & $13-\infty$ & $5-\infty$ & (1) \\
\hline $\begin{array}{l}\text { Parallel heat } \\
\text { flux, qil }\end{array}$ & $\sim 1.0 \mathrm{GW} / \mathrm{m}^{2}$ & $0.1-0.7 \mathrm{GW} / \mathrm{m}^{2}$ & $0.5-1.0 \mathrm{GW} / \mathrm{m}^{2}$ & \\
\hline Midplane ne & $0.5-1.0 \times 10^{20} \mathrm{~m}^{-3}$ & $0.1-1.0 \times 10^{20} \mathrm{~m}^{-3}$ & $0.5-5.0 \times 10^{20} \mathrm{~m}-3$ & \\
\hline Divertor plate $\mathrm{n}_{\mathrm{e}}$ & $0.5-1.0 \times 10^{21} \mathrm{~m}^{-3}$ & $0.5-1.0 \times 10^{21} \mathrm{~m}^{-3}$ & $0.1-2.0 \times 10^{21} \mathrm{~m}^{-3}$ & \\
\hline $\mathrm{T}_{\mathrm{i}}$, midplane & $100-1500 \mathrm{eV}$ & $<2000 \mathrm{eV}$ & $100-400 \mathrm{eV}$ & (2) \\
\hline Te, midplane & $100-750 \mathrm{eV}$ & $>400 \mathrm{eV}$ & $75-300 \mathrm{eV}$ & (2) \\
\hline$B$ & $2.5 \mathrm{~T}$ & $<2.1 \mathrm{~T}$ & $<9 T$ & \\
\hline Pulse duration & $\sim 1000 \mathrm{~s}$ & $<10 s$ & $<7 \mathrm{~s}$ & \\
\hline Operating time & $\sim 10^{6} \mathrm{~s} /$ year & $<4 \times 10^{4}$ s/year & $<10^{4}$ s/year & \\
\hline $\begin{array}{c}\text { Wetted plate } \\
\text { area }\end{array}$ & $1-2 m^{2}$ & $1 \mathrm{~m}^{2}$ & $\sim 0.5 \mathrm{~m}^{2}$ & \\
\hline
\end{tabular}

(1) Minimum is at one $\lambda \rho$ from separatrix at midplane for $995=3$.

(2) Depends on density. 


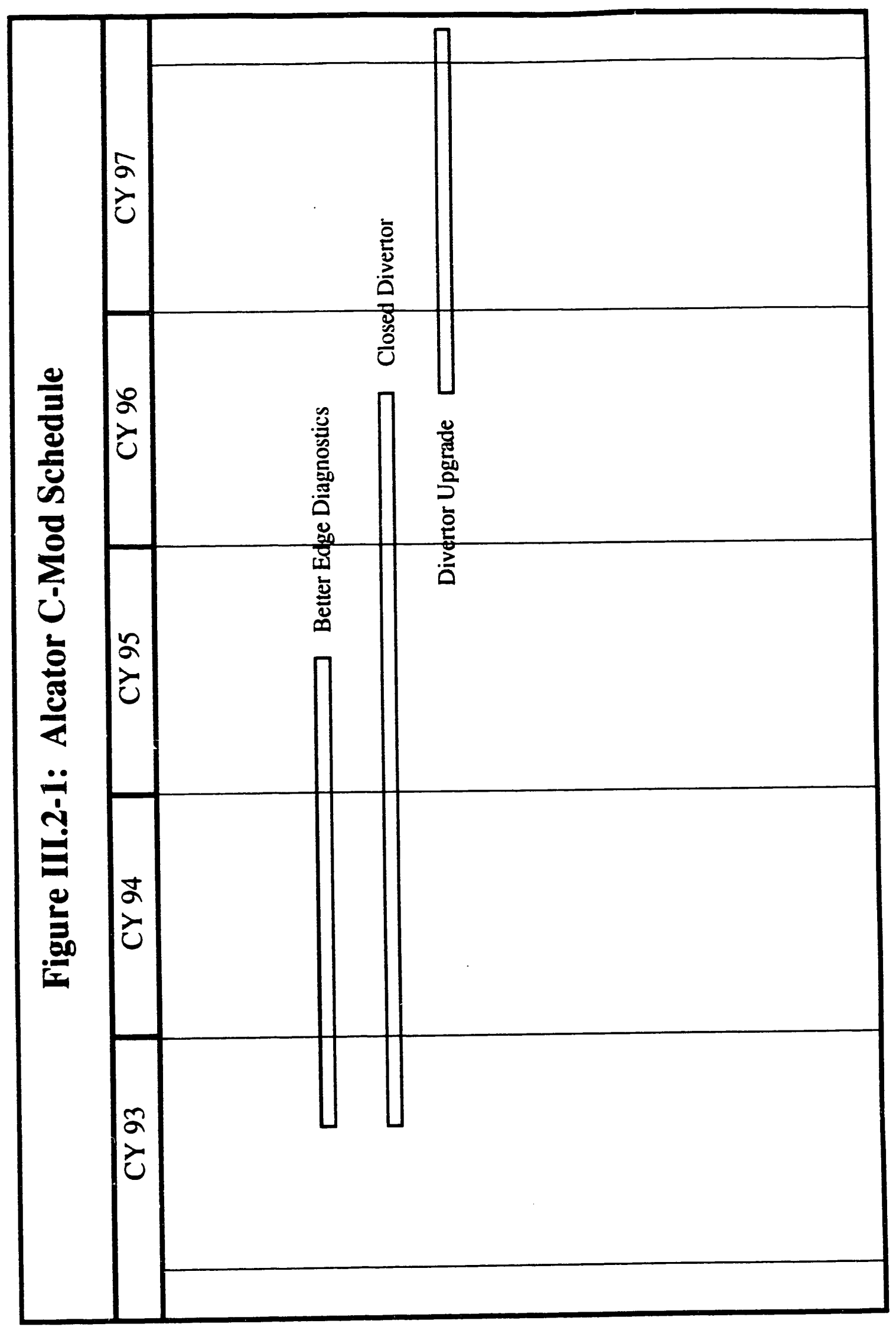

-19- 


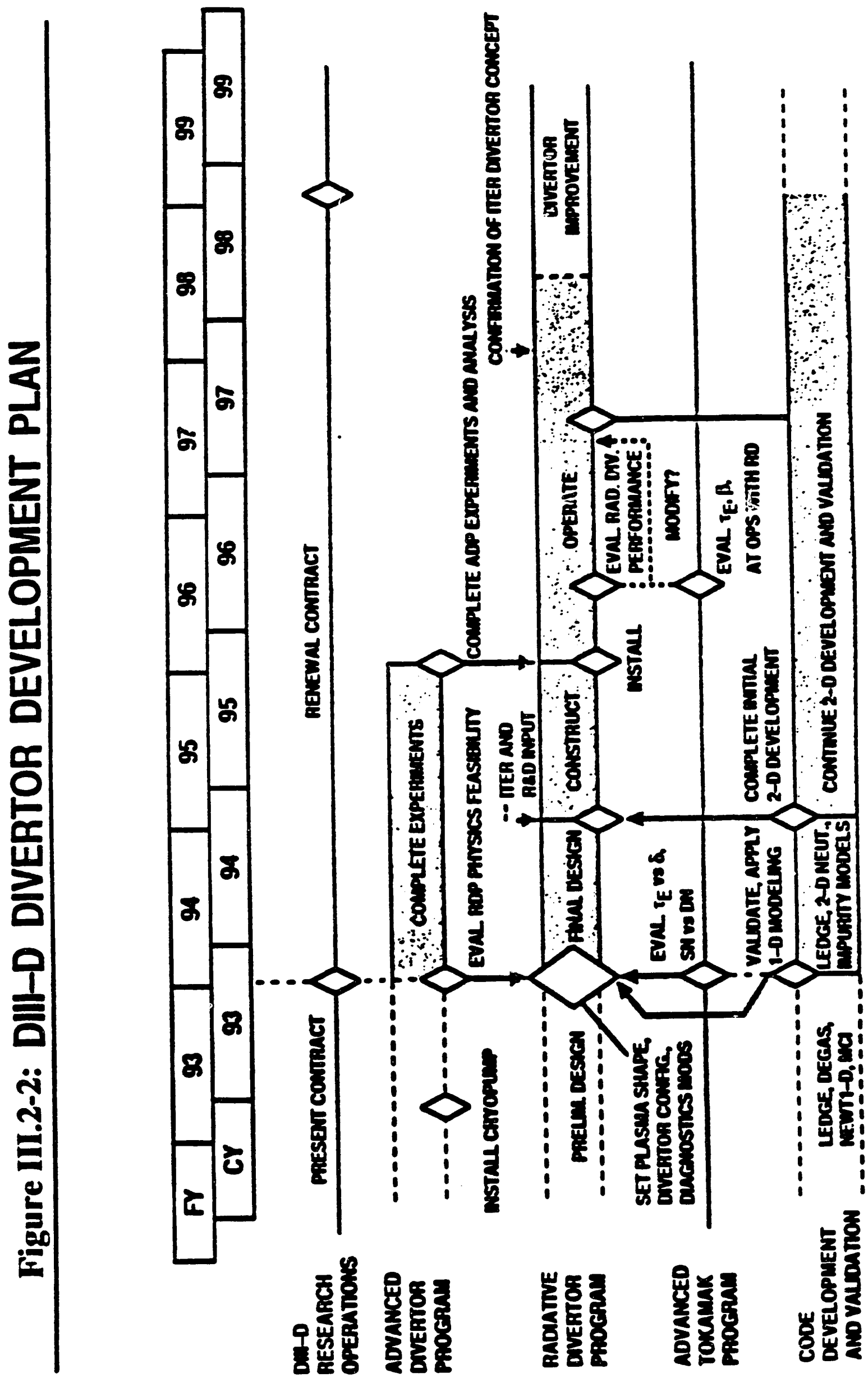




\section{III.3 Impurity Entrainment}

\section{III.3.1 Data Base Needs}

In designing a divertor for ITER, or a reactor, it is important to predict the density of a particular impurity in the central plasma. This prediction is based on the design geometry and an understanding of impurity generation and transport in the SOL and divertor regions: in particular. what fraction of impurities which are created in the divertor (or elsewhere in the vessel) e.1d up in the divertor rather than entering the central plasma. The issues which are central to this understanding of impurity entrainment are

(a) Impurity ion flow pattern including flow reversal (parallel transport) is determined by the competition between viscous drag and $\nabla \mathrm{T}$ forces.

(b) Impurity generation mechanisms at divertor, wall and antenna surfaces.

(c) Impurity ion diffusion (perpendicular transport) both towards and away from the central plasma.

(d) Direct neutral ingress to the central plasma.

In understanding the above issues we must be able to predict their dependence on

- extrinsic vs. intrinsic impurities,

- $\quad$ recycling vs. nonrecycling impurities,

- $\quad \mathrm{n}_{\mathrm{sep}}, \mathrm{T}_{\mathrm{sep}}, \mathrm{n}_{\mathrm{div}}, \mathrm{T}_{\mathrm{di}}$,

- Z of impurity,

- $\quad \mathrm{n}_{\mathrm{z}} / \mathrm{n}_{\mathrm{e}}$,

- $\quad$ type and magnitude of auxiliary heating.

\section{III.3.2 Test Facility Requirements}

The ideal facility should have a "closed" divertor geometry (or even better, various closed geometry versions). The dimensionless parameters of the divertor and SOL should be as close as possible to that of ITER (see Table III.2-1). The above requirements affect all of the issues cited in Section II.2. The power flow along a field line should be in the range $0.5-1.0 \mathrm{GW} / \mathrm{m}^{2}$ (affects flows and parallel transport). A separatrix is needed to generate perpendicular transport in a reasonable fashion. Appropriate $\mathrm{Z}$ impurities of both extrinsic and intrinsic rature should be available.

\section{III.3.3 Test Facility Evaluations}

At this point in time, modeling indicates that flow reversal in the divertor and SOL is extremely important in determining the level of impurities in the SOL and central plasma. These flows not only determine the flow of impurities out of the divertor but also determine whether wall or antenna sourced impurity neutrals which are ionized in the SOL are swept into the divertor. However. there is little experimental data to verify these flows and the subsequent transport of ions across the separatrix into the central plasma. From the modeling, factors that affect these flows are perpendicular transport, the $Z$ of the impurity and its fractional abundance in the SOL, and standard edge parameters such as the density and temperature (particularly the parallel temperature gradient). With the uncertainty in the area of flow prediction and the requirements in Section III.2. it is clear that high power density tokamaks are the ideal facilities for these studies. The primary drawback of these tokamaks is their short pulse length operation. 
The other facilities listed in Table II.2-1 were rated less highly clue to lack of some or all of the important characteristics cited in this and the previous section. Low power or steady state tokamaks are typically lacking in the high parallel power flows. $\mathrm{n}_{\text {sep }}$ and $\mathrm{T}_{\text {sep, }}$ that are available. Large linear plasma simulators lack a separatrix (and accompanying perpendicular transport) and the primary elements for studying flow reversal. Small linear plasma simulators further lack the needed power flows and density but are suitable for tests of small pieces of physics (viscous and $\nabla \mathrm{T}$ effects). Ion/electron beams, plasma guns and neutron facilities have no relevance in this area.

\section{III.3.4 Program Plan for Issue Resolution}

The short-term (2-3 years) emphasis in the area of impurity containment/entrainment should be to better diagnose existing facilities. Flows are predicted to be important in existing tokamaks. Impurity diagnostics are now being added in these experiments. In addition, important variations in geometry and plasma parameters are already available from Alcator C-Mod (high density. "closed" divertor) and DIII-D \& TEXT (lower density. more open divertors). The proper diagnostic attention to this area could result in extremely relevant data which can serve to benchmark codes and theory. Relevant programs in verifying the physics of viscous and $\nabla T$ forces can, and are. being carried out on small plasma discharge experiments (SLPS).

The same information gathered from impurity studies will also be beneficial for the understanding of the processes in the dissipative divertor studies. The efficacy of impurity entrainment, to a large extent. determines the effectiveness of the radiative divertor approach. If impurities are not well contained in the divertor region, then the limit on the impurity level in the divertor (determined by the level in the central plasma), and thus the radiation in the divertor, will be lower than required.

Over the next several years preparation must be made for further improvements in impurity studies. The improvement should be in the areas of divertor geometry and new diagnostics. Considerable understanding of the processes involved in impurity generation and transpor can be obtained through utilization of the existing variety of geometries and near-term diagnostics. However, the confidence in the ITER divertor design will be increased enormously if the divertor geometries in existing tokamaks are made even more "ITER-like." Given the state of flux in the ITER divertor design and the status of new divertor designs for existing tokamaks, it is reasonable that the implementation of new divertor geometries occur in two to three years. As the near-term diagnostics maiure and new ones are added. the evaluation of these new geomerries will be rapid.

\section{III.3.5 Program Cost and Schedule}

The cost of the program outlined above is determined, for the most part, by the high power tokamaks involved. From the U.S., the principal contributions will come from Alcator C-Mod and DIII-D. The funding of the these programs is an essential part of fulfilling not only the requirements of the ITER R\&D program in impurity entrainment but also in the development of the dissipative divertor. The cost and schedule for tokamak operations discussed in Section III.2.5 will simultaneously cover the requirements for impurity entrainment testing. It is likely that the data obtained from DIII-D and Alcator C-Mod over the next iwo years combined with modeling and ITER design studies will point to changes that would be very useful to test in a high density tokamak.

\section{III.4 Density Control and Fueling}

\section{III.4.1 Data Base Needs}

Recent experimental results have shown that the core plasma confinement times (particle and energy) are strongly dependent on wall conditions (paricle inventory and recycling) and fueling 
method (pellets, neutral beams, or gas). Reduction of particle recycling through wall conditioning and reduction of impurity influx in TFTR have resulted in more peaked density profiles and improved plasma performance. Wall conditioning using coatings (e.g., boronization) and helium glow cleaning between shots on DIII-D have improved the energy confinement time for $\mathrm{H}$-mode plasmas. Operation with a pumped divertor on DIII-D has also given a more peaked density profile in $\mathrm{H}$-mode. The frequency and character of ELMs have a strong influence on the impurity content of the core plasma in several $\mathrm{H}$-mode tokamaks. Many of these improvements are not adequately explained by detailed modeling. It is clear that further research is needed in the areas of

1. fueling and recycling control,

2. core density evolution and stability in steady state.

3. the impact of the evolution of the boundary plasma layer on confinement times, and

4. the physics of ELM formation.

The impact of dissipative divertors on particle recycling and wall conditioning needs to be investigated along with the issues discussed in Sections III.2 and III.3.

\section{III.4.2 Test Facility Requirements}

The parameters required for simulation of ITER-like piasma conditions have already been shown in Table III.2-1. In addition to those parameters, studies of density control and fueling require that the edge plasma region be connected to a core plasma and have a separatrix. This is particularly important since there is a substantial body of evidence showing that edge plasma conditions and wall conditions (PFC materials) have a strong influence on the core plasma performance.

\section{III.4.3 Test Facility Evaluations}

The high power tokamaks were given a rating of 3 because such devices are the only place where the coupling of the edge plasma and the core plasma is similar to that in ITER. Even though some extrapolation to ITER will be required, high power tokamaks will provide the best test bed for new density control and fueling method experiments. Smaller tokamaks can provide supplemental information that can be used to help verify the models developed to interpret the results of the experiments (hence the 2 rating). Linear plasma devices can be used for studies of neutral density profiles and particle pumping. Linear devices cannot study the interaction between the core plasma and the edge plasma. The data from linear devices can be used to establish the validity of some density related physics in the edge plasma. The rating of 2 is based on such contributions.

\section{III.4.4 Plan for Issue Resolution - Schedule and Estimated Cost}

The issues of density control and fueling are being actively investigated in the existing tokamak program. No additional or special effort is needed by the ITER PFC community beyond that already planned and described in Sections III. 2 and III.3 above.

\section{III.5 Erosion/Redeposition}

\section{III.5.1 Data Base Needs}

This subject refers to sputtering of PFC surfaces by plasma ion and neutral particle impact, transport of sputtered material in the plasma, and redeposition of material on exposed surfaces. There are three key tokamak performance issues affected by the erosion/redeposition process:

1. PFC lifetime-determined by the net erosion rate, i.e., the difference between sputtered and redeposited fluxes. (Also determined by disruption erosion.) Sputtering related 
lifetime is primarily limited by peak erosion areas, but areas of net growth may also be a problem if heat fluxes are high.

2. Plasma contamination-determined by the sputtering and transport of material in the nearsurface region, scrape off layer (SOL), and core plasma.

3. Tritium co-deposition and resulting inventory-this is most serious for carbon where up to $40 \% \mathrm{H} / \mathrm{C}$ concentrations are possible in the redeposited layers (depending on surface temperature). Co-deposition may also be a concern for beryllium, since although tritium concentrations in redeposited layers should be much less than for carbon, beryllium growth rates may be very high.

Numerous modeling studies of erosion/redeposition have been performed for ITER, other reactor designs, and for existing tokamaks [1-4]. A basic prediction of the modeling is that redeposition rates are generally high, typically $>90 \%$ of the sputtering rate. The redeposition process. therefore, appears to be critical in limiting erosicn and plasma contamination. Another basic observation of the modeling is that, for the plasma regimes studied, most impurity transport is confined to a $0-3 \mathrm{~cm}$ near-surface region. This is, therefore, the most important region to simulate experimentally for erosion/redeposition measurements.

Several erosion/redeposition code comparisons with experiment have been performed. This includes analysis for the TFTR carbon bumper limiter [5], carbon divertors in DIII-D [6] and JET [7-8], and the boron and molybdenum impurity transport experiments in the PISCES [9]. Good agreement has been found between code predictions and experimental data, but analysis for ITER requires considerable extrapolation of models to higher power density plasma regimes and/or different surface materials. This is particularly true of the various proposed dissipative divertor regimes where there is little experimental data, and where there are considerable uncertainties in atomic and molecular cross section data.

Physics issues of the erosion/redeposition process are discussed in the above references and summarized in [10-12]. In general, key physics issues are (1) neutral atom fluxes (including angle and energy distributions) to the divertor surface, (2) transport of plasma ions through the sheath and, in particular, their inclience angles and energies, (3) sputtered particle distributions. (4) insheath ionization, if any, of sputtered and desorbed impurity atoms and molecules, and (5) nearsurface transport of impurities via collisions with the D-T plasma and by radial field transport. Other important but less critical issues to erosion/redeposition include the transport of sputtered particles in the entire scrape off layer (see also Sec. III.3) and the role of miscellaneous plasma ions such as oxygen or noble gases (e.g., added for radiation) on sputtering.

The most critical technology related issues are the sputtering coefficients of low- $Z$ PFC materials (particularly beryllium) at near-threshold energies and at oblique incidence, and the properties of thick (>1 mm) redeposited films of all PFC materials. The latter includes films resulting both from sputtering redeposition and from resolidification of disruption melted and/or vaporized material. Data is needed on the thermomechanical and thermophysical properties of such films, e.g., adhesion, sputtering coefficients, and thermal conductivity.

In general, the data needs for both physics and technology areas are a significant function of PFC surface material. Carbon presents, by far, the most uncertainties in erosion performance due to generally high predicted erosion rates, possible presence of chemical sputtering and radiation enhanced sublimation, potentially very high tritium co-deposition, and significant concerns about the redeposited material composition. Physics and data needs relating to erosion/redeposition are the highest for carbon, due to these considerations. 
Next in terms of data requirements is beryllium. Beryllium does not suffer from chemical erosion or radiation enhanced sublimation (though its temperature limits are much less than for carbon). Also, Be, being a metal, is expected to have a redeposited layer that is reasonably similar to the asfabricated material. Nevertheless, Be may suffer from very high erosion rates for all plasma regimes. This would make accurate predictions very dependent on precise knowledge of physics related data. Self-sputtering coefficients may exceed unity (leading to a runaway condition) even at moderate plasma temperatures $(>40 \mathrm{eV})$ due to oblique incidence impingement of redeposited $\mathrm{Be}^{+2}$ and $\mathrm{Be}^{+3}$ ions.

For dissipative plasma regimes, a key technology data requirement for $\mathrm{Be}$ is the sputtering coefficients for oblique incidence, D. T, He on $\mathrm{Be}$, at near threshold energies $(-10-20 \mathrm{eV})$.

High-Z materials, e.g., Nb, Mo, W. are predicted to have far less $(\sim 10-100 \mathrm{x})$ erosion than $\mathrm{Be}$ or $\mathrm{C}$ for plasma temperature regimes up to about $50 \mathrm{eV}$. As with beryllium, there is less concern about redeposited surface composition than for carbon, though this is still an important concern for all materials. Because D-T erosion for high-Z materials is very low for low temperature and dissipative plasma regimes, an important issue for precise erosion predictions is a knowledge of trace plasma impurity content and sputtering properties, e.g., oxygen on W sputtering. At higher plasma temperatures, $50 \mathrm{eV}<\mathrm{T}_{\mathrm{e}}$, it is important to determine when runaway self-sputtering occurs. Sheath properties and related impurity transport are particularly critical here.

\section{III.5.2 Test Facility Requirements}

A test facility for erosion/redeposition testing should ideally reproduce the ITER divertor conditions closely, but there is also an area of usefulness for limited-match facilities. For fully adequate testing, it is particularly important to reproduce the high magnetic field $(B=3-5 T)$, oblique incidence $\left(=3^{\circ}\right.$ from tangential) plasma geometry of ITER. This is necessary to establish similar sheath and pre-sheath boundary conditions and structure, and near-surface impurity transport. ITER-like near-surface plasma parameters are likewise important, i.e., plasma electron density of the order of $\mathrm{N}_{\mathrm{e}}=10^{20} \mathrm{~m}^{-3}$, and temperatures of $\mathrm{T}_{\mathrm{i}}=\mathrm{T}_{\mathrm{e}}=5-75 \mathrm{eV}$. (It follows from matching these plasma parameters that power fluxes to the surface would be similar to ITER.) Other important but somewhat less critical requirements are for the test facility to have similar temperature, density, and flow velocity gradients to those expected for ITER.

In the general area of devices providing less of a match for the ITER divertor conditions, it is important to at least provide a plasma to generate sufficient sputtering, cross-magnetic field transport, and redeposition, to obtain thick redeposited films, and assess some features of the erosion/redeposition models and codes.

\section{III.5.3 Test Facility Evaluations}

Column 5 of Table II.2-1 rates the eight generic test facilities in terms of erosion/ redeposition issues. As stated, both uncertainties and data needs vary substantially for different PFC materials, and these ratings represent a rough composite for all materials.

High power density tokamaks reproduce much of the ITER divertor geometry and plasma parameters and are, consequently, rated highly for answering questions about erosion/redeposition physics issues. This assumes the availability of adequate diagnostics, e.g., for measuring plasma edge profiles, impurity charge states, and surface erosion rates. Also assumed is the ability to incorporate beryllium divertor surfaces at least in test-section form, as well as high-Z materials. 
For technology issues, the high power density tokamaks were rated a 2 for their ability to provide redeposited films under ITER-like plasma conditions. Because of their short pulse lengths, they are not able to provide thick redeposited films. needed to provide essential data.

Smaller tokamaks with dedicated PFC/divertor missions were rated. as shown, with a 1 for both physics and technology contributions. It is felt that they can certainly provide useful data regarding erosion/redeposition issues. but they are limited in addressing key data needs due to lower power density, smaller size, and limited pulse length. Erosion related data. e.g., core plasma contamination that is obtained in the normal course of operation, would certainly be helpful, from these devices.

Steady state tokamaks, as typified by the proposed ORNL SSST device, were felt to be capable of providing important supporting data for erosion/redeposition purposes. Because of the long pulse lengths. thick redeposited films could be obtained, though it is not clear how flexible this device could be for sample exposure, retraction, etc. Supporting physics data could likewise be supplied. Essential data is not believed to be obtainable, however, due to significant plasma parameter (heat flux, etc.) differences with ITER.

A large linear plasma simulator, as typified by the proposed IDEAL device. was the highest rated facility for providing technology related erosion/redeposition data. This is due to its proposed ability to produce thick redeposited films under ITER relevant plasma conditions. For physics issues. IDEAL could provide ITER-like near-surface plasma parameters of field strength, field geometry, and plasma temperatures and density. Because it is not a tokamak, there are questions about any linear device's simulated SOL plasma parameters and impurity transport. Hence, we rated the large linear plasma simulator with a 2 in the erosion/redeposition physics category.

A small linear plasma simulator, e.g., PISCES. has plasma parameters substantially different from ITER. Nevertheless, useful data can be obtained for physics modeling and code validation on a wide variety of materials. This type of facility can be viewed as being intermediate in simulation ability between a beam facility (typically used for pure sputtering measurements) and a device with full plasma-surface interactions. Since these devices are steady state, thick redeposited films could be obtained using a suitable experimental set-up. Based on the previous discussion, such films would be suitable for estimating the physical properties of redeposited layers, provided that the composition and microstructure were properly controlled so as to mimic those films formed in tokamaks.

\section{III.5.4 Plans for Issue Resolution - Schedule and Estimated Cost}

In this section a very brief view is presented of a schedule, cost, and cost-effectiveness for erosion/redeposition testing. For the large, high power density tokamaks a dedicated erosion/redeposition experiment could likely be performed for 1-4M\$ per tokamak with about a two-year time schedule. (These are direct costs without allowance for tokamak capital cost recovery.) Such an experiment would provide for test surface fabrication and installation, tokamak exposure time, near-surface plasma diagnostics, possibly additional SOL diagnostics, in situ erosion diagnostics, post-tokamak exposure surface measurements, and associated modeling/analysis. Not necessarily included, however, are costs for special beryllium handling. Because of the high rated effectiveness and moderate direct costs, such experiments would appear to be both timely and cost-effective, subject to the qualification that machine time be made available specifically for erosion experiments.

An example of the approach to using the high power density tokamaks for erosion/redeposition experiments would be to use Alcator C-Mod and DIII-D as follows. For C-Mod, very useful high- $Z$ material erosion information can be obtained simply by observing the core plasma molybdenum concentration under normal operation. i.e., with the Mo divertor, under a variety of 
plasma edge conditions. Inferences about Mo erosion and transport can be obtained in this manner through appropriate modeling. Near-surface plasma and impurity charge state diagnostics (e.g., laser fluorescence measurements) and in situ erosion measurements could be added to obtain detailed data on real time Mo erosion. Test divertor sections could be used to obtain information on beryllium and other materials.

A similar approach appears feasible for DIII-D. The existing DIMES probe will be valuable for obtaining data on erosion and disruptions, assuming adequate funding.

The cost of performing detailed erosion experiments on the smaller tokamak might be fairly similar to the high power density tokamaks, inasmuch as similar preparation, diagnostics, staff time, etc., are likely required. Due to the lower performance ratings, these devices are, therefore, perceived as less cost-effective for dedicated erosion experiments.

The incremental costs for erosion experiments on steady state tokamaks are also likely to be similar to those for the high power density machine. Jonstruction of a steady state tokamak specifically to address PFC issues was judged not to be the best utilization of the limited, available PFC resources. Schedule is clearly a problem, too, for a tokamak not already operating.

Both cost and schedule issues appear to present major concerns for the large linear plasma simulators. The proposed cost for IDEAL is $>\$ 30 \mathrm{M}$. The high power density tokamaks are already built, and incremental costs for erosion/redeposition experiments are judged to be an order of magnitude lower. Schedule considerations would also strongly favor the tokamak experiment, considering the $\sim 3$ year construction time and similar performance optimization period for the large simulator.

Small linear plasma simulators are already in operation, are relatively easy to upgrade, and are relatively inexpensive to operate. The committee considers them as cost-effective, within their area of usefulness.

A rough schedule for erosion/redeposition testing on high power density tokamaks and small plasma discharge devices is shown in Figure III.5-1. Stated broadly, the essential issues for erosion/redeposition studies are material, sputter source term, impurity atom/ion transport, and physical properties of the redeposited layers. Some testing is already in progress on large (and small) tokamaks and in small plasma discharge systems. For both test categories, testing programs consisting of several individual experiments will need to be continued until the divertor physics concept and supporting technologies have been defined. This concept definition is estimated to take place at the end of 1998, as indicated in the figure. Beyond that. final concept validation testing will need to be carried out, principally in tokamaks. 


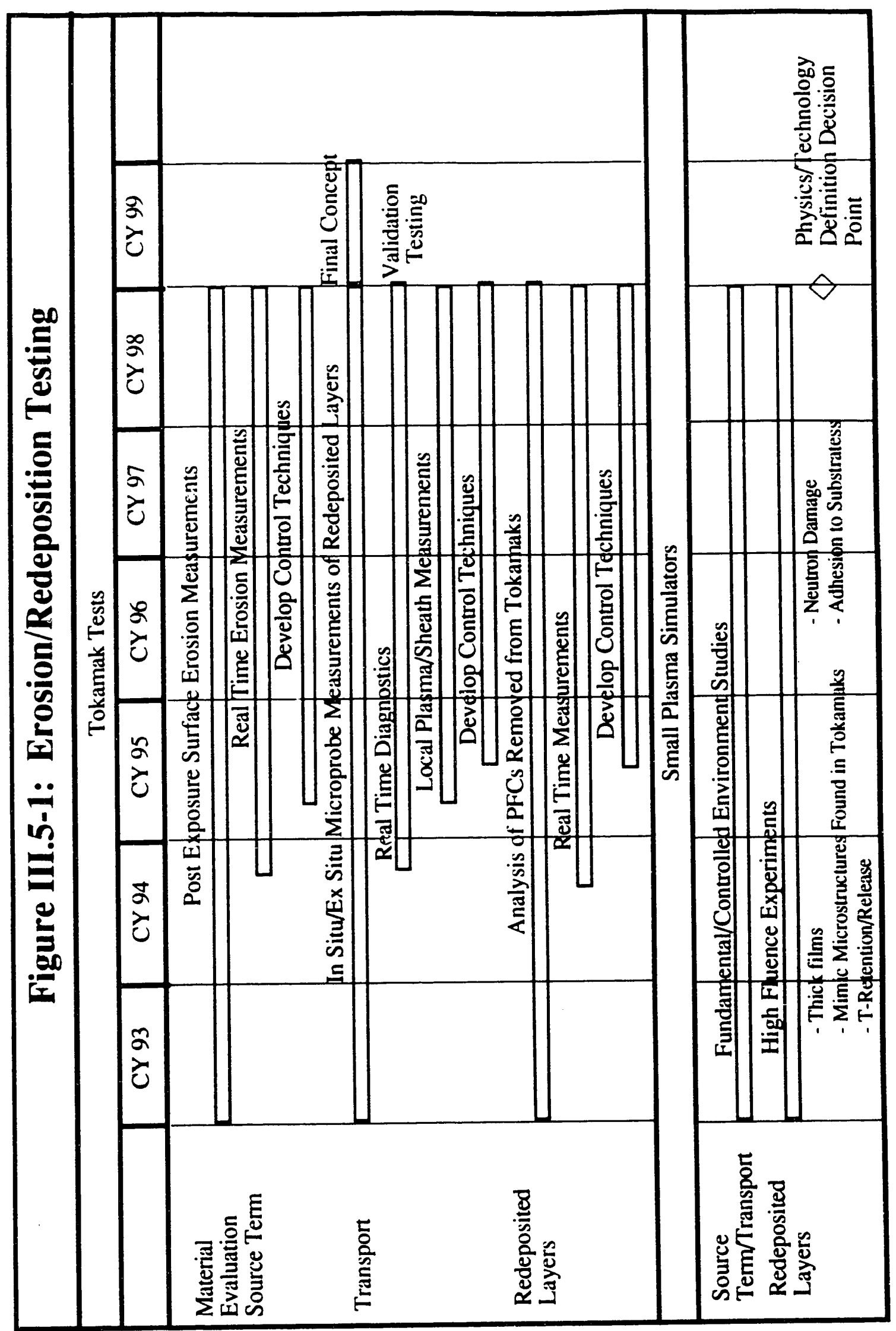




\section{III.5.5 References}

[1] J. N. Brooks, Nuc. Tech./Fusion 4 (1983) 33.

[2] J. N. Brooks, Eus.Tech. 18 (1990) 239.

[3] J. N. Brooks. Phys. Fluids 8 (1990) 1858.

[4] J. N. Brooks and D. N. Ruzic, L.Nuc. Mat. 176 \& 177 (1990) 278.

[5] T. Q. Hua and J. N. Brooks. L. Nuc. Mat. 196-198 (1992) 514.

[6] C. P. C. Wong, et al., J. Nuc Mat. 196-198 (1992) 871.

[7] P. C. Stangeby, J. Nuc. Mat. 176 \& 177 (1990) 51.

[8] P. C. Stangeby, J. Nuc. Mat. 196-198 (1992) 258.

[9] M. J. Khandagle, et al., "Impurity Transport under Steady-State Magnetized Plasma Bombardment in PISCES-B Mod," L.Nuc. Mat, to be published.

[10] M. A. Abdou, et al., Report of the Review Panel on ITER Plasma Facing Components, (Dec. 1992).

[11] S. A. Cohen. R. F. Mattas, and K. A. Werley, J Vac. Sci. Tech. A 10 (4) (1992) 1256.

[12] J. N. Brooks, "Modeling of Erosion and Redeposition Processes," in Proceedings of Atomic and Molecular Data for Fusion Reactor Technology, Cadarache 1992, R. K. Janev ed., to be published.

\section{III.6 Disruption Effects}

\section{III.6.1 Data Base Needs}

Physics and technology issues:

A disruption in a tokamak results in large heat fluxes to the plasma facing components and the induction of large currents (both eddy currents and halo currents) in plasma facing components. The duration of the various effects varies from a few hundreds of microseconds to a few tens of milliseconds. The distribution of the heat loads and currents depends on the magnetic field structure, the motion of the plasma (which is affected by the presence of the PFCs), and the external coil response. Due to the complex nature of the phenomenon, the best data on disruptions are gathered from actual tokamak experiments. Continued measurements on tokamaks are required for construction of the data base necessary to design ITER. The information needed includes time scales of energy loss and current quench, energy deposition profiles on PFC, runaway electron generation, and scaling of these phenomena with plasma parameters. Information regarding disruptions in diverted discharges is particularly important.

The tokamak measurements need to be supplemented by measurements on smaller and simpler devices in order to determine the disruption resistance of new materials and to benchmark the vapor shielding calculations that predict a significant reduction in disruption erosion. Since a disruption can occur at any time during a pulse, it is important to establish the correct temperature distribution 
in a PFC before the disruption heat loads are induced. There are existing test facilities that can be configured to do this combined exposure (e.g., EBTS at SNL). In addition, plasma guns without a steady state heat source (such as PLADIS at UNM) can study the vapor shielding issue in a controlled and more easily diagnosed environment.

Neutron irradiation effects will very likely alter the response of PFCs to disruptions because of lattice damage, helium generation, alteration of ductile-brittle transition temperature. etc. Existing facilities for neutron exposure are very limited (both in sample size and neutron energy). Disruption testing of neutron irradiated PFCs or materials will play a supporting role in ITER PFC development. A $14 \mathrm{MeV}$ neutron source would provide essential data on material irradiation. allowing for displacement damage in the lattice and helium generation via transmutation in the proper ratios. as discussed in Section III.11. Estimating the costs for a $14 \mathrm{MeV}$ neutron source was outside of the scope of this study.

\section{III.6.2 Test Facility Requirements}

A test facility should be capable of depositing $5-50 \mathrm{MJ} / \mathrm{m}^{2}$ in 0.1 to $10 \mathrm{~ms}$ on a material sample that has also been exposed to heat loads up to $5 \mathrm{MW} / \mathrm{m}^{2}$ (for a dissipative divertor operating mode) and up to $15 \mathrm{MW} / \mathrm{m}^{2}$ (for ITER CDA style operation). Simulation of runaway electron effects would require a facility capable of generating up to $300 \mathrm{MeV}$ electrons with a heat flux of 500-800 $\mathrm{MW} / \mathrm{m}^{2}$ for pulse durations of 0.1 to $10 \mathrm{~ms}$. Determination of the distribution and magnitude of halo currents, disruption induced eddy currents, and runaway electrons can only be done on a tokamak. Some diagnostic improvements (e.g., fast surface temperature measurements for heat loads, additional halo current measurements, and the DIMES experiment on DIII-D could be used to benchmark disruption erosion models) would improve the breadth and accuracy of the data base. In addition, establishment of methods to mitigate disruptions will require experiments on a tokamak.

\section{III.6.3 Test Facility Evaluations}

Disruption studies on large high power tokamaks are essential for developing the data base needed for ITER, hence the disruption physics/technology ratings of 3 and 2 , respectively, in Table II.2-1. Smaller tokamaks can provide some supporting information, but the stored energy (thermal and magnetic) in smaller lower power devices necessitates a large extrapolation to ITER conditions, resulting in a rating of 1 for these machines. Plasma guns are capable of delivering $5-50 \mathrm{MJ} / \mathrm{m}^{2}$ in 0.1 to $10 \mathrm{~ms}$. Guns that can deposit $5-10 \mathrm{MJ} / \mathrm{m}^{2}$ over a few square centimeters are commercially available. Guns capable of up to $50 \mathrm{MJ} / \mathrm{m}^{2}$ over large areas are somewhat developmental. Facilities consisting of combined plasma guns and e-beams should be part of the minimum set of facilities for ITER PFC testing because vapor shielding and disruption damage mechanisms can be more easily studied in stand-alone facilities where diagnostic access is easier (technology/physics ratings $=2 / 3$ ).

A hot cell testing facility should also be a part of the minimum set of ITER PFC testing facilities because of the need to test irradiated materials. A hot cell test facility, equipped with an electron beam for high heat flux deposition and with a small pulsed plasma gun for simulating disruption loads, would provide very valuable materials data which incorporate several important efforts. In Table II.2-1, the credit for being able to perform these combined tests for disruption technology is lumped under the neutron testing category, since this element was perceived to be the most critical. 


\section{III.6.4 Program Plan for Issue Resolution}

Physics issues can only be studied on existing tokamaks. The analysis of data from tokamaks will be done primarily by the staff at each institution. An ITER individual needs to be assigned the task of interpreting the results from the ITER standpoint. The impact of disruptions on PFCs is being studied on single effects test stands (e.g., plasma guns). The next logical step is to combine steady state heating with a disruption heat load (FY94). This will establish the correct stress state in the PFC prior to a disruption. In order to test disruption effects on near full scale ITER PFCs, it will be necessary to construct a larger plasma gun (FY95-96, with testing in FY97). Vapor shielding studies should be conducted on both single effects test stands and combined effects facilities. including tokamaks. The hot cell e-beam facility should be completed and a plasma gun added to the hot cell capability.

\section{III.6.5 Cost, Risk Assessment, and Schedule}

Single effects testing is already in progress. Measurements of disruption characteristics are being conducted on existing tokamaks. The tokamak testing should continue at its present level. The single effects testing should continue on newly developed materials (e.g., beryllium carbide. beryllium fiber composites, and "ductile beryllium"), but combined testing should begin for more established materials. Approximately $\$ 200 \mathrm{~K}$ should be spent for multiple effects testing in FY94 and FY95. Construction of a large plasma gun is estimated to cost \$2M. Testing of large size specimens should take place in FY97 and FY98. The cost of completion of the hot cell facility is estimated to be about $\$ 1 \mathrm{M}$. A time line for the disruption testing is shown in Figure III.6-1. The costs for labor and materials are summarized in Table III.6-1.

Since ITER is focusing on relatively new materials for which there is only a limited amount of tokamak experience, the risk associated with not conducting at least the small sample tests on the combined e-beam plus plasma gun facility is very high. Similarly, the risk associated with not pursuing additional high power tokamak studies will significantly decrease the confidence in the ability of any ITER design to meet the reliability requirements.

Table III.6-1 Budget for Disruption Studies

\begin{tabular}{|c|c|c|c|c|c|}
\hline & $\begin{array}{l}\text { Annual } \\
\text { Labor } \\
\text { Costs } \\
(\$ K / y r)\end{array}$ & $\begin{array}{c}\text { Duration } \\
(y r s)\end{array}$ & $\begin{array}{l}\text { Total } \\
\text { Labor } \\
\text { Costs } \\
(\$ K)\end{array}$ & $\begin{array}{l}\text { Equipment } \\
\text { Costs } \\
(\$ \mathbf{K})\end{array}$ & $\begin{array}{l}\text { Total } \\
(\$ K)\end{array}$ \\
\hline $\begin{array}{l}\text { Physics Studies } \\
\text { Small Sample Tests } \\
\text { Large Plasma Gun Fabrication } \\
\text { Large Sample Tests }\end{array}$ & $\begin{array}{r}\$ 100 \\
100 \\
250 \\
200\end{array}$ & $\begin{array}{l}4.0 \\
2.0 \\
3.0 \\
1.0\end{array}$ & $\begin{array}{r}\$ 400 \\
200 \\
750 \\
200\end{array}$ & $\begin{array}{r}\$ 100 \\
1250 \\
300\end{array}$ & \\
\hline Totals (\$K) & & & $\$ 1550$ & $\$ 1650$ & $\$ 3200$ \\
\hline
\end{tabular}




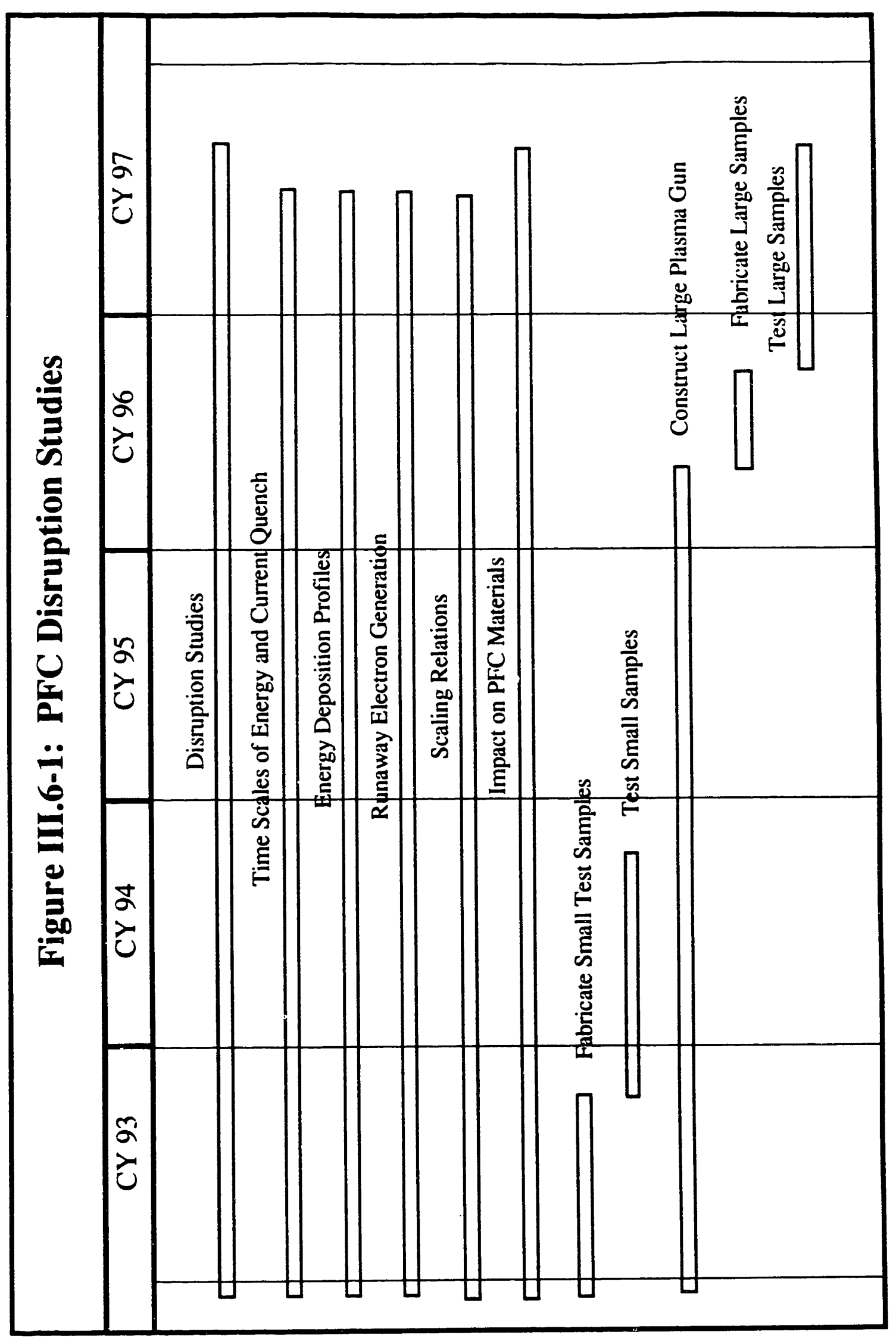




\section{III.7 Helium Exhaust}

\section{III.7.1 Data Base Needs}

Helium exhaust depends upon He transport from the core. through the scrape off layer and either through an exhaust port to a pump or to some other collection point. Buildup of He ash in the plasma dilutes the $\mathrm{D} / \mathrm{T}$ plasma and adversely affects confinement. Keeping the $\mathrm{He}$ at a reasonable level (e.g.. 10\%) implies rather high removal rates of He at the plasma edge. In the ITER CDA. 20 pumps each were to remove He plus $2 \times 10^{19} \mathrm{~T} / \mathrm{s}$.

The helium exhaust issue includes such physics energetic He ion transport in the core and SOL plasmas. He boundary layer recycling and wall interactions and the influence of ELMs. These issues can be studied only on high power density tokamaks. Experiments with burning plasmas such as those planned for TFTR and JET will provide valuable core physics data. Boundary layer physics data on He issues can be generated in divertor tokamak experiments (nonburning) using He seeded plasmas. The tokamak testing program required to address He exhaust issues is similar to that discussed in Sections III.2, III.3, and III.4. Additional divertor hardware and diagnostics specifically designed for He exhaust measurements will have to be included.

The throughput of tritium necessary to exhaust the He is the real issue since the reprocessing capacity of the tritium recovery system must be properly sized. There are associated impacts upon cost. tritium inventory and safety. Two alternatives to conventional pumping of $\mathrm{He}$ (and tritium) are being explored.

With He self-pumping, He and hydrogen $(D / T)$ ions from the plasma are implanted in a host material in which D diffuses to the surface and recycles while (most) He remains trapped. Since the tritium recycles within the plasma chamber. the needs for conventional pumping to take care of the He and a large tritium reprocessing system are essentially eliminated.

Typically, both He and $\mathrm{D} / \mathrm{T}$ are trapped in many metals at room temperature, but there is a range of temperature where $\mathrm{D} / \mathrm{T}$ becomes mobile and will diffuse out while He remains trapped. With the low plasma edge temperatures iikely in advanced tokamaks. He implantation will be quite shallow. and He trapping in the host material will rapidly saturate. A technique for replenishing the trapping surface is implicit in this concept. A modest, but successful, He self-trapping experiment was performed by Sandia and Argonne national laboratories and KFA in TEXTOR. The capacity of the collector was small, but the local trapping was about $0.3 \mathrm{He} / \mathrm{Ni}$ in surface layers of deposited nickel, and about $10 \%$ of the He in the D-He plasma was trapped. Plans are under way to perform a larger He self-pumping experiment in Alcator C-Mod.

The second alternative is selective diffusion of $\mathrm{D} / \mathrm{T}$ through semipermeable membranes adjacent to the exhaust stream. The concentration of He increases as the D/T diffuses out of the stream. Complete depletion of $D / T$ in the exhaust stream is not a requirement: a lower amount of tritium in the exhaust simply means less capacity in the tritium reprocessing system is needed.

Some fusion-specific experiments on separation of hydrogen isotopes from $\mathrm{He}$ lising a semipermeable membrane made of palladium were conducted at PPPL and did show separation of hydrogen from He. Similar experiments have been ongoing for some time at Moscow University. Extensive experience with tritium permeation through palladium-silver membranes at LANL has eliminated many past concerns regarding contamination and embrittlement. 


\section{Data Base - He Self-Pumping}

For He self-pumping. the major uncertainties are (1) sheath effects for surface at oblique angles to the magnetic field, (2) the role of implanted neutral $\mathrm{He}$ as well as implanted $\mathrm{He}$ ions in exploiting helium self-pumping for ITER. (3) the engineering of a deposition system (either intermittent or continuous) to replenish the trapping surfaces for application in a large tokamak, and (4) the amount of trapping of low energy He in materials of interest. the diffusion of hydrogen out of these materials, and the effects of hydrogen implantation on He trapping.

He self-pumping involves ions accelerated through the sheath at surfaces where magnetic flux lines are incident at an oblique angle and important neutral interactions, including reflection and trapping of reflected neutral He. Testing requirements here are similar to those required for the erosion/redeposition issue, discussed in Section III.5. These features cannot now be well simulated outside a tokamak, and experiments with an ITER-like (diverted) plasma are needed. The role of reflected neutral He that retains most of the energy imparted as parent $\mathrm{He}$ ions are accelerated through the sheath potential is expected to be important in the development of the He self-pumping concept. If trapping of reflected neutral He alone could provide adequate pumping, locations adjacent to the plasma exhaust stream could be used which would simplify engineering fearures such as heat removal from the trapping surface.

An operational data base on a deposition system is also needed both in preparation for experiments in large tokamaks and to produce the samples needed to obtain data on trapping. Development of appropriate systems for large tokamak experiments and eventually for ITER is included in this effort.

Nearly all data on He trapping in the literature are for simple, pure materials and implanted He ions with energies above $1 \mathrm{keV}$. For applications in ITER, the host material will be deposited in thin layers (e.g., 50 Angstroms) and He implantation will occur at low energies (100-300 eV). Furthermore, the trapping surfaces are likely to be contaminated with plasma impurities.

A data base is needed to guide the selection of materials for experiments in large tokamaks. The data should confirm that both adequate He trapping and adequate hydrogen recycling will occur in the tokamak environment. These data include implantations of $\mathrm{He}$ and He plus $\mathrm{D}$ over a range of temperature (dependent upon the material selected). The material samples should be surface layers deposited with a prototypic deposition system. The effects of contamination should be included. Among the likely base materials are Ni, W, Mo, V, and Nb.

\section{Data Base - Fuel Separation with a Semipermeable Membrane}

For the technique of separating $\mathrm{D}$ and $\mathrm{T}$ from He using a semipermeable membrane, the major issues are (1) stability of the membrane against radiation damage and (2) engineering of a system applicable to ITER.

The general technology for use of semipermeable membranes to selectively remove hydrogen (or tritium) from mixed gas streams is well established; systems have been designed and tested for tritium extraction for defense applications. A system with $20 \%$ of the capacity specified in the ITER CDA has been operated for several years at LANL. Previously identified problems. including embrittlement (the low temperature phase can become embrittled in the presence of hydrogen) and poisoning of the membrane surface, have been dealt with effectively. Membranes are now made from a Pd-25\% Ag alloy. The standard procedure to avoid embrittlement is to remove the hydrogen before the membrane is cooled below $400^{\circ} \mathrm{C}$. While agents such as $\mathrm{Cl}$ and $\mathrm{S}$ are known to be a problem, contamination by $\mathrm{CO}$ does not seem to pose a threat. 


\section{III.7.2 Test Facility Requirements}

Several types of facilities are needed for the development of alternative techniques for helium selfpumping. However, no new major facilities are required. For tokamak experiments, the basic requirements are (1) a diverted plasma and all-metal plasma chamber with sufficient power to produce edge temperatures of $30 \mathrm{eV}$ and greater, (2) flexible access and space for He self-pumping modules, high current leads for the module heaters and deposition system, and thermocouples, and (3) adequate diagnostics, including as a minimum some measuremen: of $\mathrm{D}$ and He, e.g., spectroscopic views on or near (connected to) the plasma strike point, $n_{e}$ and $T_{e}$ at the plasma edge. These requirements are met reasonably well in the U.S., by Alcator C-Mod.

For development of prototypic deposition systems. laboratory testing using a small plasma chamber is sufficient. Development of this type is already underway with cooperative work ongoing at Sandia and Argonne national laioratories. For materials testing, accelerators and other existing laboratory facilities for surface analysis are adequate.

In the development of fuel separation using a semipermeable membrane, the small scale experiments for materials development can be done using existing laboratory facilities. Materials development involving tritium handling and irradiation of samples requires special facilities, but this work can also be done in existing facilities. A large scale test can be done at the Tritium System Test Facility at LANL provided that the necessary facilities remain available. Current plans call for decommissioning during the next year of the large permeator that would be appropriate for ITER relevant tests.

\section{III.7.3 Test Facility Evaluation}

The tokamak systems were rated 2 because experiments can be conducted on both He selfpumping (as was done in TEXTOR) and semipermeable membranes (using deuterium). The tokamaks come the closest to reproducing the particle flux and energy conditions in ITER and the potential contamination of the process gases. The plasma simulators were rated 2 because the SLPS (particularly TPE) can be used for actual tritium exposure and plasmas similar to the ITER divertor can be produced under conditions where diagnostics are easier to perform. The large linear plasma simulators have the ability to test nearly full scale prototypes of ITER equipment. The rating of 1 for the smaller tokamaks and small linear plasma simulators in the area of physics was due to concerns about the lack of similarity to the plasma conditions in the ITER divertor.

\section{III.7.4 Plan for Issue Resolution}

The next development step is to confirm He self-pumping in a diverted plasma. Development of appropriate tokamak experiments implies an understanding of the possible options for the applications of He self-pumping in ITER. For example, if impurity seeding in the ITER divertor is anticipated, then it would be desirable to simulate this in at least one experiment.

There will be limitations on how tokamak experiments represent ITER applications. The aim of the experiments should be to maximize the He pumping and deal effectively with the plasma conditions (e.g., impurities) that will exist in the tokamak experiment itself. It can then be argued by analogy that effective solutions specific to ITER can be obtained. Some experiments should exploit trapping of reflected energetic neutral He and measure this.

The placement of the trapping surface in a tokamak experiment is likely to be a compromise based on the configurations of components, locations of diagnostics, etc. In principle, compromises in placement that decrease He pumping can be compensated by increasing the He in a D-He plasma. However, the basic objective should be to develop an experiment in which particle fluxes, heat 
loads, impurities, etc., are as representative as possible of ITER applications. This may mean that several experiments, each specific to a certain application and range of conditions, should be proposed and developed.

These experiments will require a diverted plasma, variable wall materials, sufficient edge diagnostics to measure the He and $H$ or $D$ content, $n_{e}$ and $T_{e}$ at the plasma edge at a minimum and adequate access, in terms of size and flexibility, to accommodate several trapping modules with a sufficient total area to trap the He in a D-10\% He plasma (e.g., for C-Mod this is roughly $3000 \mathrm{~cm}^{2}$ ).

Replenishment of trapping material by deposition of material injected into the divertor plasma may be a possibility. The filament system used in the TEXTOR experiment is not appropriate for other experiments or for ITER. A plasma source trapping material replenishment system is under development for use in C-Mod. Use of candidate techniques for deposition of the trapping surface in ITER will be the most appropriate method for preparing the samples needed for materials tests. In support of the tokamak experiments, sufficient data will be needed on trapping and materials to confirm that tokamak experiments are likely to be successful.

Development of a D/T separation system for [TER, based upon semipermeable membranes, has an adequate data base to move to large scale tests. A bona fide design application for ITER should be a prerequisite for ITER-specific development of semipermeable membranes. Large scale testing to show adequate throughput with an ITER-relevant geometry would be needed to confirm the design. For the application in ITER, some materials development (e.g., radiation damage resistance) on candidate materials will be needed.

\section{III.8 PFC Lifetime/Reliability and Heat Removal}

\section{III.8.1 PFC Operating Conditions for ITER}

For normal and for off-normal operation, the conditions expected for the divertor and first wall of ITER are listed in Table III.8-1. Anticipated heat and particle fluxes in the divertor for normal operation are $5 \mathrm{MW} / \mathrm{m}^{2}$ and $1-10 \times 10^{23} / \mathrm{m}^{2}$-s, respectively. The energy spectrum of incident particles on the divertor surface is dependent upon the divertor physics operational mode, discussed in Section III.2. For a highly successful dissipative divertor, the plasma may be extinguished in regions near the divertor surfaces, but fluxes of energetic $(-100 \mathrm{eV})$ charge exchange particles may be large $\left(>10^{23} / \mathrm{m}^{2}-\mathrm{s}\right)$, but only rough estimates are available at this time. Thermal loads on the first wall are expected to be on the order of $0.5 \mathrm{MW} / \mathrm{m}^{2}$. First wall particle fluxes of $1-3 \times 10^{20} / \mathrm{m}^{2}-\mathrm{s}$ are anticipated, with particle energies in the range of $10-100 \mathrm{eV}$. Misalignment of divertor and first wall surfaces may tend to localize heat and particle fluxes producing loads three times greater than those discussed above. Finally, divertor and first wall surfaces are expected to experience a neutron wall loading of $0.5-1.5 \mathrm{MW} / \mathrm{m}^{2}$ for ITER operation at a thermal fusion power level of $1.5 \mathrm{GW}$.

Off-normal loads present a major challenge for ITER PFCs. The loading conditions affecting PFC lifetime and reliability are also listed in Table III.8-1. Distuptions and other off-normal conditions are discussed in greater detail in Section III.6. Disruption thermal quenches may deposit 1-50 $\mathrm{MJ} / \mathrm{m}^{2}$ on divertor or first wall surfaces, with deposition times of $0.1-3 \mathrm{~ms}$. During the subsequent current quench, where the plasma current may drop from $20 \mathrm{MA}$ to $5 \mathrm{MA}$ in as fast as $10 \mathrm{~ms}$, vessel interior components can be subjected to large mechanical loads resulting from JxB forces produced by halo current and/or induced eddy current interaction with the toroidal field. The disruption current quench phase on ITER may also result in production of runaway electrons, achieving energies of $100-300 \mathrm{MeV}$ and energies densities $-30 \mathrm{MJ} / \mathrm{m}^{2}$. 


\section{Table III.8-1: Operating Conditions Anticlpated for the ITER Divertor and First Wall}

\section{Component}

Normal Operation

-Aver. neutron wall load

-Aver. surface heat flux

-Peak volumetric heat

load in structure

-Number of pulses (full load)

- Total bum time

-Peak neutron damage (steel)

-Min. dwell time

-Incident DT-ions:

-peak flux

-energy

-Allowed water leak rate

\section{Disruptions}

- Number (at full load)

- Thermal quench:

-time

-peak energy deposition

-Current quench:

-time

- radiative energy deposition

- runaway electron energy deposition

(at $\leq 300 \mathrm{MeV}$ )

\section{Materials}

\section{-Armor}

- design option 1

-peak surface temp.

-design option 2

-peak surface temp.

-other options

\section{Heat Sink Stnucture}

-design option 1

-design option 2

\section{Coolants}

-design option 1

-design option 2

-other options
First Wall

Divertor

$M W / m^{2}$

$M W / m^{3}$

$10^{4}$

$10^{4} \mathrm{~h}$

dpa

s

$10^{20} / \mathrm{m}^{2} \mathrm{~s}$

eV

g/s

0.5-1.0

$0.1-0.5$

20

1-5

1-3

$10-30$

200

1

$10-100$

$10^{-8}$

500

500

0.1-3

10-50

0.1-3

10-50

5-100

2

30

$5-100$

2

30

$0.5-1.0$

5

5

1-5

1-3

5-15

200

4000

50-200

$10^{-8}$

$\mathrm{MJ} / \mathrm{m}^{2}$

$\mathrm{MJ} / \mathrm{m}^{2}$
$\mathrm{Be}$

800

CFC

1800

W

V

ss-316

$V$
DS-Cu

liquid metal

$\mathrm{H}_{2} \mathrm{O}$

$\mathrm{He}$
$\mathrm{He}$

$\mathrm{H}_{2} \mathrm{O}$

$\mathrm{Be}$

800

CFC

1800

W

liquid metal 
Strong efforts are required to reduce the frequency of disruptions expected and to mitigate their effects. Progress in either area will significantly reduce the risk of PFC failure on ITER. Even if disruption mitigation and/or avoidance efforts are largely successful, PFCs should still be designed to withstand some as yet undetermined number of disruptions which could easily result due to failure of the avoidance/mitigation scheme.

\section{III.8.2 PFC Design Concept Development}

At present, there are large uncertainties concerning the performance, reliability and lifetime of the divertor and first wall design concepts proposed for ITER. In fact, the divertor design materials and coolants have each changed several times within the past year. These changes reflect the uncertainties in the design and performance data base. One approach to resolving this dilemma is to choose one divertor and one first wall design option, and then to direct all R\&D toward qualifying that particular design. This approach is high risk, in that a late discovery of a fatal flaw couid lead to a situation where insufficient resources remained to develop an alternative design concept. It could aiso lead to a less than optimal design, since advancements in new materials and technology might not be integrated into the design. On the other hand, resources are not sufficient to allow extensive development of all armor, heat sink and coolant options.

A compromise approach is to pursue two divertor and two first wall design options in parallel. Option 1 would be a high risk, advanced technology approach, while Option 2 would be a conservative design approach with minimized development risks. The recently proposed JCT divertor design would be classified as a high risk option. This design utilizes a $5 \mathrm{~mm}$ thick Be structural tube enclosing 10 small diameter vanadium tubes which are cooled with helium at $20 \mathrm{MPa}$. Heat conduction between the $\mathrm{Be}$ and vanadium tubes is accomplished by inclusion of a liquid metal interlayer. This design concept is presently being analyzed and is completely untested.

A more conservative design concept would be CFC (or $\mathrm{Be}$ ) armor tiles bonded (brazed or diffusion bonded) onto a dispersion strengthened copper heat sink cooled with high velocity water. Though there are many unresolved issues associated with this option, such as achieving $0 \%$ braze flaws during fabrication, there exists a considerable data base supporting this concept.

For the first wall, the development approach would be to consider a conservative option consisting of an easily removable, water cooled stainless steel or DS copper structure with brazed CFC or Be armor tiles. A higher risk approach, requiring more extensive development, might consist of an integrated first wall/blanket system constructed of a high strength vanadium alloy, cooled using a combined first wall/blanket liquid metal coolant system, with a mechanical armor tile attachment scheme. The mechanical attachment scheme minimizes thermal expansion stresses due to CTE mismatches between the armor and the heat sink materials. In this case, the reduced stress is obtained at the expense of thermal conductivity reduction across the armor/heat sink interface.

Promising new materials that could lead to significant improvements in PFC performance and/or reliability should not be overlooked and some resources should be directed toward their continued development. To execute the development strategy described above, an equitable distribution of available divertor and first wall resources would be to direct for both the divertor and first wall areas $40 \%$ toward the high risk design option, $40 \%$ toward the conservative design option and $20 \%$ toward continued development of promising advanced materials, coolants and design concepts. 


\section{III.8.3 Data Base Needs/Test Facility Requirements}

\section{III.8.3.1 Heat Removal}

The present PFC coolant options for ITER are water, helium and liquid metals.

Important issues for PFC heat transfer include

- Component thermal response,

- Thermal hydraulics (pressure drop, flow instabilities, etc.),

- Heat transfer coefficients:

swirled flow mixing enhancements for water, porous coatings for water and $\mathrm{He}$, micro-channel or mini-channel performance for $\mathrm{He}$,

- Heat transfer limits (e.g., critical heat flux [CHF] burnout for water).

The parameters that a test facility must provide to effectively simulate the heat removal problems for ITER divertor and first wall components are listed in Table III.8-2.

Table III.8-2: Facillty Requireinents for ITER

Divertor and First Wall Heat Removal Testing

\section{Parameter}

Peak normal heat flux $\left(\mathrm{MW} / \mathrm{m}^{2}\right)$

Burnout heat flux $\left(\mathrm{MW} / \mathrm{m}^{2}\right)$

Heat source

Heat flux angle of incidence (degrees)

Heat flux profile

Heated area for testing $\left(\mathrm{m}^{2}\right)$

Pulse length (s)

Total exposure time (hours)

Minimum awell time (s)

Water temperature $\left({ }^{\circ} \mathrm{C}\right)$

Water pressure (MPa)

Water velocity (m/s)

Allowed water leak rate $(g / s)$

Beryllium compatible

Helium coolant pressures (MPa)

Test to destruction

\section{Nominal}

Divertor

5

50

one-sided

1.5

non-uniform

0.4

200

400

200

60

3.5

10

$10^{-8}$

yes

5-20

yes

\section{First Wall}

0.5
$0.5-4.0$
one-sided and
volumetric
1.5
uniform
4.5
200
400
200
60
3.5
$1-5$
$10-8$
yes
$2-20$
yes

Desirable Range

for PFC Testing

$0.1-50$

$0.5-100$

one-sided and

volumetric

1 - 5

non-uniform

$0.001 \cdot 4.0$

$100-10,000$

40-30,000

200

20-150

$1-7$

$1 \cdot 20$

$10^{-8}$

yes

$2-20$

yes 


\section{III.8.3.2 Lifetime/Reliability}

Import nt issues affecting the divertor and first wall lifetime/reliability in ITER are

- Armor material erosion,

- Armor material redeposition (redeposited film becomes too thick or falls off),

- Thermal fatigue lifetime of structures and material interfaces.

- Armor/heat sink bond integrity,

- Survivability of off-normal events, including: intense pulsed energy deposition during disruptions, large JxB mechanical loads induced during disruptions,

- Loss of coolant or loss of flow accidents.

- Corrosion/erosion of coolant channels.

- Neutron irradiation degradation of material properties.

Related issues which affect the availability of ITER are

- Reliable fabrication technology-one poorly attached and insufficiently cooled divertor armor tile could potentially halt ITER operation.

- Development of techniques for non-destructive evaluation (NDE) of component integrity, including armor tile attachment.

- Development of technology for in situ repair of divertor and first wall armors, options including plasma spray regeneration or in situ brazing techniques using inductive or resistive heating.

The parameters desired in a test facility capable of evaluating PFC lifetimes for ITER are listed in Table III.8-3. It would be very difficult and expensive to provide all of the desired conditions, high heat flux, active cooling, disruption loads, neutrons, etc., in a single test facility. The PFC development program discussed below accomplishes the required testing mission by rotation of samples through smaller test facilities which provide subsets of the full parameter list. Repeated rotation of samples through various test stands allows for investigation of important multiple effects. This approach, discussed below, was found to be the most practical and the most costeffective plan for development of reliable, long-lived PFCs for ITER.

\section{III.8.4 Generic Test Facility Evaluations}

The panel considered the eight generic types of test facilities discussed in Section II.3. The contributions to resolving heat removal and lifetime/reliability issues for ITER PFCs are summarized in Table II.2-1 using the rating scale discussed in Section II.4.

\section{III.8.4.1 Heat Removal}

With respect to development of heat removal technology, large high power density tokamaks contribute very little due to their short duration $(\sim 10 \mathrm{~s})$ pulses. On the short pulse machines, divertor and first wall components rely on thermal inertia storage of the energy, with effective cooling of the components accomplished on long time scales in between shots. The cooling technologies presently in use on these machines, low pressure, low flow velocity water cooling, are not applicable to the ITER PFC environments. Smaller tokamaks, with dedicated PFC/divertor missions, suffer from the same short pulse length limitations. 
Table III.8-3 Facillty Requirements for ITER DIvertor and First Wall Llfetime/Rellability Testing

\begin{tabular}{|c|c|c|c|}
\hline \multirow[t]{2}{*}{ Parameter } & \multicolumn{2}{|c|}{ Nominal } & \multirow[t]{2}{*}{ Desirable Ra } \\
\hline & First Wall & Dlvertor & \\
\hline $\begin{array}{l}\text { Peak normal heat flux }\left(\mathrm{MW} / \mathrm{m}^{2}\right) \\
\text { Heat source } \\
\text { Heat flux angle of incidence (deg) } \\
\text { Heat flux profile }\end{array}$ & $\begin{array}{l}0.1-0.5 \\
\text { one-sided and } \\
\text { volumetric } \\
1.5 \\
\text { uniform }\end{array}$ & $\begin{array}{l}5 \\
\text { one-sided and } \\
\text { volumetric } \\
1-2 \\
\text { non-uniform }\end{array}$ & $\begin{array}{l}0.1-100 \\
\text { one-sided and } \\
\text { volumetric } \\
1-2 \\
\text { uniform \& non- } \\
\text { unitorm }\end{array}$ \\
\hline $\begin{array}{l}\text { Heated area for testing }\left(\mathrm{m}^{2} \text { ) }\right. \\
\text { Pulse length (s) } \\
\text { Total exposure time (hours) } \\
\text { Number of pulses } \\
\text { Minimum owell time (s) } \\
\left.\text { Water temperature ( }{ }^{\circ} \mathrm{C}\right)\end{array}$ & $\begin{array}{l}4 \\
200 \\
400 \\
10,000 \\
200 \\
60\end{array}$ & $\begin{array}{l}4 \\
200 \\
400 \\
10,000 \\
200 \\
20-150\end{array}$ & $\begin{array}{l}0.01-10 \\
100-10,000 \\
40-30,000 \\
1000-50,000 \\
200 \\
20-150\end{array}$ \\
\hline $\begin{array}{l}\text { Water temperature (C) } \\
\text { Water pressure (MPa) } \\
\text { Water velocity (m/s) } \\
\text { Allowed water leak rate }(g / s) \\
\text { Helium gas pressure }(\mathrm{MPa})\end{array}$ & $\begin{array}{l}3.5 \\
2 \\
10^{-8} \\
5\end{array}$ & $\begin{array}{l}1-7 \\
1-5 \\
10-8 \\
5-20\end{array}$ & $\begin{array}{l}1-7 \\
1-5 \\
10-8 \\
2-20\end{array}$ \\
\hline $\begin{array}{l}\text { Disruption loads } \\
\text {-Pulsed energy density (MJ/m²) } \\
\text {-Deposition times (ms) } \\
\text {-RAE energy densities (MJ/m²) }\end{array}$ & $\begin{array}{l}10 \\
0.1-3 \\
2\end{array}$ & $\begin{array}{l}10 \\
0.1-3 \\
2\end{array}$ & $\begin{array}{l}2-5 \\
0.1-10 \\
1-10\end{array}$ \\
\hline $\begin{array}{l}\text {-RAE energy (MeV) } \\
\text { Neutron wall loading (MW/m²) }\end{array}$ & $\begin{array}{l}150 \\
0.5\end{array}$ & $\begin{array}{l}150 \\
0.5\end{array}$ & $\begin{array}{l}5-300 \\
0.1-1.0\end{array}$ \\
\hline Neutron damage (dpa) & 10 & 10 & 1.40 \\
\hline Beryllium compatible & yes & yes & yes \\
\hline In situ NDE capability & yes & yes & yes \\
\hline In situ repair capability & yes & yes & yes \\
\hline Test to destruction & yes & yes & yes \\
\hline
\end{tabular}

The committee noted that both high and low power density tokamaks provide important measurements of deposited heat flux loads. It is essential that the magnitude, peaking factor, spatial profiles and temporal behavior (e.g., ELMs) of heat fluxes for tokamak interior components be well defined so that appropriate testing for ITER can be carried out. On the specific issue of heat removal technology, the committee gave both high and low power density tokamaks a rating of 1 , implying that some useful data is provided, but that the information obtained is insufficient for resolution of this issue for ITER without additional supporting data.

The Tore Supra tokamak is currently operating with pulse lengths greater than 60 s and plans for upgraded operation at 1000 s pulse lengths are under discussion. Tore Supra is a limiter machine. However, the PFC technology in use is directly relevant to ITER. Limiter heat flux loads achieved on Tore Supra are as high as $30 \mathrm{MW} / \mathrm{m}^{2}$ during normal operation. First wall heat flux loads are roughly $3 \mathrm{MW} / \mathrm{m}^{2}$. As discussed below, Tore Supra is making valuable contributions to the PFC lifetime/reliability data base. The committee noted, however, that Tore Supra is not expanding the available data base on heat transfer and heat removal. It operates only with water coolant at fixed pressure and flow conditions. In fact. Tore Supra is the beneficiary of extensive testing of water 
cooled, small size $\left(10-20 \mathrm{~cm}^{2}\right)$ PFC mock-ups carried out on electron beam high heat flux test stands. Therefore, the heat removal rating for large tokamaks in Table II.2-1 is still a 1, even considering the contributions from Tore Supra.

The committee gave low power density steady state tokamaks a rating of 2 on heat removal issues. This rating results since we presumed that a tokamak with a dedicated PFC mission would allow exploration of coolant flow regimes and would allow for coolant changes $\left(\mathrm{H}_{2} \mathrm{O}, \mathrm{He}\right.$, liquid metals). The rating here is not higher since this category of machine was defined to have a relatively low power density.

LLPS concepts considered are stated to deliver heat fluxes with the ranges shown in Table III.8-2. PFC prototypes installed on the system for testing could be cooled using a variety of coolant options. The sample test chamber and plasma vessel could be constructed to be compatible. Thus, a reliably operating LLPS is capable of performing high heat flux testing on unirradiated samples.

Past experience, such as development of the actively cooled limiters and first wall for Tore Supra, indicates that hundreds of different samples need to be tested in order to develop the heat transfer data base required to confidently design PFCs for ITER. With water cooling, for example, heat transfer enhancement techniques include twisted tapes, swirled internal fins, internal porous coatings and hypervapotron concepts. For any one of these options, heat transfer optimization requires careful study of a large number of samples. For porous coating, for example, thickness of the porous layer, surface-to-volume ratio of the porous coating, assessment of wicking action in regions where vapor coolant voids form, schemes for attachment of the coating to the coolant channel walls, and variation in coolant channel geometry must be investigated for each different heat sink material option. While the LLPS can provide the required testing conditions, the committee felt that the necessary high sample throughput would not be possible on the LLPS or would result in excessive down time. The LLPS received a rating of 2 for heat removal since supplemental data would have to be provided elsewhere in the test program to meet the needs of ITER on this issue.

An SLPS or the ion/electron beam test stands, properly equipped to accommodate various coolants and $\mathrm{Be}$ samples, can provide the environments for divertor and first wall testing listed in Table III.8-2 for small area samples $\left(10-50 \mathrm{~cm}^{2}\right)$. For larger area samples, larger power sources and coolant capacities are required. Ion/electron beams can be scaled to larger heated areas more cost effectively than the SLPS. Both the SLPS and the ion/electron beam test facilities received a rating of 3. implying that either one could provide the heat transfer data base necessary for ITER testing of unirradiated samples. Heat transfer testing of irradiated samples is discussed below.

Pulsed plasma guns, operating in a stand-alone mode, will contribute little to the heat transfer data base. They could be used to screen coolant configurations for durability to intense pulsed loads. Therefore, they received a rating of 1 .

Neutron damage will result in reduced thermal conductivity and embrittlement of heat sink materials. Irradiation testing of materials will provide data for analytical assessment of PFC performance as a function of fluence. Based on this contribution, neutron test stands received a rating of 2. Much greater confidence in the predicted performance of PFCs for ITER can be obtained, however, by sequentially exposing small, actively cooled prototypes to neutrons and to HHF environments. Tests of this type could be accomplished by installing either an SLPS or an ion/electron beam HHF test system inside a hot cell. Sequential and rotational use of various test stands to investigate important synergistic effects is discussed in greater detail in Section III.8.5. 


\section{III.8.4.2 Lifetime/Reliability}

The totality of the testing conditions required to properly assess PFC lifetime/reliability issues is listed in Table III.8-3. The full testing environment requires particle fluxes, heat fluxes, neutrons, and disruption loads. It would be extremely difficult and expensive to provide all of these test conditions in a single test facility.

Present high power density tokamaks and low power density tokamaks are again limited in their usefulness due to their short pulse lengths and the absence of neutron damage. We. therefore. rated the contributions to be made by most machines in either of these classes as 1 . The long pulse operation of Tore Supra, presently $>60$ s with proposed upgrade to 1000 s, clearly provides significantly more data. The first wall on Tore Supra has several thousand graphite armor tiles brazed onto a water cooled stainless steel structure. The first wall operates at heat flux loads of 2-5 $\mathrm{MW} / \mathrm{m}^{2}$. Each of the eight limiters on Tore Supra is water cooled and has nearly 1000 brazed graphite armor tiles. The Phase III horizontal limiter module, designed by SNL, operates steady state with a peak heat flux load of $30 \mathrm{MW} / \mathrm{m}^{2}$.

The fabrication and operation statistical data base derived from these components is invaluable. On the first wall, fabrication flaws have produced about $1 \%$ poorly attached armor tiles. Off-normal loads, such as disruptions and runaway electrons, have resulted in partial damage or detachment of another $1 \%$ of the armor tiles. Development of non-destructive evaluation (NDE) techniques has allowed the identification and subsequent repair of poorly attached armor tiles on the Phase III limiter, and while flaws have not been eliminated, their severity has been greatly reduced. As a result of these considerations, a special entry appears in Table II.2-1 under high power density tokamaks where the value of Tore Supra contributions on this issue are specifically acknowledged. The rating is 2 since neutron effects are not included.

A steady state low power density tokamak with a dedicated divertor mission would contribute to evaluation of PFC lifetimes and reliability in a fashion similar to that described above for Tore Supra. Flexibility with respect to coolant choice and change out of the divertor geometry and materials would increase the value of data from this source over that provided by a tokamak like Tore Supra which has a number of competing missions, e.g., confinement optimization, auxiliary heating optimization, current drive, pellet fueling, etc. The contribution to be expected from a steady state tokamak was rated at value $=2$. Again, neutron effects are not included. As discussed above, reliance on data rated at value $=2$ for resolution of a particular PFC issue represents a high risk development approach. We note here that the low power steady state tokamak would provide heat and particle fluxes at the low ends of the desired ranges listed in Table III.8-3 and that even with a dedicated divertor development mission, divertor change out would require at least several months, implying that only a limited number of options could be explored.

If the LLPS performs reliably and with large availability, it is well suited for performing high heat flux, thermal cyclic tests of large area, actively cooled PFC mock-ups. The LLPS offers the added advantage over HHF beam systems of delivering the heat flux load in the form of a hot plasma. with the result that the synergisms of sheath effects and energetic ion erosion are included in the lifetime tests. The LLPS test environment cannot be considered to be fully representative of the ITER environment since neutron damage effects cannot be included. Even if the LLPS were built to accommodate irradiated samples, which would be a significant additional expense, there is no possibility for irradiation of large $\left(\sim 1 \mathrm{~m}^{2}\right)$, actively cooled PFC prototypes. An alternative approach to qualifying the radiation lifetime of PFCs for ITER must be pursued whether or not the LLPS is included in the test facility set. The LLPS can investigate armor tile erosion lifetime and the thermal cyclic lifetime of large, prototypical PFC structures. Consequently, the committee awarded the LLPS a rating of 3 on lifetime/reliability issues. As discussed below, the LLPS is 
not considered to be the most cost-effective means of carrying out thermal cyclic lifetime tests of PFC prototypes.

A small linear plasma simulator (SLPS) is by definition too small to carry out thermal cyclic tests on large area $\left(\sim 1 \mathrm{~m}^{2}\right)$, actively cooled PFC prototypes. An SLPS does provide the proper particle flux for evaluation of armor erosion lifetimes, though with a relatively low incident ion energy and sheath potential. Some valuable information on thermal cyclic behavior of small, actively cooled samples would be provided. Because of its contributions on erosion and on thermal cyclic lifetimes, the SLPS was rated 2. The SLPS provides the data described above in a very costeffective way.

In the ITER CDA, the lifetime limiting factor for the divertor was disruption erosion. Pulsed plasma guns are allowing studies of material response to intense energy depositions $\left(5-50 \mathrm{MJ} / \mathrm{m}^{2}\right)$. Recently, it has been demonstrated that vapor shielding effects limit the transmission of energy to the material surface by an energetic plasma column. The data base in this area needs to be expanded in order to confidently predict disruption erosion lifetimes. This data base will come from measurements on tokamaks and on pulsed plasma guns. Since disruption measurements are difficult on tokamaks, pulsed plasma guns will continue to contribute significantly. Fortunately, there are many pulsed plasma guns available throughout the world. As a result, only incremental costs for facility operation and data reduction are required to carry out these measurements. Data provided by pulsed plasma guns addresses a single issue affecting the lifetime of ITER PFCs, namely, disruption erosion. The results obtained must be validated against comparable measurements made on a tokamak. The pulsed plasma guns were awarded a rating of 2 , since the data obtained is very valuable, but is only marginally sufficient as a basis for design of ITER components.

Fission reactor irradiations of materials and small $\left(-10-20 \mathrm{~cm}^{2}\right)$ PFC mock-ups are essential for evaluating irradiation lifetimes of PFCs. There presently is no facility for irradiation of large $\left(\sim 1 \mathrm{~m}^{2}\right)$, actively cooled PFC prototypes. Construction of such a reactor facility is beyond the limits of present worldwide budgets for fusion and such a facility was not considered in this evaluation. The only alternative is irradiation of small scale material samples and mock-ups, with extrapolation of the results to predict the behavior of larger components. This development path is acceptable, but unavoidably incorporates some risk inherent in the extrapolation process. Though limited to small samples, the data obtained is absolutely essential for the design of PFCs for ITER. Therefore, the neutron irradiation test facilities (fission fast reactor exposures) were awarded a value rating of 3 . Added value is obtained by subsequent high heat flux (HHF) testing of irradiated samples in a hot cell test stand.

\section{III.8.5 Test Plan for Issue Resolution}

Figure III.8-1 shows the testing sequence required to obtain multi-effects data from small area $\left(10-30 \mathrm{~cm}^{2}\right)$, actively cooled PFC mock-ups. Test facilities required to conduct this testing are listed on the left side of the figure and include

1. High heat flux testing in electron beam systems, with the later year test sequences being performed in a hot cell e-beam test stand. Additionally, the electron beam test stand should be equipped with a small pulsed plasma gun for delivery of pulsed disruption loads simultaneously with steady state heat flux loads. Since the sample sizes in this test matrix are small area, a plasma gun operating with only $50-100 \mathrm{~kJ}$ of stored energy will be sufficient. The capital cost for a plasma gun of this size can be under $\$ 200 \mathrm{~K}$.

2. Erosion testing primarily in SLPSs, with some supplemental measurements made in tokamaks. In later years, erosion tests of activated samples will also be required. 


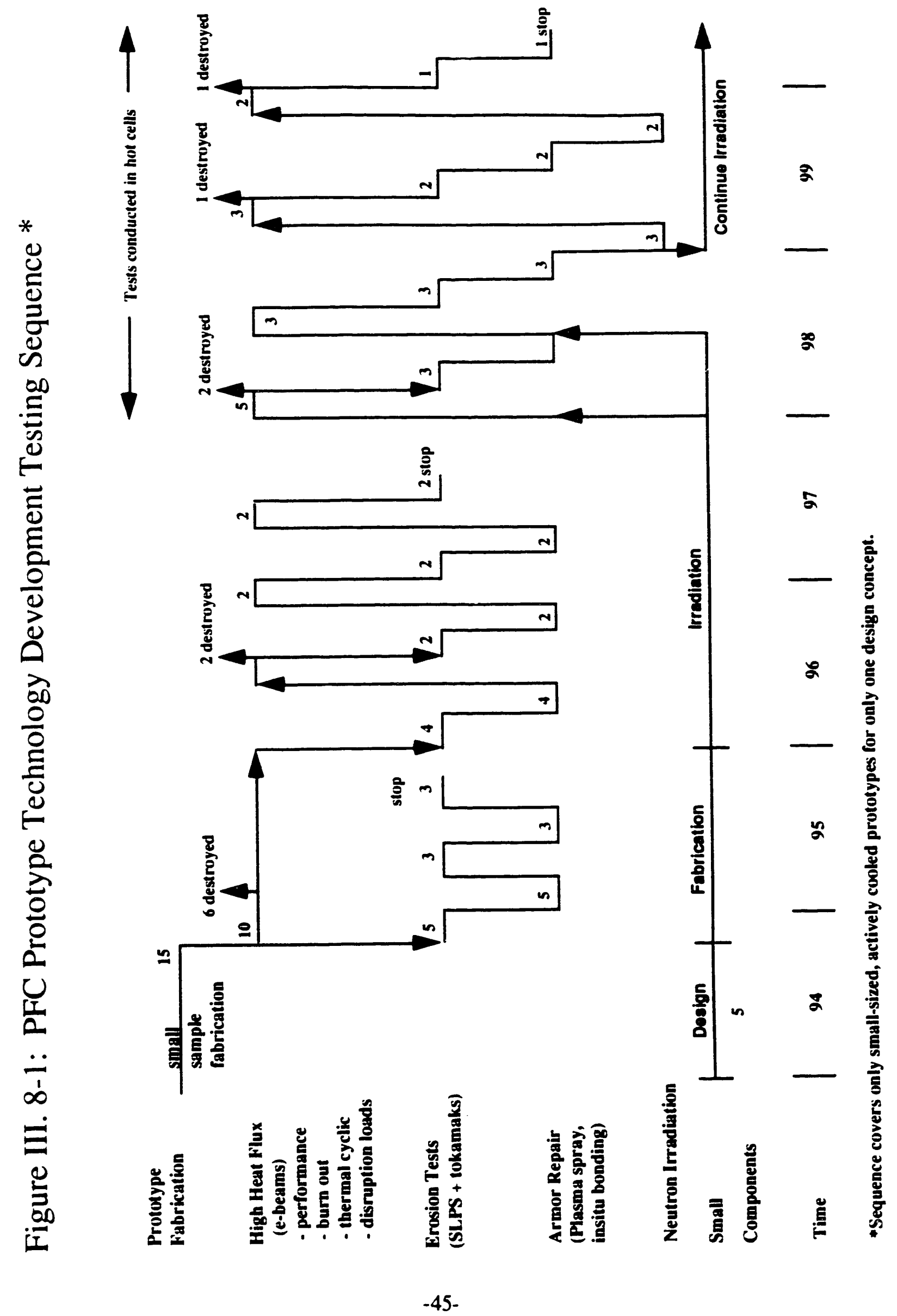


3. An armor tile replacement and/or repair facility. Replacement options might include remotely operated brazing systems which utilize inductive or resistive heating. Metallic armor tile repair might be accomplished by arc discharge surface cleaning followed by plasma spray surface regeneration. For each option, remote handling of irradiated samples is required.

4. Fission reactor fast spectra irradiations of actively cooled, duplex structure PFC prototypes.

The test sequence outlined in Figure III.8-1 begins assuming that materials selection and preliminary design concept development have been completed. Various fabrication techniques might be investigated, but ultimately 20 samples are produced for testing.

Five samples are designed for fission reactor for irradiation. Five more are subjected to a sequential armor erosion and regeneration testing. Samples could be rotated between the SLPS and the armor repair facility, or both the SLPS and repair system could be mounted on the same test chamber. The remaining ten samples are subjected to HHF testing on the electron beam test stand. Six of these ten samples are tested to failure. Two might be thermally cycled to destruction and two more destroyed in assessing loss of flow/loss of coolant accidents (LOFA/LOCA), and the final two destroyed by subjection to heat flux excursions greatly in excess of the design limits, simulating giant ELMS or large fusion power excursions. All ten samples in this sequence are subjected to intense pulsed energy loads $\left(5-50 \mathrm{MJ} / \mathrm{m}^{2}\right)$ simulating disruptions at some point in this initial test sequence.

The four samples which are not destroyed in the initial set of HHF tests would next be cycled through the armor tile erosion and repair sequence. These samples are periodically returned to the HHF test stand for further LOCA/LOFA and disruption simulation testing. The accident testing might result in the destruction of two of the samples. The remaining two continue to be cycled among the HHF, erosion and repair facilities as shown.

The five irradiated samples, after accumulating damage ranging from 0.5-10 dpa, are removed from the reactor and cycled through the HHF/erosion/repair sequence. For these tests, remote handling and hot cell facilities are required at each stage. Tests to failure continue to be carried out as part of this test matrix. Samples with low damage accumulation $(\sim 1 \mathrm{dpa})$ would be returned to the reactor after experiencing a few HHF/erosion/repair sequences.

The test sequence shown in Figure III.8-1 addresses

1. High heat flux performance and burnout limits,

2. Off-normal loads such as pulsed disruption loads, power excursions due to ELMs and excessive fusion power levels, and loss of coolanthloss of flow accidents,

3. Thermal cyclic lifetime,

4. Armor erosion lifetime and subsequent repair, and

5. Neutron damage lifetime. 
Sample rotation among various test stands allows evaluation of important synergistic effects, including neutron damage. Similar test sequences would be required for each new design concept. In parallel, HHF testing un large area, unirradiated samples would be carried out. Testing of large samples will be required to acquire a statistical data base for qualification of the armor tile attachment technology used in fabrication and repair, as well as to address large component failure modes.

\section{III.9 Safety}

\section{III.9.1 Data Base Needs}

Technology issues:

The main safety issues related to PFCs are loss of coolant accidents (LOCA), loss of flow accidents (LOFA), and the effect of coolant leaks on the hot PFC material surface. Related issues are the determination of the critical (burnout) heat flux and the heat flux safety margin in a design. In addition, loss of vacuum (LOVA) can lead to exposing hot PFC materials to atmospheric gases. Testing of such effects can lead to contamination of the test apparatus by the coolant material and/or the PFC material and reaction products. Such testing must be done in a facility that can be easily cleaned and/or repaired after a simulation of an accident. In addition, testing of irradiated material is required to measure the transport of activated species and the effect of irradiation on the reaction of PFC materials with the coolants and/or air.

\section{III.9.2 Test Facility Requirements}

A facility capable of studying coolant interactions with PFC materials at high temperatures (500$2000^{\circ} \mathrm{C}$ ) is required to improve the data base on the safety aspects of PFCs. The proposed coolants include water, helium, and liquid metals (e.g., lithium, sodium, indium/gallium). Hydrogen generation in the case of a water leak must also be studied. In addition, there is a safety hazard associated with a potential vacuum leak. which could lead to oxidation of the PFC materials. Any facility for testing neutron irradiated materials must be properly shielded and certified for handling radioactive materials (including cleanup after testing).

\section{III.9.3 Test Facility Evaluation}

Single effects test stands (ion/electron beams and the INEL reaction facility) can be used to study the interactions of PFC materials with air and coolants while the materials are at high temperature. Such facilities can be easily cleaned or repaired after the safety tests. Since the tests can be conducted in a very realistic manner and the full range of coolant interactions can be studied, the ion/electron beam guns were given a rating of 3 . It is unlikely that extensive testing of coolant or vacuum accidents can be conducted on large plasma simulators or small plasma simulators because of the time required to clean the devices after the accident. Those types of devices were given the lower rating of 2 for those reasons. Testing of irradiated materials in a large simulator is not feasible. Such facilities are better devoted to physics studies of dissipative divertors. Hot cell ebeam facilities can study accident scenarios on irradiated materials. Small linear plasma simulators have been aesigned to be used with tritium (e.g., TPE). Such facilities can be used to study the effect of accidents on tritium containing samples. Examination of damage from disruptions in tokamaks can be used to determine the relative survivability of PFC materials. This data is also useful for benchmarking thermal and stress models of disruptions.

\section{III.9.4 Program Plan for Issue Resolution}

Measurement of burnout heat fluxes and actual LOCA and LOFA tests are best conducted on electron beam facilities in parallel with single effects testing in the INEL reaction facility vapor in 
order to establish a data base on reactions with coolants and air exposure. The e-beam testing is required for air and water exposures because the proper temperature gradient, with associated stored energy and energy transfer rate, is important to assess the net generation of reaction byproducts (volatile oxides and/or hydrogen). If liquid metals are to be used for part of the PFCs, it will be necessary to construct a liquid metal coolant loop at an e-beam facility in order to assess the reaction of PFC materials with the liquid metal.

\section{III.9.5 Program Plan, Cost, Risk Assessment, and Schedule}

About $\$ 200 \mathrm{~K}$ over the next two years will be required for the coolant effects testing on candidate materials. A liquid metal test facility may cost $\$ 2 \mathrm{M}$ and take two years to construct. Testing of liquid metal effects may cost an additional $\$ 150 \mathrm{~K}$. Safety program costs are summarized in Table III.9-1. A schedule for program execution is shown in Figure III.9-1.

\section{Table III.9-1 Budget for Safety Studies}

\begin{tabular}{|c|c|c|c|c|c|}
\hline & $\begin{array}{l}\text { Annual } \\
\text { Labor } \\
\text { Costs } \\
(\$ K / y \mathbf{r})\end{array}$ & $\begin{array}{c}\text { Duration } \\
\text { (yrs) }\end{array}$ & $\begin{array}{l}\text { Total } \\
\text { Labor } \\
\text { Costs } \\
(\$ K)\end{array}$ & $\begin{array}{l}\text { Equipment } \\
\text { Costs } \\
(\$ K)\end{array}$ & $\begin{array}{l}\text { Total } \\
(\mathbf{\$ K})\end{array}$ \\
\hline $\begin{array}{l}\text { LOCA/LOFA Testing } \\
\text { LOVA Testing } \\
\text { Liquid Metal Facility Fabrication } \\
\text { Liquid Metal Tests }\end{array}$ & $\begin{array}{r}\$ 160 \\
160 \\
200 \\
200\end{array}$ & $\begin{array}{l}1.25 \\
0.75 \\
3.00 \\
1.00\end{array}$ & $\begin{array}{r}\$ 200 \\
120 \\
600 \\
200\end{array}$ & $\begin{array}{r}\$ 50 \\
50 \\
2000 \\
50\end{array}$ & \\
\hline Totals (\$K) & & & $\$ 1120$ & $\$ 2150$ & $\$ 3270$ \\
\hline
\end{tabular}

\section{III.10 Tritium}

\section{III.10.1 Data Base Needs}

Technology issues:

Tritium retention and inventory will be a very important issue for ITER. The trapping of tritium in layers of eroded and redeposited material is one of the main retention mechanisms. For some materials (graphites and hydride forming elements) there can also be significant retention in the bulk of the material. In the case of carbon based materials, neutron irradiation can increase the bulk retention because of vacancies produced by radiation damage. The retention in eroded and redeposited layers can be studied in small plasma devices (PISCES and TPE). Such devices are best suited for the scoping studies needed to construct a data base on retention. TPE is the only device that can actually use tritium for such studies. A complete investigation of neutron effects would require the development of a $14 \mathrm{MeV}$ neutron source. Cost and schedule definition for such a source is outside the scope of this panel. Exposures in lower energy neutron sources will provide some data, but the ratio of helium production to radiation damage will not be correct in such studies. Since helium bubbles can act as sites for trapping tritium, the data from lower energy neutron exposures may not provide a sufficient data base. 


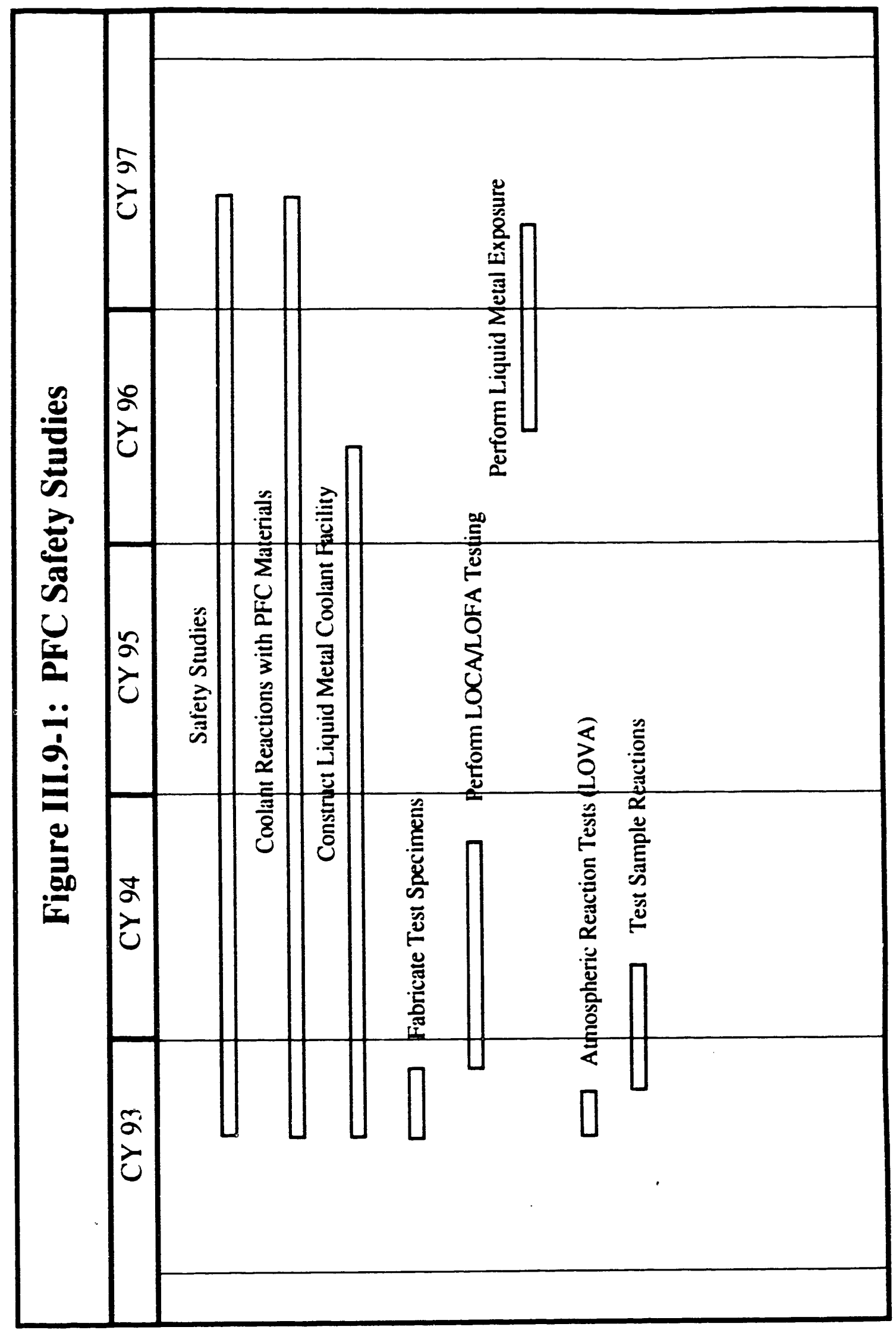




\section{III.10.2 Test Facility Requirements}

The test facility for tritium retention and release studies must be capable of exposing both irradiated and unirradiated samples to tritium ions with fluxes of $10^{19}$ to $10^{24} / \mathrm{m}^{2}$ s while the sample is at high temperature $\left(500-2000^{\circ} \mathrm{C}\right)$.

\section{III.10.3 Test Facility Evaluation}

The only facility capable of performing the required tests is the TPE at LANL (designed and operated by SNL). Hence, the SLPS devices were rated 3. Tritium retention can be studied in samples from tokamaks that perform D-T experiments. In addition, deuterium retention can be studied in samples from LLPS, plasma guns. and tokamaks. Deuterium studies can provide supporting information for modeling. For these reasons, those types of devices were given a rating of 1 .

\section{III.10.4 Program Plan for Issue Resolution}

Retention mechanism studies and permeation studies need to be carried out on candidate materials. Once retention and permeation have been determined, the release mechanisms for trapped tritium must be conducted. Finally, the at risk inventory can be determined for the candidate materials.

\section{III.10.5 Cost, Risk Assessment, and Schedule}

Approximately $\$ 500 \mathrm{~K}$, directed as shown in Table III.10-1, should be devoted over the next three years to study this issue. A schedule for program execution is shown in Figure III.10-1.

\section{Table III.10-1 Budget for Tritium Studies}

\begin{tabular}{|c|c|c|c|c|c|}
\hline & $\begin{array}{l}\text { Annual } \\
\text { Labor } \\
\text { Costs } \\
(\$ K / y r)\end{array}$ & $\underset{(y r s)}{\text { Duration }}$ & $\begin{array}{l}\text { Total } \\
\text { Labor } \\
\text { Costs } \\
(\$ K)\end{array}$ & $\begin{array}{l}\text { Equipment } \\
\text { Costs } \\
(\$ \mathbf{K})\end{array}$ & $\begin{array}{l}\text { Total } \\
(\$ K)\end{array}$ \\
\hline $\begin{array}{l}\text { At-Risk Inventory Assessment } \\
\text { Permeation Measurements } \\
\text { Retention Mechanism Studies } \\
\text { Release Mechanism Studies } \\
\text { Inventory Reduction Studies }\end{array}$ & $\begin{array}{r}\$ 150 \\
150 \\
150 \\
150 \\
150\end{array}$ & $\begin{array}{l}2.0 \\
1.5 \\
1.5 \\
2.0 \\
3.0\end{array}$ & $\begin{array}{l}\$ 300 \\
225 \\
225 \\
300 \\
450\end{array}$ & $\begin{array}{r}\$ 100 \\
100 \\
200 \\
200\end{array}$ & \\
\hline Totals (\$K) & & & $\$ 1500$ & $\$ 600$ & $\$ 2100$ \\
\hline
\end{tabular}

\section{III.11 Neutron Effects}

The Plasma Facing Components in ITER will not only be subjected to high heat fluxes but will also have the added constraint of being exposed to neutron irradiation. While earlier D-D machines will produce neutrons, the flux rate and spectrum will be significantly different for a D-T machine. The total fluence anticipated in ITER for the first wall and divertor components is shown in Table III.8.-1. From this table it can be seen that the equivalent neutron damage in steel for a first wall is in the range of 10-30 dpa and for a divertor it is 5-15 dpa. Type 316 stainless steel would experience nominally $11 \mathrm{dpa}$ per $\mathrm{MW} / \mathrm{m}^{2}$ of neutron wall loading. (Note, though, that both 


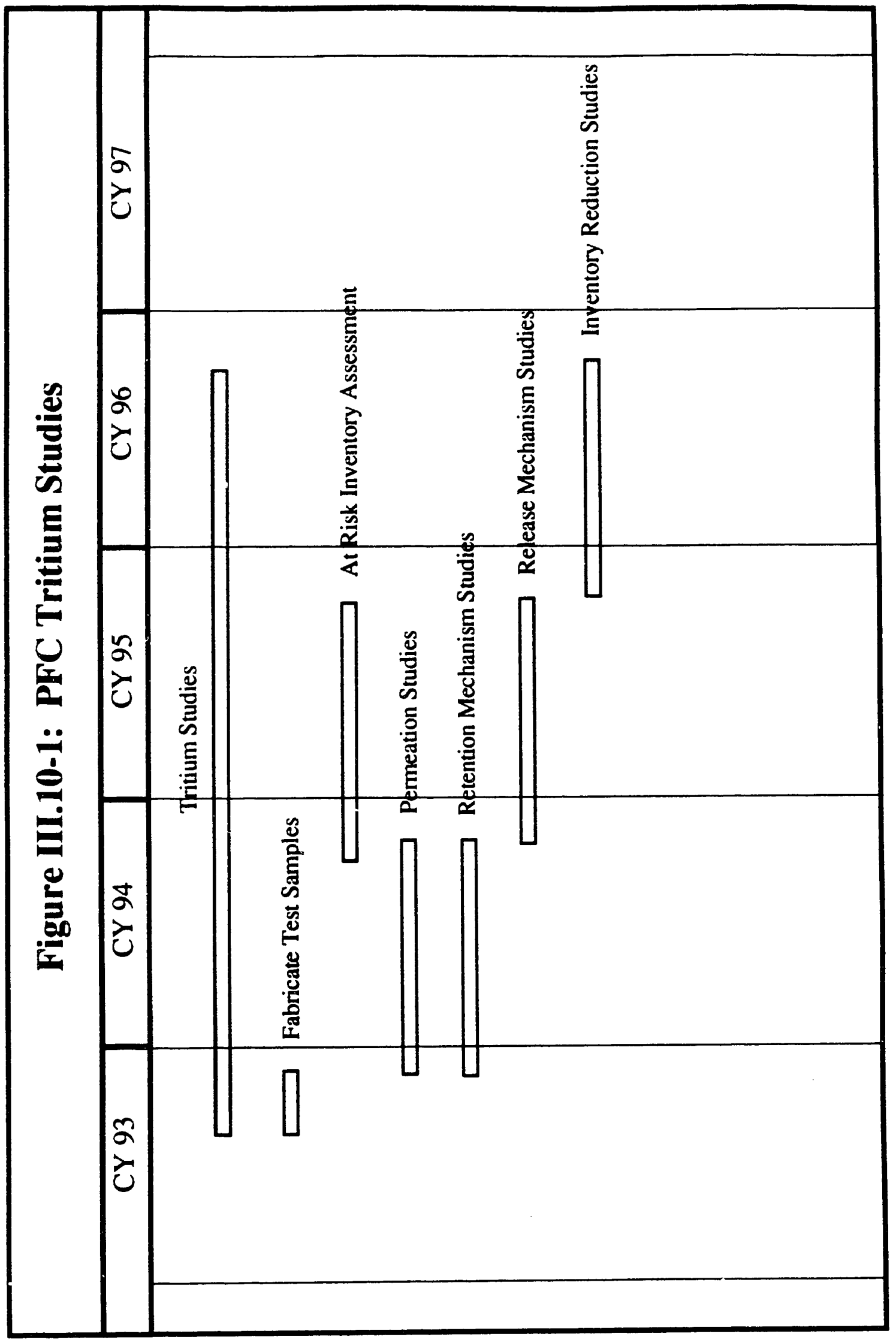


vanadium alloys and austenitic steels are being considered for the first wall.) These doses would represent roughly $0.5-3 \mathrm{MW}-\mathrm{yr} / \mathrm{m}^{2}$ of operation in a reactor, corresponding roughly to an integrated operation time of three years at a fusion power level of $1.5 \mathrm{GW}_{\text {th }}$. The response of a material to neutron damage is a function not only of dose but also of irradiation temperature. For stainless steel these doses are below the threshold for swelling if the operating temperature is held below $450^{\circ} \mathrm{C}$, though some matrix hardening is anticipated. The primary reason for holding the operating temperature low is to prevent the transmuted helium from migrating to the grain buundaries and embrittling the material. Another concern for stainless steel with water cooling is stress corrosion cracking at temperatures above $150^{\circ} \mathrm{C}$. In fusion, because of the energy of the neutrons produced by the D-T reaction, the production of transmuted helium, with minor exceptions, will be significantly higher than produced in a fission reactor. A comparison of the predicted generation rate of helium and hydrogen for ITER is shown in Table III.11-1. From this table it can be seen that for the shortest operation the helium generation rate is almost an order of magnitude higher for carbon-carbon composites, and roughly a factor of 20 higher for beryllium. than stainless steel. These higher gas generation rates can result in significant internal stresses, embrittlement, swelling and failure. To better understand how these interactions relate to the lifetime of a plasma facing component requires a detailed irradiation program beginning now.

\section{III.11.1 Data Base Needs}

Candidate plasma facing materials can be divided into two groups, coatings/clads or structural substrate. The candidate coatings/clads can be beryllium, carbon composites, graphites, or tungsten. The structural materials would be copper (dispersion strengthened or precipitation) or vanadium. Because the response to radiation damage will vary depending if the material is a coating or structural, the data base needs will also vary. The neutron interactive materials program and the ITER structural materials programs are designed to develop engineering information on candidate structural materials, dispersion strengthened copper, stainless steels, and vanadium. This information will include the changes in mechanical properties such as strength and elongation. time dependent properties such as irradiation creep, stress rupture, and fracture toughness and the dimensional changes such as swelling. While this will provide much needed information to design and analyze a divertor, it is only part of the information needed. Information lacking is the response of the coating/cladding material to the radiation environment and the interaction of the coating/cladding with the structural material during irradiation. Therefore, while the irradiation data base is being developed on the structural material, a companion program needs to be conducted to look at the effect of irradiation on the thermal conductivity of one dimensional carbon composites along with the change in mechanical properties. Since composites can have high sputtering rates, the feasibility of coatings or various matrix materials such as $\mathrm{Be}_{2} \mathrm{C}$ and $\mathrm{B}_{4} \mathrm{C}$ need to be explored. Beryllium swelling as a function of helium generation needs to be determined along with the changes in tensile strength. Since plasma spraying is a potential repair technique, specimens that have been plasma sprayed need to also be irradiated and the same properties evaluated as described above. In addition to developing a data base for the coatings/claddings, irradiations of brazed joints need to be conducted. For the dispersion strengthened copper, welding will destroy the dispersion structure and, as a result, joining will either have to be done inertially or by braze. Brazes tend to produce brittle intermetallic compounds. Since irradiations increase diffusion rates, brazed joints need to be made both with copper to copper and with beryllium or carbon composites to structural material (copper or vanadium). In developing this data base the logic that is developed is to first start with simple elemental materials (beryllium. copper, or vanadium) then progress to interactive structures, claddings brazed to structures, and finally to the prototype which would be irradiated and then subjected to appropriate heat fluxes. The prototype would be a miniaturization of the actual divertor component and have the representative coating substrate and coolant channels. The structure would be irradiated to an appropriate damage level and then subjected to the appropriate heat loads anticipated in reactor operation using either plasma sources or electron/ion beams. The sample would also be actively 
cooled. Since this test would require a large volume for fission reactor irradiation. as well as the requirement of post neutron handling of irradiated samples, testing will be very expensive. As discussed in the Lifetime/Reliability portions of this report, Section III.8, inclusion of a pulsed plasma gun in the hot cell facility would allow for testing of disruption pulsed loads.

\section{Table III.11-1 Comparison of Helium and Hydrogen Gas Generation for ITER Components}

\begin{tabular}{|l|l|l|l|l|l|l|}
\hline Material & \multicolumn{3}{|c|}{ First Wall } & \multicolumn{3}{c|}{ Divertor } \\
\hline & \multicolumn{1}{|c|}{ DPA } & He (appm) & H (appm) & DPA & He (appm) & H (appm) \\
\hline 316 SS & $10-30$ & $158-475$ & $547-1642$ & $5-15$ & $79-237$ & $274-820$ \\
\hline $\mathrm{Cu}$ & $14-41$ & $91-272$ & $494-1482$ & $7-20$ & $45-136$ & $247-741$ \\
\hline $\mathrm{Be}$ & $5-15$ & $3382-10145$ & $54-164$ & $3-8$ & $1691-5073$ & $27-82$ \\
\hline $\mathrm{C}$ & $6-19$ & $1727-5182$ & -0 & $3-10$ & $864-2591$ & -0 \\
\hline
\end{tabular}

Note: Damage levels are for the same level of irradiation-fixed fluence.

\section{III.11.2 Test Facility Requirements}

Ideally. one would like to develop an irradiation data base using a spectrum that is close to the actual operating environment of the reactor. This was done in the fast reactor program using EBRII and the FFTF. Unfortunately, there are no $14 \mathrm{MeV}$ neutron sources that can provide either the test volume or fluence necessary to develop a complete irradiation data base within the time frame of ITER. As a result, we must rely on fission reactors which have reasonable test volumes and can produce the necessary displacement damage in a short time. However, fission spectrums tend to either produce too little or too much transmuted helium. This is a concern in developing a data base on beryllium coatings and requires careful selection of irradiation facilities as well as the design of the irradiation capsule. The various experimental fission reactors in the world have a variety of test volumes, heating capabilities, and flux rates, which can be an advantage to the PFC program because it provides a lot of testing flexibility at a reasonable cost. In the previous section the data base requirements were discussed along with the approach to testing. Initial scoping studies would involve irradiating small elemental specimens roughly $1-2 \mathrm{~cm}$ in length and roughly $1-2 \mathrm{~cm}$ wide. The specimens should be irradiated over the temperature range one would see in operation which is nominally $500-1000^{\circ} \mathrm{C}$. The total irradiation doses would be between $1-15 \mathrm{dpa}$ for the divertor and 10-30 dpa for the first wall.

\section{III.11.3 Test Facility Evaluations}

Within the U.S., the EBR-II and HFIR reactors could be used. Also available are the Petten and Saclay reactors in the E.C., and the SM-2 or BOR-60 reactors in the Russian Federation. After neutron irradiation, the samples should be tested in a surface heating facility that has hot cell capability. One such system, JUDITH, is potentially available at KFA Jülich. Unfortunately, an operating license for this system has prevented its operation with irradiated samples for the past two years. An additional hot cell, high heat flux test stand has been designed and partially constructed at SNL. Additional funds (roughly $\$ 1 \mathrm{M}$ ) must be provided before the SNL test stand can be completed.

Similar testing can be done with brazed joints. However, testing of large assemblies, several centimeters in size, is limited to essentially two reactors, the OSIRUS in Saclay or the BOR-60 in Russia. Both of these reactors can accommodate a test assembly up to $60 \mathrm{~mm}$ in diameter and do have the capability of active cooling the test assemblies. In summary, while not perfect. the 
combination of surface heating facilities and fission reactors is capable of supplying a large portion of the required data base for design of PFC components.

\section{III.11.4 Plan for Issue Resolution - Schedule and Estimated Costs}

The cost and schedule for an irradiation can vary widely depending on the type of experiment. Key elements in conducting an experiment are design of the capsule, safety review, procurement and fabrication of the test elements, assembling the irradiation capsule, the actual irradiation, removal and disassembly of the capsule after irradiation, and finally post irradiation testing and evaluation. The interrelation of the activities that must be performed in conducting an irradiation experiment along with the time it takes to conduct these activities is shown in Figure III.11-1. Typically, it takes 6-12 months to prepare for an irradiation. Reactor irradiation displacement damage rates can range from $6 \mathrm{dpa} / \mathrm{year}$ to as high as $22 \mathrm{dpa} / \mathrm{year}$. In general, the closer the sample to the reactor core, the greater the irradiation damage rate. Unfortunately, closer to the core. smaller irradiation capsules are smaller. For example, in HFIR the capsule size close to the core is roughly $1 \mathrm{~cm}$ in diameter and can achieve $22 \mathrm{dpa} /$ year. Moving to an outer position increases the capsule size to roughly $4 \mathrm{~cm}$ in diameter but reduces the damage rate to $6 \mathrm{dpa} / \mathrm{year}$. To achieve ITER, relevant damage rates in the range of 10-30 dpa would require irradiations on the order of 1-4 years. After irradiation there is usually a 6-month delay, which includes allowing the high activation products to decay, and disassembly of the capsule at which time the test specimens can be evaluated. What this means is that one must allow a minimum of 2-3 years in the test plan for obtaining irradiation information. The greater the size and complexity of the experiment the longer it takes. For example, to use the $60 \mathrm{~mm}$ irradiation spaces for an integrated test would require a minimum of 2 years to design and flux map the reactor test space, and one year to fabricate and ship the test assembly to the reactor site. Irradiation of this size assembly in OSIRUS would accumulate $1-2 \mathrm{dpa} / 10$ months or $8 \mathrm{dpa} /$ year in BOR-60. Assuming the same disassembly time, an integrated experiment could easily take 4-5 years before information would become available. In summary, irradiation experiments both for the scoping phase and for the integrated experiments need to be initiated now if the information is to be of use for ITER.

The cost of irradiations are difficult to estimate because the cost of neutrons vary by country. Typically, the cost of a small irradiation capsule with about a year's irradiation would be in the range of $\$ 70-100 \mathrm{~K}$. An integrated large irradiation would be in the range of $\$ 0.75-1.0 \mathrm{M}$. These costs do not include any post irradiation testing and evaluation. 
Figure III.11-1: Time Schedule for Irradiation Testing

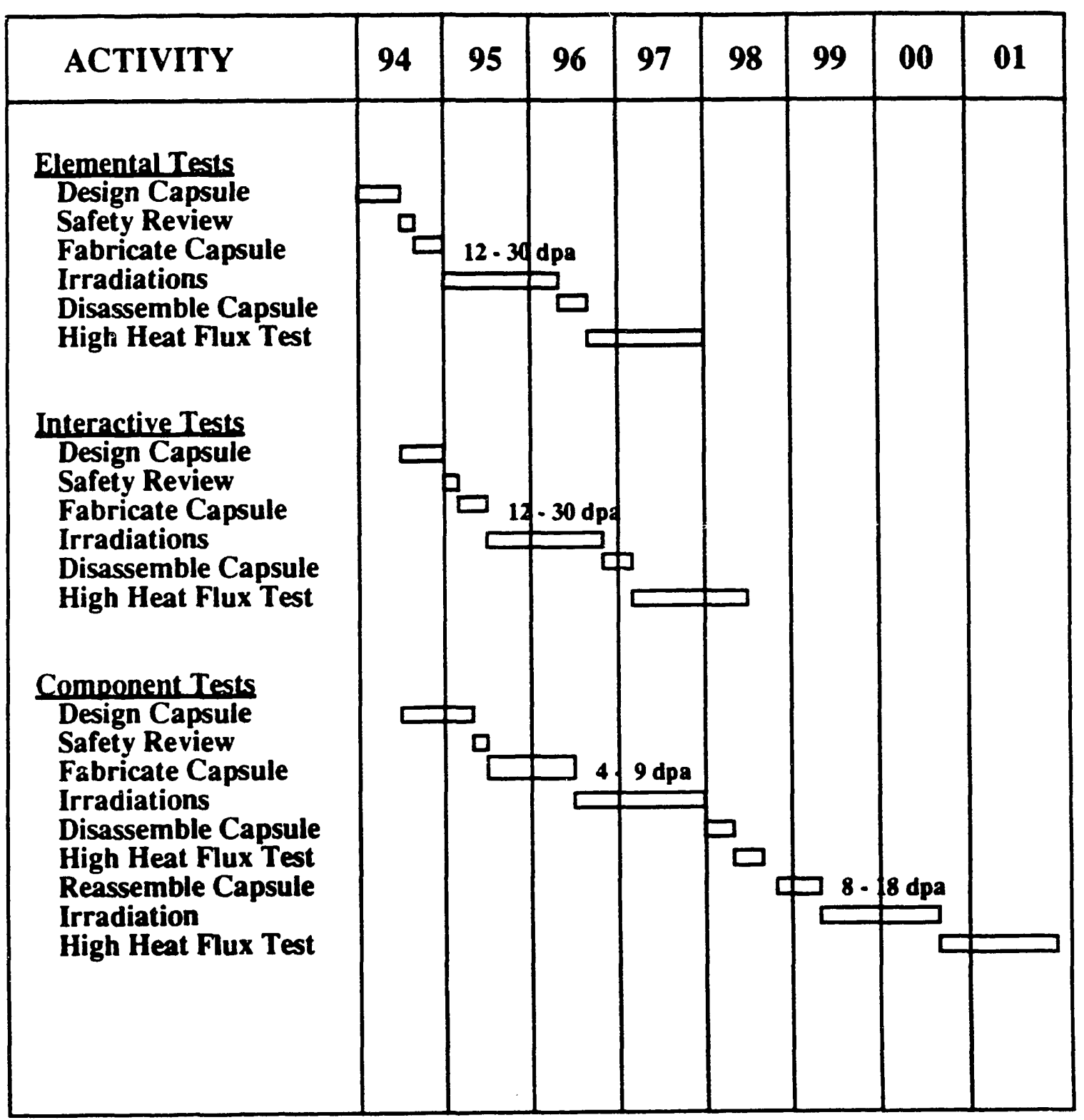


(This page intentionally left blank.) 


\section{Summary and Conclusions: PFC Development Plan}

PFC development for ITER requires resolution of the following critical physics and technology issues:

\section{Physics Issues}

- Divertor Physics Concept Development

- Impact on Confinement

- Impurity Entrainment

- Density/Fueling Control

- Helium Exhaust

- Erosion/Redeposition

- Disruption Effects
Technology Issues

- Heat Removal

- Component Lifetime/Reliability

- Safety

- Tritium Inventory

- Helium Exhaust

- Erosion/Redeposition

- Disruption Effects

- Neutron Irradiation Effects

The panel identified a program plan for resolution of each PFC issue, and identified the necessary and sufficient set of test facilities required to support that plan. The test facility set required for development and validation PFC physics and technology concepts for ITER includes

- High power density tokamaks.

- Small. linear plasma simulation devices,

- Ion/electron beam high heat flux test stands,

- Pulsed, high power density plasma guns for simulation of disruption thermal loads,

- Fission reactors for neutron irradiation damage studies.

The development plan identified, supported by the test facilities listed above, minimizes the risks for ITER associated with PFC reliability and lifetime within the constraints imposed by available budgets.

The panel's major conclusions are summarized below. Test facilities, schedules, and budgets required to execute the program plan are briefly discussed.

\section{IV.I Divertor Concept Validation and Related Physics Issues}

Any divertor physics operational mode proposed for ITER will need to be successfully demonstrated on an operating tokamak. The risks to ITER of not performing divertor physics concept validation testing on tokamaks are unacceptably high. Only tokamaks provide the synergistic physics environment for concept validation testing, linking divertor action to critical core plasma performance, such as particle/energy confinement, impurity contamination. density/fueling control, helium exhaust and ELM/disruption behavior. Related technology aspects are discussed below.

Presently operating tokamaks provide most of the test conditions required for divertor concept development and validation, connections length $(\sim 5-15 \mathrm{~m})$, parallel heat flux $\left(0.1-1.0 \mathrm{GW} / \mathrm{m}^{2}\right)$, plasma density $\left(0.1-2.0 \times 10^{21} / \mathrm{m}^{3}\right)$, electron temperature $(75-400 \mathrm{eV})$, ion temperature $(100-2000 \mathrm{eV})$, wetted area $\left(0.5-1.0 \mathrm{~m}^{2}\right)$, and magnetic field strength $(2-9 \mathrm{~T})$ and curvature. Pulse lengths on present tokamaks of 5-10 s are sufficient for development of a divertor physics concept for ITER since all important atomic, molecular, radiative and transport processes take place on sub-millisecond time scales. Wall conditioning times for graphite armored machines can be long (10-100 s), but steady state wall interactions can be achieved through various wall conditioning techniques. 
The divertor concept for ITER is not well defined at present. There is a need to provide as much near-term data as possible to support divertor concept development. At a later time, it will be necessary to demonstrate the successful operation of any divertor concept proposed.

The most useful data, and that most directly extrapolated to ITER. will come from high power density tokamaks. The committee concluded that attempts to reproduce high power density ITER flow conditions in simulation devices introduced so many additional, non-tokamak parameters that extrapolation of the results obtained to ITER would be very difficult. Small. inexpensive plasma discharge systems, providing well-controlled and easily diagnosed environments, can and should be used for measurement of specific physics processes that can assist in interpreting and extrapolating tokamak divertor data. A well-coordinated modeling effort, tied very closely to the tokamak and small plasma discharge experiments, is also required. Further model development and validation are necessary in order to be able to confidently predict the operating conditions for the ITER divertor.

To develop and validate a divertor physics concept for ITER, the committee concluded that within the U.S. program the best use of available funds was for installation and operation of new divertor configurations both on DIII-D and C-Mod. The U.S. should plan for installation of at least one new divertor configuration on each machine in the 1995-1997 time frame. Schedules for divertor development on DIII-D and C-Mod are shown in Figures III.2-1 and -2. An additional \$5M annually is required to maintain the divertor development schedules shown for these two machines. This should be a high priority for the U.S. fusion program.

\section{IV.2 Erosion/Redeposition}

The principal issues for ITER on erosion/redeposition are (1) PFC component lifetime, (2) plasma contamination, and (3) at risk tritium inventory accumulating in redeposited layers.

The fundamental physics of erosion redeposition processes in the presence of strong sheaths and glancing magnetic field incidence (e.g., sputtering yield, ejected atom direction and energy, sheath magnitude and spatial extent, ionization in the sheath and charge state achieved) needs to be investigated. Present high power density tokamaks provide the proper test environment, and results obtained on these devices will be directly extrapolatable to ITER.

The plan for resolution of erosion/redeposition issues requires that emphasis be placed on (1) development and operation of specific erosion/redeposition experiments and diagnostics on tokamaks and (2) supporting measurements of fundamental plasma-surface interactions using small plasma discharge devices. Real time measurements of erosion and redeposition rates using laser interferometry and elipsometry are planned on DIII-D. Data obtained will supplement that being provided by experiments such as DIMES, where post plasma exposure measurement of erosion has been made using thin film and implantation markers and where measurement of redeposition has been made using a variety of high energy ion surface microprobe techniques.

Measurement of transport and ionization processes affecting erosion/redeposition will require the operation of divertor region diagnostics, such as those for spectroscopic, laser scattering, and implantation measurements. Development and calibration of these diagnostics will require operation of small plasma discharge devices.

PFC lifetimes for ITER will be affected by (1) armor material erosion, (2) buildup of thick redeposited layers which are insufficiently cooled, and (3) accumulation of at risk tritium in redeposited layers. Composition, microstructure, and hydrogen isotope retention in thin films $(\sim 10-50 \mathrm{~mm})$ produced in present tokamaks have been measured. Continued measurements of this type are required. In parallel, high fluence, small plasma discharge devices, such as PISCESUpgrade and the Tritium Plasma Experiment (TPE), will be needed to generate thick redeposited 
layers with composition and microstructure mimicking that found in thin redeposited films in tokamaks. These thick films can then be used in tritium permeation/retention studies for understanding in-vessel inventory, in assessment of physical and mechanical properties. such as thermal conductivity, stability during exposure to air or coolant while at high temperature, and adhesion to substrates.

For the large, high power density tokamaks a dedicated erosion/redeposition experiment could likely be performed for $\$ 1-4 \mathrm{M}$ per tokamak with about a two-year time schedule. Such an experiment would provide for test surface fabrication and installation, tokamak exposure time. near-surface plasma diagnostics, possibly additional SOL diagnostics, in situ erosion diagnostics. post-tokamak exposure surface measurements. and associated modeling/analysis.

\section{IV.3 Disruptions}

PFC issues for disruptions are (1) large inducted currents, both halo and eddy, and associated mechanical forces, (2) surface armor erosion due to intense $\left(20-50 \mathrm{MJ} / \mathrm{m}^{2}\right)$ pulsed heat loads resulting from the thermal quench. and (3) runaway electron energy deposition $\left(\sim 30 \mathrm{MJ} / \mathrm{m}^{2}\right)$ in armor and heat sink structures.

Disruption avoidance and mitigation, as well as induced current and runaway electron formation, can only be studied only in high power density tokamaks. An expanded effort, including development and operation of new diagnostics, is required in this area. As disruptions are offnormal events, avoided as best possible on large tokamaks, it is essential that physicists on site at the various tokamaks be funded to support this effort. A small JCT ITER team, one or two scientists, might serve to compile data from various machines, but a collaborating local expert familiar with all of the details of the data collected will be required.

Materials and component response to intense pulsed disruption-like heat loads can be studied on pulse plasma discharge devices. A variety of such systems is available worldwide providing controlled, well-diagnosed environments for measurements on (1) plasmia interaction with the radiative vapor cloud that limits the amount of directed energy that can reach the material surface and (2) the stability and subsequent physical properties of melt layers formed on metal (e.g., Be, Mo, W) PFC armors. For each of these items, the influence of the magnetic field is important, and some pulsed plasma cusp devices are being used for investigations of this type.

At present, the program lacks the ability to measure armor material and PFC prototype response to pulsed disruption loads while at steady state operating temperatures. These measurements are important since stress profiles in the material are directly affected by the temperature gradient. Additional budget, about $\$ 4-5 \mathrm{M}$ as outlined in Table III.6-1, will be required over the next five years for construction and operation of a small, and then a large, pulsed plasma gun operating simultaneously with an electron beam providing steady state heating.

\section{IV.4 Helium Exhaust}

To develop a workable helium exhaust scheme for ITER will require experiments on tokamaks, coupled with supporting experiments on small plasma discharge devices and ion beam test stands. Concept development, including proposed methods for helium removal such as selective trapping by implantation in metals or using semipermeable membranes, will be carried out on small plasma discharges and ion beam test stands. Concept validation experiments will need to be fielded on tokamaks. Small modular experiments for proof of principal operation of a given concept are estimated to cost $\sim \$ 1-2 \mathrm{M}$ each, based upon costs for proposed experiments of this type for C-Mod. Helium seeding experiments on high power density tokamaks will be required to demonstrate helium removal simultaneously with dissipative operation. The major costs for 
demonstration experiments for helium removal on tokamaks should be covered in the tokamak divertor program budget. Incremental costs for specific helium removal hardware and associated diagnostics could range from $\$ 5-20 \mathrm{M}$ depending upon the concept.

\section{IV.5 Lifetime/Reliability and Heat Removal}

Thermal cyclic and high heat flux tests required to assess PFC performance, lifetime and reliability for ITER are most easily and most cost effectively carried out on ion or electron beam test stands. These systems are inexpensive, $\sim \$ 2 \mathrm{M}$ for $1 \mathrm{MW}$ of electron beam power; reliable: and easy to maintain. Thermal cyclic tests of large $\left(\sim 1 \mathrm{~m}^{2}\right)$ PFC, actively cooled prototypes will require tens of thousands of thermal cycles. Testing to destruction will be required to assess off-normal events such as choked coolant flows or delivery of heat loads greatly in excess of design specification values (as high as $100 \mathrm{MW} / \mathrm{m}^{2}$ ). Finally, simultaneous high heat flux testing and pulsed disruption load testing will be required since the thermal shock response of materials and components will be influenced strongly by steady state temperature gradients. The simplest and most cost-effective path for conducting these tests is joint mounting of an electron beam and a pulsed plasma gun onto the same sample test chamber.

As discussed in Section III.8.5, it will only be possible to assess the effects of neutron damage by looking at small samples (surface areas ranging from $5-20 \mathrm{~cm}^{2}$ ), since there are no facilities capable of irradiating larger samples. The maximum reactor assembly diameter available for sample exposures is $60 \mathrm{~cm}$. Bonded material samples need to be tested as well as small actively cooled prototypes. This can only be accomplished by rotation of sample through several test stands, reactor irradiation, high flux testing, erosion testing, armor repair and permutations as shown in Figure III.8-1. A hot cell high heat flux test system will be required. At present, such a system exists at KFA Juilich, but has been unable to operate using irradiated samples for the past two years due to licensing problems. A similar system has been designed and partially fabricated at SNL. An additional $\$ 1 M$ is required to complete construction of the SNL facility.

\section{IV.6 Safety}

Loss of coolant (LOCA) and loss of flow (LOFA) accidents will need to be evaluated by testing full-scale sized PFC prototypes to destruction. These tests can most easily and cost effectively be conducted on electron or ion beam test stands. Large $(\sim 1 \mathrm{MW})$ beam systems, capable of continuous operation and testing of water-cooled PFC mock-ups, are available at SNL, JET and JAERI. As indicated in Table III.9-1, additional funds will be needed ( $\$ 2.5 \mathrm{M})$ if testing of liquid metal-cooled components is required.

A test stand for measurement of PFC materials interaction at high temperature with air, during a loss of vacuum accident (LOVA), or coolants, as a result of coolant line rupture, is available at INEL.

\section{IV.7 Tritium}

Assessment of at risk tritium inventory requires continued operation of small plasma discharge systems for investigation of plasma materials interaction. Continued measurement of trapping, permeation and retention of tritium in redeposited layers and in bulk PFC armor materials will be required. Techniques developed to purge tritium from in-vessel surfaces will need to be tested. using deuterium and/or seeded tritium, on tokamaks. As shown in Table III.10-1, a budget of about $\$ 650 \mathrm{~K}$ will be required over the next three years to support this effort. 


\section{IV.8 Neutron Effects}

Irradiation of candidate material samples and small $\left(\sim 10-30 \mathrm{~cm}^{2}\right)$, actively cooled PFC mock-ups will be required to assess neutron damage efforts. Neutron damage will adversely affect PFC lifetime and reliability as discussed in Sections III.8 and IV.5.

Reactors around the world will be required to accommodate the necessary sample throughput. As shown in Figure III.11-1, sample preparation exposure, cool down, and evaluation may take three years to complete.

Irradiation of candidate materials or simple bonded duplex structures will cost $\$ 70-100 \mathrm{~K}$. An integrated test sequence, including neutron irradiation, high heat flux tests, erosion tests, and armor repair, will cost $\$ 0.75-1.0 \mathrm{M}$.

\section{IV.9 Test Facilities Considered and Not Selected as Necessary to Develop and Validate PFCs for ITER}

The generic test facility types considered and not selected as part of the minimum. most costeffective set required to support the development plan are

1. Large linear divertor plasma simulation devices, such as IDEAL.

2. Small tokamaks with only modest boundary layer power flux densities,

3. Small, low power density steady state tokamaks.

\section{IV.9.1 Large Linear Plasma Simulation Devices (LLPS), Such as IDEAL}

The committee spent considerable time evaluating the contributions to be made to divertor physics and to PFC technology development by an LLPS. As a basis for our evaluations, we accepted the performance parameters postulated for IDEAL, but did not independently verify them. We accepted that the test device operated reliably and with high $(>75 \%)$ availability. We assumed that the device would provide plasma conditions representative of those to be expected in the ITER divertor region, $\mathrm{q}_{\| 1} \sim 1 \mathrm{GW} / \mathrm{m}^{2}, \mathrm{n}_{\mathrm{e}} \sim 0.1-1.0 \times 10^{21} / \mathrm{m}^{3}, \mathrm{~T}_{\mathrm{e}}>100 \mathrm{eV}, \mathrm{T}_{\mathrm{i}}>300 \mathrm{eV}, \mathrm{B} \sim 2-3 \mathrm{~T}$, connection lengths $\sim 10 \mathrm{~m}$, heated areas $\sim 0.01 \mathrm{~m}^{2}$, and puise durations of $>1000 \mathrm{~s}$. Finally, we accepted the capital cost for the device considered to be $\$ 30 \mathrm{M}$, though recent estimates are larger $(\$ 45-70 \mathrm{M})$.

Considering the schedule for data delivery and the fact that a more cost-effective path for obtaining the same or similar data was identified, the LLPS was not included in the minimum, most costeffective set of test facilitates required to support PFC physics and technology development for ITER.

The LLPS did not reduce the number or complexity of physics validation experiments required to be executed elsewhere in the development program plan, primarily on tokamaks. The committee noted that the LLPS provided some basic physics data on atomic, molecular, radiative and transport processes supporting divertor physics concept development, but more directly applicable data can be obtained at significantly lower cost on tokamaks.

The LLPS did not replace other expensive technology test facilities and did not significantly reduce the number of tests which need to be conducted outside of the LLPS. Therefore, the U.S. PFC development budget would have to be increased by more than a factor of two to include the LLPS and still maintain other critically needed testing and development efforts. Effective utilization of the available PFC budget and timeliness of the data provided also influenced the decision of the committee not to include the LLPS in the minimum PFC test facility set. Construction of a device 
like IDEAL is expected to take three years. With a total capital cost of at least $\$ 30 \mathrm{M}$, the construction project would require an annual budget of $\$ 10 \mathrm{M}$. The U.S. FY93 budget for PFC technology development was $\sim \$ 8 \mathrm{M}$.

The LLPS cannot contribute useful data on the physics issues of dissipative divertor impact on the core plasma behavior since it obviously has no high current. central plasma confined inside a separatrix to influence. Consequently, the LLPS received low ratings for contributions in the areas of confinement. density/fueling control and disruptions. The LLPS also contributes no dr.a on the technology aspects of PFC response to disruptions.

Plasma flow conditions in the LLPS are significantly different from those found in tokamaks. There is no field curvature to influence particle and energy cross field transport ( $\chi_{\perp}$ and $D_{\perp}$ ), and there is no plasma flow across a separatrix driving the system. IDEAL proposes to use direct ICRF particle heating. Ion and electron distribution functions will be markedly different from those found in tokamak boundary regions.

Direct extrapolation of results obtained on the LLPS to tokamak conditions will be difficult. Plasma wall interactions in tokamaks and in mirror machines have been found to strongly influence the local plasma conditions. A significant modeling effort will therefore be required to interpret LLPS results, understand the important parameters influencing the results, and extrapolate to ITER tokamak conditions. Similar data obtained on tokamaks requires much less extrapolation to ITER.

Data on erosion/redeposition processes can be most cost effectively obtained by properly diagnosing operating tokamaks. The LLPS could investigate the fundamental physics of erosion processes in the presence of strong sheaths and glancing magnetic field incidence (e.g., sputtering yield, ejected atom direction and energy, sheath magnitude and spatial extent, ionization in the sheath and charge state achieved), but this can also be done on tokamaks. The LLPS or small plasma discharge devices could be used to generate thick redeposited films for subsequent materials property measurements. The program plan for resolution of erosion/redeposition processes, which relies on small plasma discharge devices, is described in Section III.5.

An LLPS operating at high power flux density, delivering heat fluxes of $5.50 \mathrm{MW} / \mathrm{m}^{2}$, and capable of reliabie cyclic operation could provide valuable technology data on heat removal and lifetime/reliability. The LLPS could conduct thermal cyclic, heat removal and accident testing on large scale, unirradiated PFC mock-ups. The same high heat flux data as in the LLPS can be generated, in a much more cost-effective manner, on ion/electron beam test stands $(\$ 3-5 \mathrm{M}$ for the beam systems vs. $\$ 30 \mathrm{M}$ or more for the LLPS). Several ion and several electron beam systems are already in operation at SNL, JET, KFA Jülich, CEA, JAERI and Efremov. These systems will continue to be available for fusion studies.

The test conditions in the LLPS would not be a complete reproduction of the ITER environment since neutron effects cannot be included. Inclusion of the LLPS in the test plan provided an alternative, more expensive path for some of the high heat flux testing, but did not reduce the number or complexity of lifetime/reliability tests which would have to be performed, outside of the LLPS, to address synergistic effects of neutron damage on thermal cyclic fatigue, material embrittlement, etc. There are no irradiation facilities capable of accommodating large area $\left(\sim 1 \mathrm{~m}^{2}\right)$ PFC mock-ups, and construction of such a facility cannot be considered within the present budgetary limits of the worldwide fusion research program. The program plan for resolution of PFC lifetime/reliability issues is described in Sections III.8 and III.11. As discussed in Section III. addressing synergistic neutron damage effects requires rotation of samples through a number of single effects test stands, which will be required whether or not the LLPS is available. 
Test data for ITER from LLPS would not be forthcoming until 1999, assuming that construction began immediately. Based on experience in the mirror program, ISCUS recently estimated that an LLPS such as IDEAL would require a three-year start-up feriod before reliable operation with full parameters could be expected.

\section{IV.9.2 Low Power Density Tokamaks}

Small, low power density tokamaks were identified as capable of providing some data on divertor physics concept development issues. However, the data obtained would be at plasma densities. temperatures. sheath strengths and fluxes below those provided by high power density tokamaks. For this rea ;on. low power density tokamaks are not included in the minimum, most cost-effective test facility set for development of PFCs. We fully acknowledge, however, the valuable contributions being made in many areas by small tokamaks.

\section{IV.9.3 Small, Low Power Density Steady State Tokamaks}

A steady state tokamak could provide additional data on erosion/redeposition beyond that obtained on short pulse tokamaks. A more cost-effective and timely alternative path for resolution of this issue, utilizing thin film measurements on short pulse machines and using small plasma discharge devices to produce thicker redeposited films, was identified. The required high heat flux testing was determined to be most cost effectively carried out on ion/electron beam test stands. The number of required thermal cycles (10-30 thousand), as well as testing to destruction, especially at very high heat flux loads $\left(50-100 \mathrm{MW} / \mathrm{m}^{2}\right)$, would be difficult to accomplish on a tokamak. 
(This page intentionally left blank.) 


\section{EXTERNAL DISTRIBUTION:}

D. Christensen, ETWMD

U.S. Department of Energy

Albuquerque Operations OHfice

P.O. Box 5400

Albuquerque NM 87115

C. W. Boltor:

U.S. Department of Energy

Office of Energy Research

ER-55, Germantown

Washington, DC 20585

D. H. Crandall

U.S. Department of Energy

Office of Energy Research

ER-542, Germantown

Washington, DC 20585

\section{R. J. Dowling}

U.S. Department of Energy

Office of Energy Research

ER-53, Germantown

Washington, DC 20585
R. A. Blanken

U.S. Department of Energy Otfice of Energy Research ER-542, Germantown

Washington DC 20585
M. M. Cohen

U.S. Department of Energy Office of Energy Research ER-532, Germantown

Washington, DC 20585
N. A. Davies

U.S. Department of Energy Office of Energy Research ER-50, Germantown Washington, DC 20585
T. V. George

U.S. Department of Energy Office of Energy Research ER-531, Germantown Washington, DC 20585
T. R. James

U.S. Department of Energy

Office of Energy Research

ER-55, Germantown

Washington, DC 20585

\section{W. A. Marton}

U.S. Department of Energy Office of Energy Research ER-532, Germantown Washington, DC 20585 
E. Oktay

U.S. Department of Energy

Office of Energy Research

ER-55, Germantown

Washington, DC 20585

R. E. Price

U.S. Department of Energy

Office of Energy Research

ER-55, Germantown

Washington, DC 20585

W. L: Sadowski

U.S. Department of Energy

Office of Energy Research

ER-541, Germantown

Washington, DC 20585

J. W. Willis

U.S. Department of Energy

Otfice of Energy Research

ER-55, Germantown

Washington, DC 20585

D. Ehst

Argonne National Laboratory

Building 205/FPP

9700 South Cass Avenue

Argonne, IL 60439
A. Opdenacker

U.S. Department of Energy

Oftice of Energy Research

ER-531, Germantown

Washington, DC 20585

\section{Roberts}

U.S. Department of Energy Office of Energy Research ER-52, Germantown Washington, DC 20585

H. S. Staten

U.S. Department of Energy Otfice of Energy Research

EF-531, Germantown

Washington, DC 20585
J. Brooks

Argonne National Laboratory Building 205/FPP 9700 South Cass Avenue Argonne, IL 60439
P. Finn

Argonne National Laboratory Building 205/FPP 9700 South Cass Avenue Argonne, IL 60439 
Y. Gohar

Argonne National Laboratory

Building 205/FPP

9700 South Cass Avenue

Argonne, IL 60439
A. Hassanein Argonne National Laboratory Building 205/FPP 9700 South Cass Avenue Argonne, IL 60439
A. Krauss

Argonne National Laboratory

Chemistry Building 200

9700 South Cass Avenue

Argonne, IL 60439
D. L. Smith

Argonne National Laboratory

Building 205/FPP

9700 South Cass Avenue

Argonne, IL 60439
R. Mattas

Argonne National Laboratory Building 205/FPP

9700 South Cass Avenue

Argonne, IL 60439
D. $S z e$

Argonne National Laboratory Building 205/FPP 9700 South Cass Avenue Argonne, IL 60439
Argonne National Laboratory

Building 205/FPP

Attn: Fusion Library

9700 South Cass Avenue

Argonne, IL 60439
J. F. Clarke

Battelle Pacific Northwest Laboratory P.O. Box 999

Richland, WA 99352
H. Heinisch, 326

Battelle Pacific Northwest Laboratory

P.O. Box 999

Richland, WA 99352
G. Hollenberg

Battelle Pacific Northwest Laboratory P.O. Box 999

Richland, WA 99352 
Battelle Pacific Northwest Laboratory

Attn: Library

P.O. Box 999

Richland, WA 99352

Bechtel Group, Inc.

Research Engineering

Attn: Library

P.O. Box 3965

San Francisco, CA 94105
H. K. Forsen

Bechtel Group. Inc.

Research Engineering

P.O. Box 3965

San Francisco, CA 94105

R. W. Gould

California Institute of Technology

Department of Applied Physics

128-95

Pasadena, CA 91125
California Institute of Technology

Department of Applied Physics

Attn: Library

128-95

Pasadena, CA 91125
M. Abdou

University of California

School of Enginnering \&

Applied Sciences

6291 Boetter Hall

Los Angeles, CA 90024
R. W. Conn

University of Califomia

School of Engineering \&

Applied Sciences

6291 Boelter Hall

Los Angeles, CA 90024
R. Doerner University of California School of Engineering \& Applied Sciences 6291 Boetter Hall Los Angeles, CA 90024
N. Ghoniem

University of Califomia

School of Engineering \&

Applied Sciences

6291 Boelter Hall

Los Angeles, CA 90024
Y. Hirooka

University of California School of Engineering \& Applied Sciences 6291 Boelter Hall Los Angeles, CA 90024 
L. Schmitz

University of Califomia

School of Engineering \&

Applied Sciences

6291 Boelter Hall

Los Angeles, CA 90024
M. Tillack

University of California

School of Engineering \&

Applied Sciences

6291 Boelter Hall

Los Angeles, CA 90024
W. S. Cooper

Lawrence Berkeley Laboratory

University of California

One Cyclotron Road

Berkeley, CA 94720
R. A. Gross

Columbia University

Plasma Physics Laboratory

Department of Applied Physics and

Nuclear Engineering

Room 510

New York, NY 10027
Columbia University

Plasma Physics Laboratory

Department of Applied Physics and

Nuclear Engineering

Attn: Library

New York, NY 10027
D. F. Holland

EG\&G Idaho, Inc.

INEL

P.O. Box 1625

Idaho Falls, ID 83415-3523
L. C. Cadwallader

EG\&G Idaho, Inc.

INEL

P.O. Box 1625

Idaho Falls, ID 83415-3523
D. Knoll

EG\&G Idaho, inc.

INEL

P.O. Box 1625

Idaho Falls, ID 83415-3895
B. J. Merrill

EG\&G Idaho, Inc.

INEL

P.O. Box 1625

Idaho Falls, ID 83415-3523

\section{A. Petti}

EG\&G Idaho, Inc.

INEL

P.O. Box 1625

Idaho Falls, ID 83415-3880 
S. J. Piet

EG\&G Idaho, Inc.

INEL

P.O. Box 1625

Idaho Falls, ID 83415-3523
EG\&G, Idaho, inc.

INEL

Attn: Library

P.O. Box 1625

Idaho Falls, ID 83415
T. Knowles

Energy Science Laboratories

6888 Nancy Ridge Drive

San Diego, CA 92121

Fiber Materials, Inc.

Attn: Library

Biddeford Industrial Park

Biddeford, ME 04005

C. B. Baxi

General Atomics

Fusion and Advanced Technology

P.O. Box 85608

San Diego, CA 92186-9784

T. Evans

General Atomics

Fusion and Advanced Technology

P.O. Box 85608

San Diego, CA 92186-9784
J. Smith

Fiber Materials, Inc.

Biddeford Industrial Park

Biddeford, ME 04005

S. O. Dean

Fusion Power Associates, Inc.

2 Professional Drive, Suite 249

Gaithersburg, MD 20760

J. deGrassie

General Atomics

Fusion and Advanced Technology P.O. Box 85608

San Diego, CA 92186-9784

R. L. Freeman

General Atomics

Fusion and Advanced Technology

P.O. Box 85608

San Diego, CA 92186-9784 
R. Gallix

General Atomics

Fusion and Advanced Technology

P.O. Box 85608

San Diego, CA 92186-9784

G. Jackson

General Atomics

Fusion and Advanced Technology

P.O. Box 85608

San Diego, CA 92186-9784

D. Overskei

General Atomics

Fusion and Advanced Technology

P.O. Box 85608

San Diego, CA 92186-9784

L. Sevier

General Atomics

Fusion and Advanced Technology

P.O. Box 85608

San Diogo, CA 92186-9784

J. Smith

General Atomics

Fusion and Advanced Technology

P.O. Box 85608

San Diego, CA 92186-9784
D. Hi甘

General Atomics

Fusion and Advanced Technology

P.O. Box 85608

San Diego, CA $92186-9784$

\author{
A. Mahdavi \\ General Atomics \\ Fusion and Advanced Technology \\ P.O. Box 85608 \\ San Diego, CA 92186-9784
}

\author{
K. R. Schultz \\ General Atomics \\ Fusion and Advanced Technology \\ P.O. Box 85608 \\ San Diego, CA 92186-9784
}

T. Simonen General Atomics

Fusion and Advanced Technology P.O. Box 85608

San Diego, CA 92186-9784
R. D. Stambaugh General Atomics Fusion and Advanced Technology P.O. Box 85608

San Diego, CA $92186-9784$ 
General Atomics

Fusion and Advanced Technology

Attn: Fusion Library

P.O. Box 85608

San Diego, CA 92186-9784

Georgia Institute of Technology

Fusion Research Center \&

Nuclear Engineering Program

Attn: Fusion Library

Atlanta, GA 30332

\section{S. Fixler}

Grumman Aerospace Corporation

Energy Systems Division

Bethpage, NY 11714

G. Miley

University of Illinois

Fusion Studies Laboratory

214 Nuclear Engineering Lab

103 South Goodwin Avenue

Urbana, IL 61801
W. M. Stacey, Jr.

Georgia Institute of Technology

Fusion Research Center \&

Nuclear Engineering Program

Atlanta, GA 30332

\section{Berwald}

Grumman Aerospace Corporation

Energy Systems Division

Bethpage, NY 11714
Grumman Aerospace Corporation Energy Systems Division

Attn: Library

Bethpage, NY 11714
D. Ruzic

University of Illinois

Fusion Studies Laboratory

214 Nuclear Engineering Lab

103 South Goodwin Avenue

Uibana, IL 61801
University of lllinois

Fusion Studies Laboratory

Attn: Fusion Library

214 Nuclear Engineering Lab

103 South $G_{c}$ Jwin Avenue

Umana, IL 61801
J. N. Doggett, L-641

Lawrence Livermore National Laboratory

P.O. Box 808

Livermore, CA 94550 
M. Fenstermacher, L-637

Lawrence Livermore National Laboratory P.O. Box 808

Livermore, CA 94550

J. D. Lee, L-644

Lawrence Livermore National Laboratory

P.O. Box 808

Livermore, CA 94550
A. Glass, L-001

Lawrence Livermore National Laboratory P.O. Box 808

Livermore, CA 94550
G. Logan, L-640 Lawrence Livermore National Laboratory P.O. Box 808

Livermore, CA 94550
R. Moir, L-644

Lawrence Livermore National Laboratory P.O. Box 808

Livermore, CA 94550
W. Nevins, L-644

Lawrence Livermore National Laboratory P.O. Box 808

Livermore, CA 94550
L. J. Perkins, L-644

Lawrence Livermore National Laboratory P.O. Box 808

Livermore, CA 94550
J. Pitts, L-481

Lawrence Livermore National Laboratory P.O. Box 808

Livermore, CA 94550
K. I. Thomassen

Lawrence Livermore National Laboratory P.O. Box 808

Livermore, CA 94550
Lawrence Livermore National Laboratory Attn: Fusion Library

P.O. Box 808

Livermore, CA 94550 
C. Bathke

Controlled Thermonuclear Research Div.

Los Alamos National Laboratory

P.O. Box 1663

Los Alamos, NM 87545

J. Downing

Controlled Thermonuclear Research Div. Los Alamos National Laboratory

P.O. Box 1663

Los Alamos, NM 87545

R. Linford

Controlled Thermonuciear Research Div.

Los Alamos National Laboratory

P.O. Box 1663

Los Alamos, NM 87545

K. Werley

Controlled Thermonuclear Research Div.

Los Alamos National Laboratory

P.O. Box 1663

Los Alamos, NM 87545

B. Lipschultz, NW 17-103

Plasma Fusion Center

Massachusetts Institute of Technology

175 Albany Street

Cambridge, MA 02139
T. Cayton

Controlled Thermonuclear Research Div. Los Alamos National Laboratory

P.O. Box 1663

Los Alamos, NM 87545

R. Krakowski

Controlled Thermonuclear Research Div.

Los Alamos National Laboratory

P.O. Box 1663

Los Alamos, NM 87545

R. E. Siemon

Controlled Thermonuclear Research Div. Los Alamos National Laboratory

P.O. Box 1663

Los Alamos, NM 87545

Controlled Thermonuclear Research Div. Los Alamos National Laboratory

Attn: Fusion Library

P.O. Box 1663

Los Alamos, NM 87545

B. Montgomery, NW 17-288

Plasma Fusion Center

Massachusetts institute of Technology 175 Albany Street

Cambridge, MA 02139 
R. R. Parker, NW 16-288

Plasma Fusion Center

Massachusetts Institute of Technology

167 Albany Street

Cambridge, MA 02139

T. Yang, NW 17-254

Plasma Fusion Center

Massachusetts Institute of Technology

175 Albany Street

Cambridge, MA 02139
D. J. Sigmar, NW 16-250

Plasma Fusion Center

Massachusetts Institute of Technology

167 Albany Street

Cambridge, MA 02139
Plasma Fusion Center

Massachusetts Institute of Technology Attn: Fusion Library, NW 16-284

167 Albany Street

Cambridge, MA 02139
J. W. Davis

High Energy Systems

McDonnell Douglas Corp.

Mail Code 306-4204

P.O. Box 516

St. Louis, MO 63166
D. Dreernyer

High Energy Systems McDonnell Douglas Corp.

P.O. Box 516

St. Louis, MO 63166
D. Morgan

High Energy Systems

McDonnell Douglas Corp.

P.O. Box 516

St. Louis, MO 63166
McDonnell Douglas Corp

St. Louis Division

ACC/E030/287/1

Attn: Library

P.O. Box 516

St. Louis, MO 63166

\section{J. Gahl}

University of New Mexico

Electrical \& Computer Engineering Dept.

Campus Station

Albuquerque, NM 87131

\section{El-Genk}

University of New Mexico

Department of Nuclear Engineering Campus Station

Albuquerque, NM 87131 
A. Prinja

University of New Mexico

Department of Nuclear Engineering

Campus Station

Albuquerque, NM 87131
University of New Mexico

Department of Nuclear Engineering Attn: Engineering Library Campus Station

Albuquerque. NM 87131
J. Gilligan

North Carolina State University

Department of Nuclear Engineering

P.O. Box 7909

Raleigh, NC 27695
C. C. Baker

Fusion Energy Division

Oak Ridge National Laboratory

P.O. Box 2009

Oak Ridge, TN 37831-8070

\section{A. Berry}

Fusion Energy Division

Oak Ridge National Laboratory

P.O. Box 2009

Oak Ridge, TN 37831-8070
R. A. Dory

Fusion Energy Division

Oak Ridge National Laboratory

P.O. Box 2009

Oak Ridge, TN 37831-8070
J. L. Dunlap

Fusion Energy Division

Oak Ridge National Laboratory

P.O. Box 2009

Oak Ridge, TN 37831-8070
C. A. Flanagan

Fusion Energy Division Oak Ridge National Laboratory P.O. Box 2009

Oak Ridge, TN 37831-8070
J. Haines

Fusion Energy Division

Oak Ridge National Laboratory

P.O. Box 2009

Oak Ridge, TN 37831-8070
J. H. Hamis

Fusion Energy Division

Oak Ridge National Laboratory

P.O. Box 2009

Oak Ridge, TN 37831-8070 
D. L. Hillis

Fusion Energy Division

Oak Ridge National Laboratory

P.O. Box 2009

Oak Ridge, TN 37831-8070

W. Houlberg

Fusion Energy Division

Oak Ridge National Laboratory

P.O. Box 2009

Oak Ridge, TN 37831-8070

R. Langley

Fusion Energy Division

Oak Ridge National Laboratory

P.O. Box 2009

Oak Ridge, TN 37831-8070

P. K. Mioduszewski

Fusion Energy Division

Oak Ridge National Laboratory

P.O. Box 2009

Oak Ridge, TN 37831-8070

M. J. Saltmarsh

Fusion Energy Division

Oak Ridge National Laboratory

P.O. Box 2009

Oak Ridge, TN 37831-8070
J. T. Hogan

Fusion Energy Division

Oak Ridge National Laboratory

P.O. Box 2009

Oak Ridge, TN 37831-8070

C. C. Klepper

Fusion Energy Division

Oak Ridge National Laboratory

P.O. Box 2009

Oak Ridge, TN 37831-8070

S. Milora

Fusion Energy Division

Oak Ridge National Laboratory

P.O. Box 2009

Oak Ridge. TN 37831-8070

M. Murakami

Fusion Energy Division

Oak Ridge National Laboratory

P.O. Box 2009

Oak Ridge, TN $37831-8070$

J. Sheffield

Fusion Energy Division

Oak Ridge National Laboratory

P.O. Box 2009

Oak Ridge, TN 37831-8070 
D. W. Swain

Fusion Energy Division

Oak Ridge National Laboratory

P.O. Box 2009

Oak Ridge, TN $37831-8070$

T. Uckan

Fusion Energy Division

Oak Ridge National Laboratory

P.O. Box 2009

Oak Ridge, TN 37831-8070

Y. K. M. Peng

Fusion Erigineering Design Center

Oak Ridge National Laboratory

P.O. Box 2009

Oak Ridge, TN 37831-8218

Oak Ridge National Laboratory

Fusion Engineering Design Center

Attn: FEDC Library

P.O. Box 2009

Oak Ridge, TN 37831-8218
N. A. Uckan

Fusion Energy Division

Oak Ridge National Laboratory

P.O. Box 2009

Oak Ridge, TN 37831-8070
Fusion Energy Division

Oak Ridge National Laboratory Attn: Fusion Energy Div. Library P.O. Box 2009

Oak Ridge, TN 37831-8070
T. Shannon

Fusion Engineering Design Center Oak Ridge National Laboratory

P.O. Box 2009

Oak Ridge, TN 37831-8218
Dr. T. Burchell

Metals and Ceramics Division Oak Ridge National Laboratory P.O. Box 2088

Oak Ridge, TN 37831-6088
L. Snead

Metals and Ceramics Division

Oak Ridge National Laboratory

P.O. Box 2088

Oak Ridge, TN 37831-6088
E. Klevans

Pennsylvania State University 231 Sackett Building University Park, PA 16802 
Pennsylvania State University

Attn: Engineering Library

231 Sackett Buikting

University Park, PA 16802

C. Bushnell

Princeton Plasma Physics Laboratory

P.O. Box 451

Princeton, NJ 08543

\section{R. Fleming}

Princeton Plasma Physics Laboratory

P.O. Box 451

Princeton, NJ 08543

D. Ignat

Princeton Plasma Physics Laboratory

P.O. Box 451

Princeton, NJ 08543

W. Langer

Princeton Plasma Physics Laboratory

P.O. Box 451

Princeton, NJ 08543
R. Budny

Princeton Plasma Physics Laboratory P.O. Box 451

Princeton, NJ 08543

\section{S. Cohen}

Princeton Plasma Physics Laboratory P.O. Box 451

Princeton, NJ 08543

R. J. Goldston

Princeton Plasma Physics Laboratory P.O. Box 451

Princeton, NJ 08543

S. Kilpatrick

Princeton Plasma Physics Laboratory

P.O. Box 451

Princeton, NJ 08543

\section{M. Meade}

Princeton Plasma Physics Laboratory P.O. Box 451

Princeton, NJ 08543 
R. Ritter

Princeton Plasma Physics Laboratory

P.O. Box 451

Princeton, NJ 08543

N. Sauthoff

Princeton Plasma Physics Laboratory

P.O. Box 451

Princeton, NJ 08543

Princeton Plasma Physics Laboratory

Attn: P.P.P.L. Lit:-arian

F.O. Box 451

Princeton, NJ 08543

Rensselaer Polytechnic Institute Nuclear Engineering Department Attn: Library

NES Building, Tibbetts Avenue

Troy, NY 12181
R. Rutherford

Princeton Plasma Physics Laboratory P.O. Box 451

Princeton, NJ 08543

J. Schmict

Princeton Plasma Physics Laboratory P.O. Box 451

Princeton, NJ 08543
D. Steiner

Rensselaer Polytechnic Institute Nuclear Engineering Department NES Building, Tibbetts Avenue Troy, NY 12181
F. Puhn

San Diego ITER Co-Center 11025 N. Torrey Pines Road La Jolla, CA 92037
D. Post

San Diego ITER Co-Center 11025 N. Torrey Pines Road La Jolla, CA 92037
P. H. Rebut San Diego ITER Co-Center 11025 N. Torrey Pines Road La Jolla, CA 92037 
J. Gordon

TRW

Building R-1/Room 2120

One Space Park

Redondo Beach, CA 90278

J. Maniscalco

TRW

Building R-1/Room 2120

One Space Park

Redondo Beach, CA 90278

TRW

Attn: Library

Building R-1/Room 2120

One Space Park

Redondo Beach, CA 90278

\section{P. Edmonds}

The University of Texas at Austin

Fusion Research Center

RLM 12.220

Austin, TX 78712

R. Hazeltine

The University of Texas at Austin

Fusion Research Center

RLM 11.222

Austin, TX 78712
G. Listvinsky

TRW

Building R-1:'Room 2120

One Space Park

Redondo Beach, CA 90278

\section{J. Weede}

TRW

Building R-1/Room 2120

One Space Park

Redondo Beach, CA 90278

\section{R. Carrera}

The University of Texas at Austin Center for Fusion Engineering ENS 125

Austin, TX 78712

\section{K. W. Gentle}

The University of Texas at Austin Fusion Research Center

RLM 12.220

Austin, TX 78712

The University of Texas at Austin Fusion Research Center

Attn: Fusion Library

RLM 12.220

Austin, TX 78712 
J. D. Callen

University of Wisconsin

Fusion Technology Institute

Engineering Research Building

1500 Johnson Drive

Madison, WI 53706-1687
University of Wisconsin

Fusion Technology Institute

Engineering Research Building

Attn: Fusion Librarian

1500 Johnson Drive

Madison, WI 53706-1687
Australian National University Attn: Plasma Research Lab

P.O. Box 4

Canberra, A. C. T. 2601

AUSTRALIA
N. Reheis

Metallwerk Plansee GmbH.

A-6600 Reutte-Tirol

AUSTRIA
E. Kny Metallwerk Plansee $\mathrm{GmbH}$. A-6600 Reutte-Tirol

AUSTRIA
I. Smid

Osterreichisches Forschungszentrum

A-2444 Seibersdort

AUSTRIA
R. Staffler

Metallwerk Plansee GmbH. A-6600 Reutte-Tirol AUSTRIA
Dr. D. Jackson National Fusion Program Atomic Energy of Canada Limited Chalk River Nuclear Laboratories Chalk River, Ontario KOJ $1 \mathrm{JO}$ CANADA
Dr. R. A. E. Bolton

Canadian Centre for Magnetic Fusion 1804 Montee Ste. Julie

Varennes, Quebec JOL 2PO

CANADA
Canadian Centre for Magnetic Fusion Attn: Library

1804 Montee Ste. Julie Varennes, Quebec JOL 2PO CANADA 
P. Gierszewski

Canadian Fusion Fuels Technology Project 2700 Lakeshore Road West

Mississauga, Ontario, L5J 1K3

CANADA

University of Toronto

Institute of Aerospace Studies

Attn: Library

4925 Dufferin Street

Downsview, Ontario, M3H 5T6

CANADA

M. Chatelier

DRFC/SPPF

Centre d'Etudes Nucleaires de Cadarache

F-13108 Saint Paul-Les-Durance CEDEX

FRANCE

R. Gravier

DRFC, Batiment 513

Centre d'Etudes Nucleaires de Cadarache

F-13108 Saint Paul-Les-Durance CEDEX

FRANCE

D. Guilhem

DRFC/SPPF

Centre d'Etudes Nucleaires de Cadarache

F-13108 Saint Paul-Les-Durance CEDEX

FRANCE
A. A. Haasz

University of Toronto

Institute of Aerospace Studies

4925 Dufferin Street

Downsview, Ontario, M3H 5 T6

CANADA

P. Chappuis

DRFC/STIF

Centre d'Etudes Nucleaires de Cadarache

F-13108 Saint Paul-Les-Durance CEDEX .

FRANCE

P. Deschamps

DRFC/STIF

Centre d'Etudes Nucleaires de Cadarache F-13108 Saint Paul-Les-Durance CEDEX FRANCE

D. Grossman

DRFC/SPPF

Centre d'Etudes Nucleaires de Cadarache F-13108 Saint Paul-Les-Durance CEDEX FRANCE

P. Hertout DRFC/STIF

Centre d'Etudes Nucleaires de Cadarache

F-13108 Saint Paul-Les-Durance CEDEX FRANCE 
C. Klepper DRFC/SPPF

Centre d'Etudes Nucleaires de Cadarache F-13108 Saint Paul-Les-Durance CEDEX FRANCE

T. Loarer DRFC/SPPF

Centre d'Etudes Nucleaires de Cadarache F-13108 Saint Paul-Les-Durance CEDEX FRANCE
M. Lipa

DRFC/STIF

Centre d'Etudes Nucleaires de Cadarache F-13108 Saint Paul-Les-Durance CEDEX FRANCE

T. Lutz DRFC/STIF, Batiment 506

Centre d'Etudes Nucleaires de Cadarache F-13108 Saint Paul-Les-Durance CEDEX FRANCE

\section{F. Prevot}

DRFC/STIF

Centre d'Etudes Nucleaires de Cadarache F-13108 Saint Paul-Les-Durance CEDEX FRANCE
J. Tachon

DRFC

Centre d'Etudes Nucleaires de Cadarache F-13108 Saint Paul-Les-Durance CEDEX FRANCE
Centre d'Etudes Nucleaires de Cadarache Attn: Bibliotheque

F-13108 Saint Paul-Les-Durance CEDEX FRANCE
S. Tobin DRFC/SPPF

Centre d'Etudes Nucleaires de Cadarache F-13108 Saint Paul-Les-Durance CEDEX FRANCE
Prof. K. Koizlik

Kernforschungsanlage Jülich $\mathrm{GmbH}$ IRW

Postfach 1913

D-5170 Jülich

GERMANY 
Dr. J. Linke

Kernforschungsanlage Jülich $\mathrm{GmbH}$

IRW

Postfach 1913

D-5170 Jülich

GERMANY

Kerntorschungsanlage Jülich $\mathrm{GmbH}$ Institut für Nuclearchemie

Attn: V. Philipps

Postfach 1913

D-5170 Jülich

GERMANY

\section{H. Conrads}

Kernforschungsanlage Jülich $\mathrm{GmbH}$ Institut für Plasmaphysik (KFA-IPP)

Postfach :913

D-5170 Jülich

GERMANY

G. Fuchs

Kernforschungsanlage Jülich $\mathrm{GmbH}$ Institut für Plasmaphysik (KFA-IPP)

Postfach 1913

D-5170 Jülich

GERMANY
Prof. H. Nickel

Kernforschungsanlage Jülich $\mathrm{GmbH}$ IRW

Postfach 1913

D-5170 Jülich

GERMANY
Dr. Claassen

Kernforschungsanlage Jülich $\mathrm{GmbH}$ Institut für Plasmaphysik (KFA-IPP)

Postfach 1913

D-5170 Jülich GERMANY

\section{K. H. Finken}

Kernforschungsanlage Jülich $\mathrm{GmbH}$ Institut für Plasmaphysik (KFA-IPP)

Postfach 1913

D-5170 Jülich

GERMANY
W. Kohlhaas

Kernforschungsanlage Jülich $\mathrm{GmbH}$ Institut für Plasmaphysik (KFA-IPP)

Postfach 1913

D-5170 Jülich

GERMANY
E. Hintz

Kernforschungsanlage Jülich $\mathrm{GmbH}$ Institut für Plasmaphysik (KFA-IPP)

Postfach 1913

D-5170 Jülich

GERMANY

\author{
A. Pospieszczyk \\ Kernforschungsanlage Jülich $\mathrm{GmbH}$ \\ Institut für Plasmaphysik (KFA-IPP) \\ Postfach 1913 \\ D-5170 Jülich \\ GERMANY
}


U. Samm

Kernforschungsanlage Jülich $\mathrm{GmbH}$ Institut für Plasmaphysik (KFA-IPP)

Postfach 1913

D-5170 Jülich

GERMANY

J. Winter

Kernforschungsanlage Jülich $\mathrm{GmbH}$

Institut für Plasmaphysik (KFA-IPP)

Postfach 1913

D-5170 Jülich

GERMANY

Kernforschungsanlage Jülich $\mathrm{GmbH}$ Institut für Plasmaphysik (KFA-IPP)

Attn: Bibliothek

Postfach 1913

D-5170 Jülich

GERMANY

Kernforschungszentrum Karlsruhe - IRE

Attn: Bibliothek

Postfach 3640

D-7500 Karisruhe

GERMANY
F. Waelbroeck

Kernforschungsanlage Jülich GmbH Institut für Plasmaphysik (KFA-IPP)

Postfach 1913

D-5170 Jülich

GERMANY

\section{G. Wolf}

Kernforschungsanlage Jülich $\mathrm{GmbH}$

Institut für Plasmaphysik (KFA-IPP)

Postfach 1913

D-5170 Jülich

GERMANY

K. Kleefeldt

Kernforschungszentrum Karlsruhe - IRE Attn: Bibliothek

Postfach 3640

D-7500 Karlsruhe

GERMANY

Dr. R. Behrisch

Max Planck Institut für Plasmaphysik

D-85748 Garching GERMANY
Prof. V. Dose

Max Planck Institut für Plasmaphysik

D-85748 Garching

GERMANY

\author{
J. Roth \\ Max Planck Institut für Plasmaphysik \\ D-85748 Garching \\ GERMANY
}


Dr. H. Vemickel

Max Planck Institut für Plasmaphysik D-85748 Garching GERMANY

\section{J. Dietz}

ITER Co-Center Garching

Max Planck Institut für Plasmaphysik

Boltzmann Str. 2

D-85748 Garching bei Mũnchen

GERMANY

R. Parker

ITER Co-Center Garching

Max Planck Institut für Plasmaphysik

Boltzmann Str. 2

D-85748 Garching bei München

GERMANY

M. Budd

The NET Team

Max Planck Institut für Plasmaphysik

Boltzmann Str. 2

D-85748 Garchiny bei Mūnchen

GERMANY

M. Chazolon

The NET Team

Max Planck Institut für Plasmaphysik

Boltzmann Str. 2

D-85748 Garching bei München

GERMANY
Max Planck Institute für Plasmaphysik

Attn: Bibliothek

D-85748 Garching GERMANY
H. Bolt

The NET Team

iviax :Planck Institut für Plasmaphysik

Boltzmann Str. 2

D-85748 Garching bei München GERMANY
A. Cardella The NET Team

Max Planck Institut für Plasmaphysik Boltzmann Str. 2 D-85748 Garching bei München GERMANY
G. Vieider

The NET Team

Max Planck Institut für Plasmaphysik

Boltzmann Str. 2

D-85748 Garching beii München

GERMANY 
C. Wu

The NET Team

Max Planck Institut für Plasmaphysik

Boltzmann Str. 2

D-85748 Garching bei München

GERMANY

The NET Team

Max Planck Institut für Plasmaphysik

Attn: Bibliothek

Boltzmann Str. 2

D-85748 Garching bei München

GERMANY

Centro Richerche Energia Frascati

Attn: Library

C. P. 65

1-00044 Frascati (Roma)

ITALY

Commission of the European Communities Joint Research Conter Ispra

Attn: Library

1-21020 Ispra (Varese)

ITALY
M. Zohi

The NET Team

Max Planck Institut für Plasmaphysik

Boltzmann Str. 2

D-85748 Garching bei München

GERMANY

E. Franconi

Centro Richerche Energia Frascati

C. P. 65

I-00044 Frascati (Roma)

ITALY

Dr. P. Schiller

Commission of the European Communities Joint Research Center Ispra

1-21020 ispra (Varese)

ITALY

Dr. F. Gnesotto

Instituto Gas lonizzati

Associazione EURATOM-CNR

Piazza Salvemini 13

I-35131 Padova

ITALY
Instituto Gas lonizzati

Associazione EURATOM-CNR

Attn: Library

Piazza Salvemini 13

1-35131 Padova

ITALY
International Centre for Theoretical Physics Attn: Library

P.O. Box 586

1-34100 Trieste

ITALY 
Dr. Y. Gotoh

Hitachi Research Laboratory

Hitachi, Ltd.

Hitachi-shi, Ibaraki-ken 317

JAPAN

M. Akiba

Japan Atomic Energy Research Institute Naka Fusion Research Establishment

Naka-machi, Naka-gun, Ibaraki-ken, 311-02 JAPAN

Dr. M. Seki

Japan Atomic Energy Research Institute

Naka Fusion Research Establishment

Naka-machi, Naka-gun, Ibaraki-ken, 311-02 JAPAN

Japan Atomic Energy Research Institute Naka Fusion Research Establishment

Attn: Library

Naka-machi, Naka-gun, Ibaraki-ken, 311-02

JAPAN

\section{Ogawa}

Japan Atomic Energy Research Institute Division of High Temperature Engineering Heat Transfer Laboratory

Tokai-mura, Ibaraki-ken 319-11

JAPAN

\section{Dr. Ohara}

Japan Atomic Energy Research Institute Naka Fusion Research Establishment Naka-machi, Naka-gun, Ibaraki-ken, 311-02 JAPAN

Dr. H. Takatsu

Japan Atomic Energy Research Institute Naka Fusion Research Establishment Naka-machi, Naka-gun, Ibaraki-ken, 311-02 JAPAN

S. Yamazaki

Kawasaki Heavy Indus., Lid.

Nuclear Systems Division

R\&D Dept., Section 1

Tokyo Design Office

4-25, 2-chone, Minamisuna Koto-Ku

Tokyo 136

JAPAN

Prof. A. liyoshi

Plasma Physics Laboratory

Kyoto University

Gokasho, Uji, Kyoto 611

JAPAN

Attn: Library

4-25, 2 chone, Minamisuna, Koto-Ku

Tokyo 136

JAPAN 
Plasma Physics Laboratory

Kyoto University

Attn: Library

Gokasho, Uji, Kyoto 611

JAPAN

Mitsubishi Fusion Center

Attn: Library

2-3 Manunouchi, 2-chone, Chiyoda-Ku Tokyo 100

JAPAN
K. loki

Mitsubishi Fusion Center

2-3 Marunouchi, 2-chone, Chiyoda-Ku Tokyo 100

JAPAN

S. Takamura

Nagoya University

Department of Electronics

Chikusa, Nagoya

JAPAN

Prot. A. Miyahara

National Institute for Fusion Science

Engineering Department

Nagoya 464-01

JAPAN
O. Motojima

National Institute for Fusion Science

Engineering Department

Nagoya 464-01

JAPAN
FOM-Instituut voor Plasmafysica

Attn: Library

P.O. Box 1207, Rijnhuizen

NL-3430 BE Nieuwegein

THE NETHERLANDS
Dr. Noda

National Institute for Fusion Science Engineering Department

Nagoya 464-01

JAPAN
Dr. Jaap G. van der Laan

Materials Department

Netherlands Energy Research Foundation

ECN

P.O. Box 1

1755 ZG Petten

THE NETHERLANDS 
A. P. Navarro

Division de Fusion Termonuclear

EURATOMVIEMAT

Avenida Complutense 22

E-28040 Madrid

SPAIN

Centre de Recherches

en Physique des Plasmas

Ecole Polytechnique Federale de Lausanne

Attn: Bibliotheque

21 Avenue des Baines

CH-1007 Lausanne

SWITZERLAND

Rachel Moylan

The Library

Culham Laboratory

UKAEA

Abingdion

Oxfordshire OX14-3DB, England

UNITED KINGDOM

L. de Koch

JET Joint Undertaking

Abingdon

Oxfordshire OX14-3EA, England

UNITED KINGDOM

M. Pick

JET Joint Undertaking

Abingdon

Oxfordshire OX14-3EA, England

UNITED KINGDOM
Division de Fusio:i Termonuclear EURATOMVIEMAT

Attn: Library

Avenida Complutense 22

E-28040 Madrid

SPAIN

G. McCracken

Culham Laboratory

UKAEA

Abingdon

Oxfordshire OX14-3DB, England

UNITED KINGDOM

P. Coad

JET Joint Undertaking

Abingdon

Oxfordshire OX14-3EA, England UNITED KINGDOM

E. Deksnis

JET Joint Undertaking

Abingdon

Oxfordshire OX14-3EA, England

UNITED KINGDOM

K. Sonnenberg

JET Joint Undertaking

Abingdon

Oxfordshire OX14-3EA, England UNITED KINGDOM 

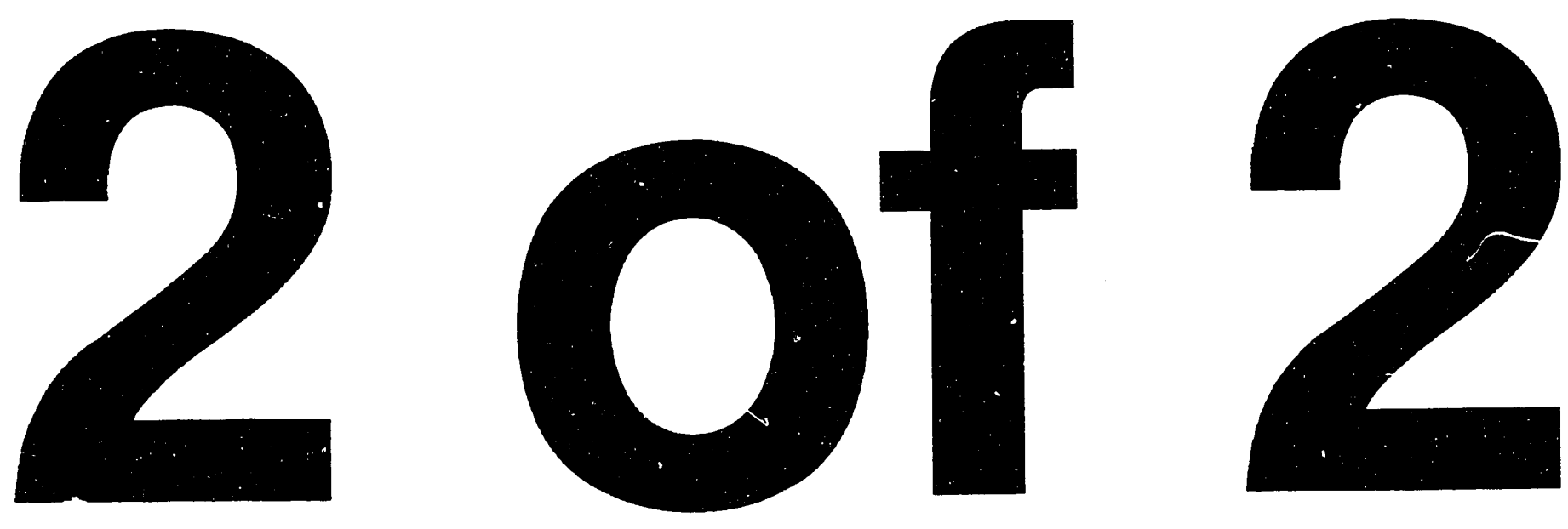
JET Joint Undertaking

Attn: Library

Abingdon

Oxfordshire OX14-3EA, England

UNITED KINGDOM 


\section{INTERNAL DISTRIBUTION:}

1111

1111

1111

1111

1111

1111

1111

1111

1111

1111

1111

1111

1111

6500

6503

6531

6531

6531

6531

6531

6531

6531

6531

6531

6531

6531

6531

6531

8304

8347

8347

8347

8347

8347

8347

8347

8347

8347

8347

8347

8347

8347

8347

8347

8523-2

7141

7151

7613-2
B. L. Doyle

M. C. Adams

G. W. Arnold

J. C. Banks

J. C. Barbour

D. L. Buller

J. A. Knapp

S. R. Lee

K. G. Minor

C. H. Seager

H. J. Stein

W. R. Wampler

D. S. Walsh

J. K. Rice

R. T. McGrath (5)

M. A. Ulrickson

R. B. Campbell

J. P. Freshour

K. J. Hollis

J. A. Hunter

R. Kretzer

J. M. McDonald

R. E. Nygren

P. D. Rockett

B. J. Tafoya

K. P. Troncosa

R. D. Watson

D. L. Youchison

K. L. Wilson

A. E. Pontau

R. J. Bastasz

D. A. Buchenauer

R. A. Causey

W. L. Chrisman

J. W. Cuthbertson

M. L. Hildner

W. L. Hsu

R. Q. Hwang

M. C. McMaster

D. H. Morse

D. A. Outka

K. D. Phillips

J. O. Weeks

J. A. Whaley

Central Technical Files

Technical Library (5)

Technical Publications

Document Processing for DOE/OSTI (10) 
(This page intentionally left blank.) 

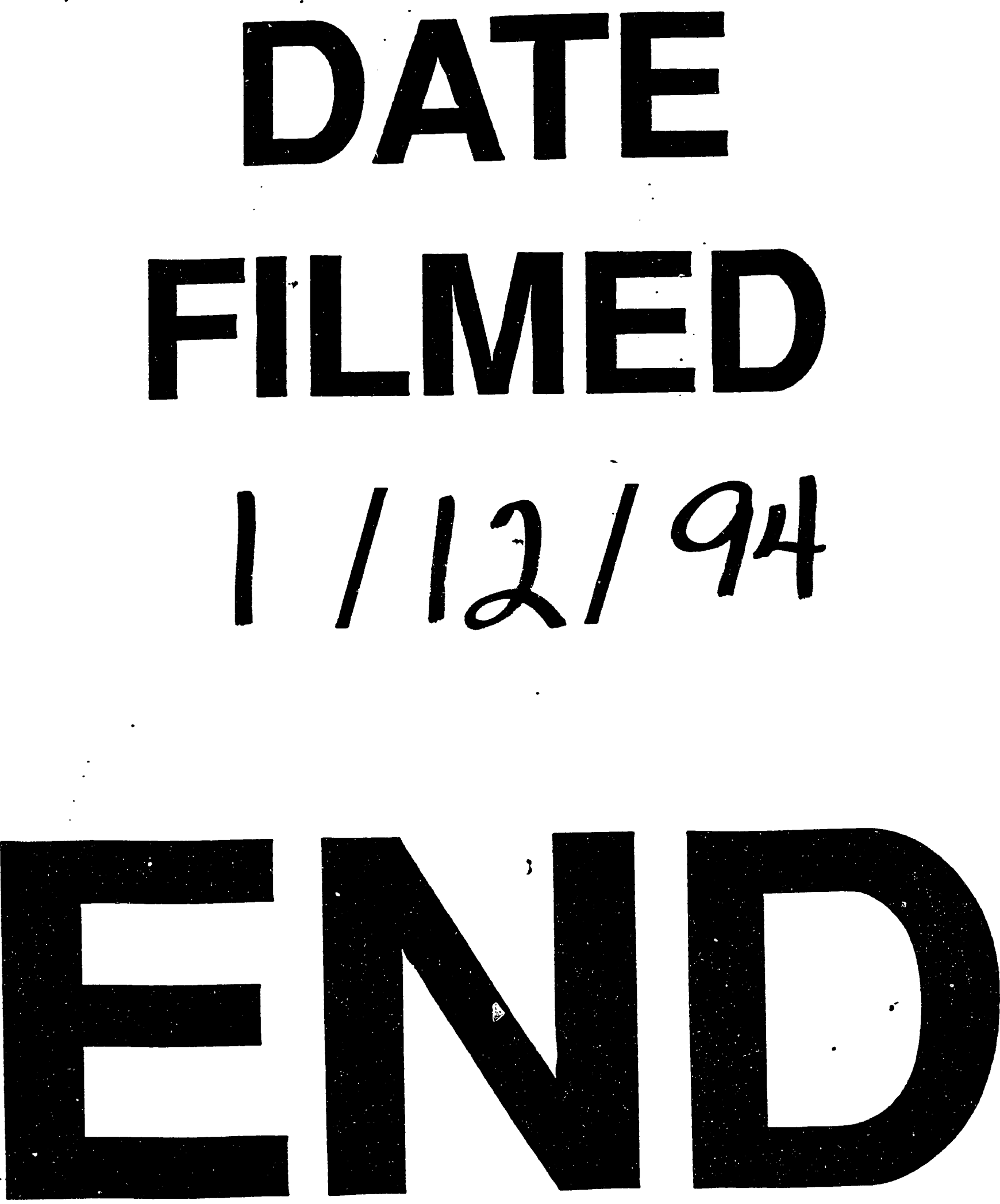